\title{
STATISTICAL EVALUATION OF TRAVEL TIME ESTIMATION BASED ON DATA FROM FREEZE-BRANDED CHINOOK SALMON ON THE SNAKE RIVER, 1982-1990
}

\author{
Prepared by: \\ Steven G. Smith \\ John R. Skalski \\ Center for Quantitative Science \\ University of Washington \\ Seattle, WA \\ and \\ Albert Giorgi \\ Don Chapman Consultants, Inc. \\ Redmond, WA
}

\author{
Prepared for: \\ U.S. Department of Energy \\ Bonneville Power Administration \\ Division of Fish and Wildlife \\ P.O. Box 3621 \\ Portland, OR 97283-3621 \\ Project Number 9 1-05 1 \\ Task Number DE-AT79-91BP16570 \\ Contract Number DE-BI79-91BP35885
}

OCTOBER 1993 


\section{EXECUTIVE SUMMARY}

The purpose of this investigation is to assess the strengths and limitations of existing freeze brand recapture data in describing the migratory dynamics of juvenile salmonids in the mainstem, impounded sections of the Snake and Columbia Rivers. With the increased concern over the threatened status of spring and summer chinook salmon in the Snake River drainage, we used representative stocks for these races as our study populations. However, statistical considerations resultant from these analyses apply to other species and drainages as well.

This report describes analyses we conducted using information derived from freezebranded groups. We examined both index production groups released from hatcheries upstream from Lower Granite Dam (1982- 1990) and freeze-branded groups used as controls in smolt transportation evaluations conducted by the National Marine Fisheries Service $(1986,1989)$. The scope of our analysis was limited to describing travel time estimates and derived relationships, as well as reach survival estimates through the mainstem Snake River from Lower Granite to McNary Dam.

We found that existing brand recovery data provide broad, general estimates of travel time for expansive reaches. The estimation procedure is based on estimated passage distributions, which are dependent on numerous parameter values that are presumed general estimates. The parameter values are often unverified and have no associated measures of variability.

Consequently, it is not possible to estimate standard errors of the point estimates of travel time, a serious shortcoming of the brand recovery data.

A further limitation of the complicated adjustment procedure is that both the estimated travel times and derived relationships are sensitive to assumed values for the input parameters Fish Guidance Efficiency and Spill Effectiveness. This pertains to brand groups that encounter spill conditions at Lower Granite, Little Goose, or McNary Dam.

The relationships between the travel time estimates and predictor variables are also necessarily general and have poor resolution, but can serve as general descriptions. The expansive distances for which travel time can be estimated necessitate the development of environmental indices that span protracted periods of time. Consequently, the resolution of the travel time estimates is not fine enough to detect small changes in travel time in response to changing conditions in the individual reaches Furthermore, direct measures of physiological indices are not available for branded groups. Thus, we must use surrogate measures that may not capture true effects. 
We found that commonly-held values for adjustment of fish passage indices led to population indices (estimated abundance) at McNary Dam that are usually larger than abundance estimated at Lower Granite Dam, in many cases by several fold. This indicates that certain unidentified input parameter values are in error. This condition precludes the opportunity to use the brand recovery data to estimate reach survival. Perhaps more importantly, this condition indicates that some commonly-held values for key parameters, e.g. FGE, spill effectiveness, or dam and reservoir mortality are substantially in error.

In the regression analyses the hatchery release data, we found that numerous models could equally explain the travel time response. Typically, these models include as key predictor variables some measure of flow, a surrogate for smolt development, and an index for spill at the projects of the lower reach. Measures of turbidity were also important variables in some models. In the analyses of the transportation control releases, the variables that were most significant were factors related to the time of year. The fish released later in the season traveled faster, as the river waters became clearer and warmer. A high degree of collinearity among the independent variables makes it difficult to discern the relative importance of the respective predictor variables. Summarization of environmental covariates over long periods of time precludes the determination of any causal mechanisms.

We recommend that future research efforts be directed at improving the resolution of travel time estimates by measuring responses through shorter reaches of river. This improves our capability to detect changes in fish behavior in response to river conditions. Direct measurements of all important predictor variables should also accompany each experimental group, including indices of smolt development. Furthermore, efforts to estimate reach survival should be advanced. 


\section{CONTENTS}

List of Figures $\ldots \ldots \ldots \ldots \ldots \ldots \ldots \ldots \ldots \ldots \ldots \ldots \ldots \ldots \ldots \ldots \ldots \ldots \ldots \ldots \ldots \ldots \ldots$
List of Tables $\ldots \ldots \ldots \ldots \ldots \ldots \ldots$

Section 1: Introduction

Section 2: Regression Analyses for Hatchery Groups $\ldots \ldots .3$

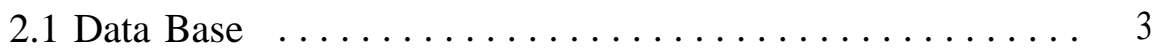

2.2 Travel Time Estimation Through the Lower Granite to

McNary Reach ..................... 10

2.2.1 Adjustment Algorithm for Passage Indices ........ 11

2.2.2 Discussion ........................... 15

2.3 Regression Results $\ldots \ldots \ldots \ldots \ldots \ldots \ldots \ldots \ldots$

2.3.1 Variables $\ldots \ldots \ldots \ldots \ldots \ldots \ldots \ldots \ldots \ldots \ldots \ldots$

2.3.2 Response Model ...................... 18

2.3.3 Basic Analysis ...................... 19

2.3.4 Discussion ....................... 25

Section 3: Sensitivity of Travel Time Estimation to Underlying

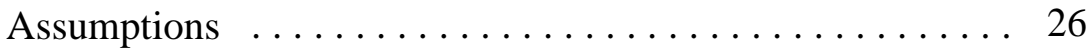

3.1 Methods ............................ 26

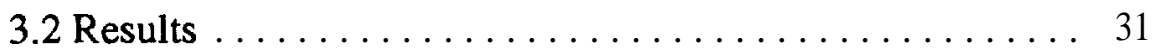

Fish guidance efficiency $\ldots \ldots \ldots \ldots \ldots \ldots \ldots \ldots \ldots, 31$

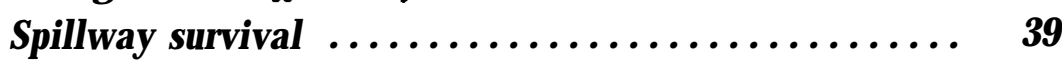

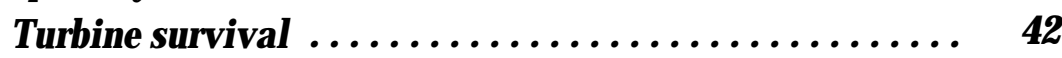

Bypass survival $\ldots \ldots \ldots \ldots \ldots \ldots \ldots \ldots \ldots \ldots \ldots \ldots \ldots, 42$

Travel time from Low er G ranite to Little G oose . . . . . . 42

Survival from Low er G ranite to Little G oose . . . . . . . . . 42

Spilleffectiveness $\ldots \ldots \ldots \ldots \ldots \ldots \ldots \ldots \ldots \ldots \ldots \ldots, 42$

3.3 Discussion $\ldots \ldots \ldots \ldots \ldots \ldots \ldots \ldots \ldots \ldots \ldots \ldots \ldots \ldots \ldots$

Section 4: Sensitivity of Regression Results $\ldots \ldots \ldots \ldots \ldots 50$

4.1 Sensitivity of Selected Regression Models to Underlying

Assumptions .................... 50

4.2 Sensitivity of Regression Equations to Underlying

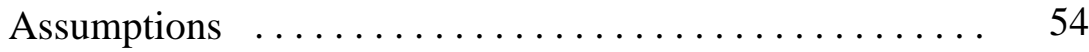

4.3 "Leave-One-Year-Out" Sensitivity $\ldots \ldots \ldots \ldots \ldots \ldots 56$

4.4 Discussion ........................ 59 
Section 5: Effects of Sampling Precision on Regression Relationships: Weighted Regression ... . . . . . . 59

Section 6: Regression Analyses Using Independent Variables

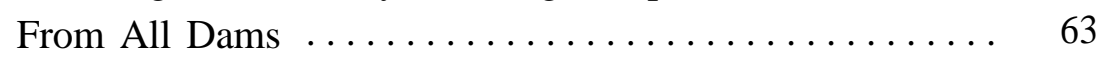

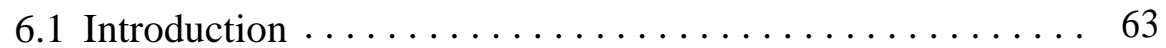

6.2 All-Dam Analysis $\ldots \ldots \ldots \ldots \ldots \ldots \ldots \ldots \ldots \ldots \ldots \ldots \ldots$

6.3 Individual-Dam Analysis $\ldots \ldots \ldots \ldots \ldots \ldots \ldots \ldots \ldots 68$

6.4 Discussion ...................... 70

Section 7: Value of Surrogate Measures of Smoltification $\ldots .70$

7.1 General Comments . . . . . . . . . . . . . . . . 71

7.2 Direct Measurements of Smolt Condition $\ldots \ldots \ldots \ldots 72$

Section 8: Regression Analyses for Transportation Control

Releases .................... 76

8.1 Data base ...................... 76

8.2 Correlation and Regression Analyses $\ldots \ldots \ldots \ldots \ldots . \ldots 78$

8.3 Comparison with Results for Hatchery Brand Releases . . 82

Section 9: Summary and Recommendations $\ldots \ldots \ldots \ldots . \ldots 84$

9.1 Summary of Findings $\ldots \ldots \ldots \ldots \ldots \ldots \ldots \ldots$

9.2 Conclusions $\ldots \ldots \ldots \ldots \ldots \ldots \ldots \ldots \ldots$

9.3 Recommendations $\ldots \ldots \ldots \ldots \ldots \ldots \ldots \ldots \ldots . \ldots . \ldots . \ldots 2$

Literature Cited . . . . . . . . . . . . . . . . . . . . . . . . . . . 94

Appendix A: Complete Regression Data for Snake River Releases of Freeze-Branded Juvenile Spring and Summer Chinook 96

Appendix B: Complete Regression Data for Transportation

Control Releases. . . . . . . . . . . . . . . . . . . . . 103

Appendix C: Comment Letters and Responses to Comments. . . . 113 


\section{LIST OF TABLES}

Number

Title

Page

1 Release groups considered for use in multiple regression analyses.

2 Summary of brand recovery data at Lower Granite and McNary dams for 42 release groups.

3 Standard values assumed for parameters in adjustment of passage distributions for travel time estimation.

4 Pairwise linear correlations between estimated median travel time and potential predictor variables in basic regression analysis. Based on 42 observations listed in Table 1.

5 Pair-wise correlations between river conditions at Ice Harbor Dam and conditions at other dams. Based on 42 observations listed in Table 1.

6 Summary of results from best subsets regression and stepwise regression analyses. Potential predictors were surrogates of smoltification and flow velocity and spill measured at Ice Harbor Dam. Based on 42 observations listed in Table 1.

7 Detailed regression results for selected models in basic regression analysis. Spill and flow volumes measured at Ice Harbor Dam. Based on 42 observations listed in Table 1.

8 Brand groups used in the study of the sensitivity of travel time estimates to assumed parameter values.

9 Summary of travel time sensitivity analysis. Travel times for 7 representative brand groups under a variety of assumed parameter values.

10 Ranges of estimated travel times for varying assumptions for Fish Guidance Efficiency and Spill Effectiveness.

11 Models selected by stepwise regression algorithm under varying assumptions for Fish Guidance Efficiency and Spill Effectiveness. Stepwise procedure applied using data from Ice Harbor dam only. 


\section{LIST OF TABLES (Cont.)}

Number

Title

Page

12 Models selected by best-subsets regression algorithm under varying assumptions for Fish Guidance Efficiency and Spill Effectiveness.

13 Models selected by best-subsets regression algorithm under varying assumptions for Fish Guidance Efficiency and Spill Effectiveness.

14 Summary of analysis of sensitivity of regression to underlying parameters. Coefficient estimates, standard errors, and R-squared under a variety of assumed parameter values.

15 Summary of analysis of sensitivity of regression to yearby-year omission of observations. Coefficient estimates, standard errors, and R-squared for model with indicated year omitted.

16 Total number sampled (see Figure 1) at Lower Granite and McNary Dams for each of 40 brand groups and resulting weights for weighted regression.

17 Results of weighted regressions for selected models from "basic analysis" (Section 2.3.3). Observation weights based on number of smolt sampled at Lower Granite and McNary Dams.

18 Descriptive statistics for variables used in regression analyses. Statistics are for the 42 release groups listed in Table 1, and used in the regression analyses.

19 Pairwise correlations between Travel Time through index reach and 62 continuous predictor variables. Correlations based on all 42 brand groups listed in Table 1.

20 Results of stepwise regression analysis using full suite of potential predictor variables. All-Dam analysis.

21 Best 4-variable models using full suite of potential predictor variables. Individual-Dam analysis.

22 Direct measurements of smolt condition for selected hatchery brand groups. Sample means for fish sampled at Lower Granite Dam at three times during the passage of the groups. 


\section{LIST OF TABLES (Cont.)}

Number

Title

Page

23 Pairwise correlations between estimated travel time through Lower Granite to McNary reach (TTIME) and estimated travel time between release and Lower Granite Dam (TTLGR) with direct measurements of gill ATPase at Lower Granite Dam. Based on brand groups in Table 18.

24 Transportation program control releases used in travel time analyses.

25 Pair-wise correlations between Travel Time through index reach and 45 continuous predictor variables. Based on 18 transportation program control releases listed in Table 24.

26 Comparison of regression analyses of transportation control release data and hatchery release data. Independent variables measured at Ice Harbor.

A.1 Complete regression data for Snake River releases of freeze-branded juvenile spring and summer chinook salmon

B.1 Complete regression data for transportation program control releases. 


\section{LIST OF FIGURES}

Number

Title

Page

1 Sample report sec tion from Fish Passage Center recovery reports

2 Equation used to model Fish Guidance Efficiency as function of Julian date.

3 Equation used to model Spill Effectiveness as a function of the proportion of flow spilled at Lower Granite Dam. Derived from estimates presented in Wilson et al (1991).

$4 \quad$ Plots of estimated travel time versus assumed fish guidance efficiency value for 7 representative groups.

5a Estimated Lower Granite departure distributions and derived travel time estimates from Lower granite to McNary using various assumed values of FGE and Lower Granite spill volumes for 1986 group RD-Y-3.

5b Estimated Lower Granite departure distributions and derived travel time estimates from Lower granite to McNary using various assumed values of FGE and Lower Granite spill volumes for 1983 group RD-SU-3.

5c Estimated Lower Granite departure distributions and derived travel time estimates from Lower granite to McNary using various assumed values of FGE and Lower Granite spill volumes for 1988 group RD-T- 1.

6 Plot of estimated travel times under assumption of FGE as a function of the date (Eq. 7) versus estimated travel times under standard assumption of constant FGE

7 Plots of estimated travel time versus assumed spillway survival value for 7 representative groups.

8 Plots of estimated travel time versus assumed turbine survival value for 7 representative groups. survival value for 7 representative groups.

10 Plots of estimated travel time versus assumed value of travel time between Lower Granite to Little Goose Dams for 7 representative groups.

11 Plots of estimated travel time versus assumed value of spill effectiveness for 7 representative groups. 


\section{LIST OF FIGURES (Cont.)}

Number

Title

Page

12 Plot of estimated Travel Time through index reach vs. Inverse Average Flow at Ice Harbor Dam. The year of observation is indicated by the plotting character. The regression line is fitted through all 42 observations.

13 Scatterplots among selected variables for transportation control releases.

14 Scatterplots among selected predictor variables for transportation control releases. 


\section{Section 1: Introduction}

The purpose of this phase of the project is to assess the strengths and limitations of freeze brand data in describing the migratory dynamics of smolt migrating through the Snake River system. The available sources of data are production releases from hatcheries above Lower Granite Dam as well as releases below Little Goose Dam that served as controls for the smolt transportation program. Of particular interest is the examination of the relationship between river conditions, especially flow volumes, and the travel time and survival rates of smolt migrating through the system. This report documents our methods, findings, and recommendations regarding the usefulness of the historical freeze-brand data for analyzing smolt travel times and survival rates.

This first task in this phase of the project was to select a model or set of models relating estimated travel times with independent variables. The primary statistical method used for this task was multiple linear regression. For the purpose of this evaluation, each batch of branded smolts is considered to be a single observation. The dependent variable is the estimated median travel time for the batch. For the hatchery releases the index reach was from Lower Granite Dam to McNary Dam. The independent variables are characterizations of the river conditions encountered by the batch while it was migrating. Recently, researchers at the Fish Passage Center (FPC) have used bivariate and multiple regression models to analyze data from hatchery brand releases in the Snake River (Berggren and Filardo, 1993). The hatchery release data, the method of estimating median travel time in the index reach, and the regression approach we used were nearly the same as those used by Berggren and Filardo (1993). Our objective was not to re-create those analyses, but to use the regression analyses as a starting point for examining key assumptions associated with deriving travel time estimates, and for testing the sensitivity of estimates to key parameter values.

The seven key objectives of this phase of the study are as follows:

1. To examine the sensitivity of travel time estimates to underlying assumptions.

2. To investigate alternative regression models for the travel time estimates, using the tools of stepwise and best-subsets regression.

3. To examine the sensitivity of regression relationships to violations of assumptions underlying estimation of travel times.

4. To assess the effects of sampling precision of travel time estimates on the regression relationships. 
5. To determine whether surrogate measures of smoltification correctly represent the biological process of smoltification.

6. To compare results of regression analyses based on different types of data sets (hatcheries vs. transportation controls).

The organization of this report parallels the objectives:

Section 1: This introduction.

Section 2: Presents basic regression analyses based on the hatchery releases, setting the stage for accomplishing the seven objectives listed above. Section 2.1 describes the data base, our data sources, and our criteria for inclusion of brand groups in the analysis. Differences from the FPC analyses are noted. Section 2.2 explains the algorithm for estimating travel times, with particular emphasis on the assumptions required to estimate the median travel time in the Lower Granite to McNary reach. Section 2.3 presents basic regression results and contrasts them with those obtained in the FPC analyses (Berggren and Filardo, 1993).

Section 3: Describes investigations of the sensitivity of the travel time estimates to the assumed values of key underlying parameters.

Section 4: Describes investigations of the sensitivity of the basic regression results to the assumed values of key underlying parameters, and to omissions of selected observations.

Section 5: Presents rationale and results of a weighted regression analysis based on the estimated sampling precision of the travel time estimates.

Section 6: Presents results of regression analyses using an expanded set of independent variables. Rather than using variables only from a single index dam, measurements from all dams in the index reach are analyzed. There is ample multicollinearity in these data, and the effects of the correlations on the selection of the regression model are investigated.

Section 7: Discusses the appropriateness of surrogate measurements of smoltification as representations of the biological process. Includes quantitative investigation of relationships among measurable variables related to smoltification.

Section 8: Presents results of regression analyses based on the control releases from the transportation program and contrasts the results with those based on the hatchery groups. 
Section 9: A summary of our findings, the problems we encountered using the freeze brand data, recommendations regarding the strengths and limitations of the freeze brand data, and recommendations regarding the future collection of data for investigating migratory dynamics.

\section{Section 2: Repression Analvses for Hatcherv Groups}

\subsection{Data base}

The collection of data began with the identification of all groups of branded yearling spring and summer chinook smolts released from hatcheries in the Snake River drainage system between 1982 and 1990. The sources for this information were reports published annually by the Fish Passage Center (FPC) from 1984 through 1991 and by the Coastal Zone and Estuarine Studies (CZES) section of the National Marine Fisheries Service (NMFS) prior to 1984.

For the purposes of estimating smolt travel times between Lower Granite and McNary Dams, we considered only groups of branded smolts that were released above Lower Granite. In addition, we considered only the annual production releases from each of the hatcheries, and not experimental releases. There are two reasons for this restriction. First, brand releases that are part of hatchery experiments tend to be very small, leading to minimal'recoveries at downstream sites. This in turn leads to unreliable estimates of travel time. Second, and more importantly, experimental subjects may have characteristics that render their behavior or travel times unrepresentative of the bulk of the migrating smolts. Experimental releases are not representative of the vast number of production smolts and their experiences may not be extrapolable to the usual release circumstances. Some of the production releases were split into two or more subgroups prior to release, each subgroup with a distinct brand code (e.g. LA-J-2 and LA-J-4 were released from Lookingglass hatchery in 1987). Because the date and site of release were identical among the different subgroups, and because the subgroups of a single release might not be independent of each other, as required by the assumptions of linear regression, the subgroups were pooled and treated as a single release batch. Henceforth in this report, unpooled brand releases will be referred to by their full brand code, while the pooled releases will have the character "\#" replacing the part or parts of the code that was pooled. For example, the combined LA-J-2 and LA-J-4 brand codes are referred to as "LA-J-\#" and the combined LD-7U-1, RA-7U-1, and RA-7U-3, released from Dworshak hatchery in 1990, are referred to as “\#-7U-\#”. 
After pooling the subgroups of the production releases where appropriate, we identified the 43 release groups listed in Table 1 as candidates for analysis. One of these, RD-T-2 from McCall hatchery in 1988, had exceptionally low recovery rates at Lower Granite Dam (a total of only 17 recovered out of nearly 54,000 released, according to FPC records). Reliable estimation of the Lower Granite-McNary travel time is impossible based on such low recovery numbers and consequently the RD-T-2 batch was omitted from further consideration. This leaves a total of 42 observations for the multiple regression analysis. By comparison, the analyses by Berggren and Filardo (1993) were based on 31 observations. The additional 11 release groups are four annual groups from Lookingglass Hatchery from 1987 through 1990, one group from McCall Hatchery in 1982 and six groups reared at Rapid River Hatchery and released in Hell's Canyon. The criterion used by Berggren and Filardo (1993) for exclusion of these groups from analysis was that they were not part of a series that spans the entire time frame from 1982 to 1990 (Berggren, personal communication). Because the releases from different sites are ultimately all pooled in a single analysis, we do not agree that shorter series of releases need be omitted,

Data on recoveries of branded fish at Lower Granite and McNary Dams were obtained from FPC. The FPC reports give daily recovery numbers at each dam for each brand code. Figure 1 shows the header information and a few lines of data from a typical FPC report section. The first line of the header identifies the recovery location (Lower Granite in Figure 1) and the species (yearling chinook, or "Chinook 1 's"). The remainder of the header gives release information on the indicated brand group, including the FPC's internal identification code for the release, the number released, the release site, the release date, the agency responsible for the release, and the source hatchery. The daily entries include the following data:

Date,

Sample quality code (SC) is 1 for normal sampling with no problems;

Number of days (\#D) is the number of accumulated days for sample (left blank in the typical case of a single day);

Number of gatewells (GW) is the number of gatewells sampled (left blank for Lower Granite and McNary, which are not gatewell sampling systems);

Number of hours (HR.S) is the number of hours represented by the sample;

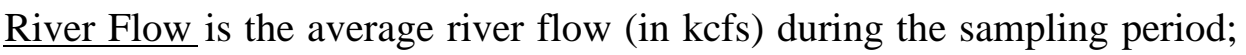


Table 1. Release groups considered for use in multiple repression analvses. The symbol "\#” in the "Brand" column denotes groups representing multiple pooled brand codes.

\begin{tabular}{|c|c|c|c|c|c|c|c|}
\hline Year & Brand & Strain & Start & Finish & Source & Release & Number \\
\hline 83 & RD-SU-3 & $\mathrm{sp}$ & $01 \mathrm{Apr}$ & $01 \mathrm{Apr}$ & Dworshak & $\mathrm{N}$ Fork Clearwater & 18,194 \\
\hline 85 & RD-R-2 & $\mathrm{sp}$ & $03 \mathrm{Apr}$ & $04 \mathrm{Apr}$ & Dworshak & Dworshak & 23,100 \\
\hline 86 & RA-Y-2 & $\mathrm{sp}$ & $02 \mathrm{Apr}$ & $03 \mathrm{Apr}$ & Dworshak & $\mathrm{N}$ Fork Clearwater & 40,675 \\
\hline 87 & RA-R-1 & sp & $02 \mathrm{Apr}$ & $02 \mathrm{Apr}$ & Dworshak & Dworshak & 61,580 \\
\hline 88 & LA-T-2 & $s p$ & $30 \mathrm{Mar}$ & $30 \mathrm{Mar}$ & Dworshak & Dworshak & 60,631 \\
\hline 89 & R\#-7H-\# & $\mathrm{sp}$ & $30 \mathrm{Mar}$ & 30 Mar & Dworshak & Dworshak & 58,716 \\
\hline 90 & \#-7U-\# & $\mathrm{sp}$ & 05 Apr & $05 \mathrm{Apr}$ & Dworshak & Dworshak & 59,869 \\
\hline 83 & RD-T-1 & su & 04 Apr & $07 \mathrm{Apr}$ & McCall & S Fork Salmon & 24,853 \\
\hline 84 & LD-J-1 & su & 09 Apr & $11 \mathrm{Apr}$ & McCall & S Fork Salmon & 25,555 \\
\hline 85 & RD-R-3 & $\mathrm{su}$ & $01 \mathrm{Apr}$ & 04 Apr & McCall & S Fork Salmon & 25,600 \\
\hline 86 & RD-Y-3 & su & $24 \mathrm{Mar}$ & $31 \mathrm{Mar}$ & McCall & S Fork Salmon & 43,487 \\
\hline 87 & LD-R-3 & $\mathrm{su}$ & $30 \mathrm{Mar}$ & $02 \mathrm{Apr}$ & McCall & S Fork Salmon & 56,500 \\
\hline 89 & RA-R-\# & su & $21 \mathrm{Mar}$ & $21 \mathrm{Mar}$ & McCall & S Fork Salmon & 52,950 \\
\hline 90 & LD-T-\# & su & $21 \mathrm{Mar}$ & $21 \mathrm{Mar}$ & McCall & S Fork Salmon & 62,200 \\
\hline 82 & RD-4-1 & $\mathrm{sp}$ & $27 \mathrm{Mar}$ & $27 \mathrm{Mar}$ & Rapid River & Rapid River & 11,072 \\
\hline 83 & RD-12-1 & sp & $18 \mathrm{Mar}$ & $26 \mathrm{Mar}$ & Rapid River & Rapid River & 68,788 \\
\hline 84 & RD-J-3 & $\mathrm{sp}$ & $21 \mathrm{Mar}$ & $01 \mathrm{Apr}$ & Rapid River & Rapid River & 23,840 \\
\hline 85 & LD-R-1 & $\mathrm{sp}$ & $31 \mathrm{Mar}$ & $10 \mathrm{Apr}$ & Rapid River & Rapid River & 34,225 \\
\hline 86 & LD-Y-1 & $\mathrm{sp}$ & 04 Apr & $07 \mathrm{Apr}$ & Rapid River & Rapid River & 44,692 \\
\hline 87 & LD-R-2 & $\mathrm{sp}$ & $16 \mathrm{Mar}$ & 07 Apr & Rapid River & Rapid River & 53,500 \\
\hline 88 & RD-T-4 & $\mathrm{sp}$ & $15 \mathrm{Mar}$ & $25 \mathrm{Mar}$ & Rapid River & Rapid River & 54,500 \\
\hline 89 & L\#-7H-\# & $\mathrm{sp}$ & $15 \mathrm{Mar}$ & 30 Mar & Rapid River & Rapid River & 59,522 \\
\hline 90 & RA-T-\# & $\mathrm{sp}$ & $22 \mathrm{Mar}$ & 26 Mar & Rapid River & Rapid River & 60,750 \\
\hline 83 & RD-T-2 & $\mathrm{sp}$ & $29 \mathrm{Mar}$ & $29 \mathrm{Mar}$ & Sawtooth & Upper Salmon R & 26,549 \\
\hline 84 & LD-J-3 & $\mathrm{sp}$ & $27 \mathrm{Mar}$ & 29 Mar & McCall & Sawtooth & 33,934 \\
\hline 85 & RD-R-1 & $\mathrm{sp}$ & 25 Mar & 29 Mar & Sawtooth & Sawtooth & 39,875 \\
\hline 86 & RD-Y-1 & sp & 17 Mar & 17 Mar & Sawtooth & Sawtooth & 35,851 \\
\hline 87 & RD-R-1 & $\mathrm{sp}$ & $11 \mathrm{Mar}$ & $13 \mathrm{Mar}$ & Sawtooth & Sawtooth & 58,400 \\
\hline 88 & RD-T-1 & $\mathrm{sp}$ & 15 Mar & 15 Mar & Sawtooth & Sawtooth & 52,300 \\
\hline 89 & LA-R-\# & $\mathrm{sp}$ & $15 \mathrm{Mar}$ & $15 \mathrm{Mar}$ & Sawtooth & Sawtooth & 55,250 \\
\hline 90 & LA-T-\# & $\mathrm{sp}$ & 17 Mar & 17 Mar & Sawtooth & Sawtooth & 57,425 \\
\hline 87 & LA-J-\# & $\mathrm{sp}$ & $01 \mathrm{Apr}$ & $01 \mathrm{Apr}$ & Lookingglass & Lookingglass Hat. & 40,619 \\
\hline 88 & \#A-I\#-\# & $\mathrm{sp}$ & $01 \mathrm{Apr}$ & $01 \mathrm{Apr}$ & Lookingglass & Lookingglass $\mathrm{Cr}$. & 83,230 \\
\hline 89 & \#D-J-\# & sp & $03 \mathrm{Apr}$ & $03 \mathrm{Apr}$ & Lookingglass & Lookingglass $\mathrm{Cr}$. & 78,056 \\
\hline 90 & \#A-A-\# & $\mathrm{sp}$ & $02 \mathrm{Apr}$ & $02 \mathrm{Apr}$ & Lookingglass & Lookingglass $\mathrm{Cr}$. & 82,786 \\
\hline 82 & RD-SU-\# & $\mathrm{sp}$ & $08 \mathrm{Apr}$ & $10 \mathrm{Apr}$ & McCall & S Fork Salmon & 21,196 \\
\hline 88 & RD-T-2 & $\mathrm{sp}$ & 23 Mar & 24 Mar & McCall & S Fork Salmon & 53,900 \\
\hline 83 & RD-T-3 & $\mathrm{sp}$ & $18 \mathrm{Mar}$ & 18 Mar & Rapid River & Hells Canyon & 43,112 \\
\hline 84 & RD-J-1 & $\mathrm{sp}$ & $20 \mathrm{Mar}$ & 21 Mar & Rapid River & Hells Canyon & 85,664 \\
\hline 85 & LD-R-3 & $\mathrm{sp}$ & $18 \mathrm{Mar}$ & 20 Mar & Rapid River & Hells Canyon & 35,825 \\
\hline 86 & LD-Y-3 & $\mathrm{sp}$ & $26 \mathrm{Mar}$ & 27 Mar & Rapid River & Hells Canyon & 44,754 \\
\hline 87 & LD-R-4 & $s p$ & $23 \mathrm{Mar}$ & 23 Mar & Rapid River & Hells Canyon & 51,350 \\
\hline 88 & LD-T-4 & $\mathrm{sp}$ & $22 \mathrm{Mar}$ & $23 \mathrm{Mar}$ & Rapid River & Hells Canyon & 53,900 \\
\hline
\end{tabular}

* Release group used in analyses by Berggren and Filardo (1993). 
Figure 1.Sample report section from Fish Passage Center recoverv redorts.

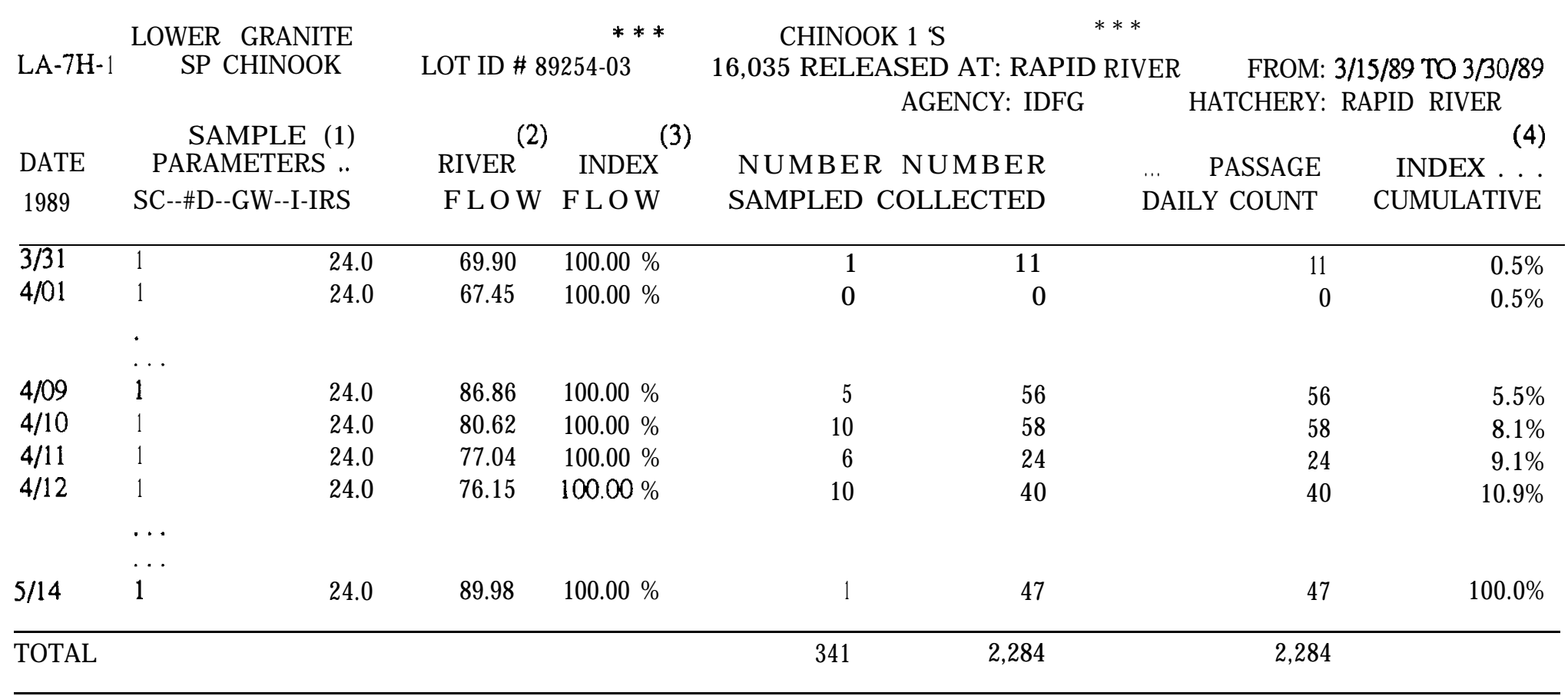


Passage Index Flow is the percentage of the river flow flowing through the sampling system. For Lower Granite and McNary Dams, this "index flow" is calculated as:

Powerhouse flow / (Powerhouse flow + Spill);

Number Sampled is the number of branded fish observed. Total sample counts are given at the end of each report section.

Number Collected is the estimated number of fish collected in the entire collection system during the sampling period. If the collection is not subsampled, the number sampled and the number collected are equal At McNary and Lower Granite the sample rate is based on the proportion of time the bypass collection system was sampled. The total estimated number collected is given at the end of each report section.

Passage Index is an index of abundance for the entire population passing the dam, reflecting an adjustment for fish spilled. However, it is not an accurate population estimate, because the estimated number collected is not expanded by a known overall dam collection rate. In particular, it is assumed that the fish population splits between the powerhouse and spill way in equal proportion to the proportion of flow through those routes. Passage index is calculated as follows:

$$
\text { Passage Index }=(\# \text { collected } * 100) /(\% \text { passage index flow }) \text {. }
$$

The cumulative percent passage index is printed to the right of each passage index estimate. These percentages are based on the total counts printed at the end of each report section.

The recovery data for the 42 release groups are summarized in Table 2 . The table gives for each release group the median release date, the estimated number released (release numbers are not always known exactly), the first and last days that fish from the group were collected at Lower Granite and McNary Dams, the total estimated number of fish collected, and the total passage index at Lower Granite and McNary Dams.

Our data on river conditions include flow volumes through the powerhouses and through the spillways, river temperature, and water turbidity. The U.S. Army Corps of Engineers (COE) maintain these data for each dam in the Snake River system. COE was our source for the following data: 
Table 2. Summarv of brand recoverv data at Lower Granite and McNarv Dams for 42 release groups. All dates are Julian.

\begin{tabular}{|c|c|c|c|c|c|c|c|c|c|c|c|}
\hline Year & $\begin{array}{l}\text { Brand } \\
\text { Code }\end{array}$ & $\begin{array}{c}\text { Median } \\
\text { Release Date } \\
\text { (Julian) }\end{array}$ & $\begin{array}{l}\text { Estimated } \\
\text { Number } \\
\text { Released }\end{array}$ & $\begin{array}{c}\text { First Day of } \\
\text { Lower } \\
\text { Granite } \\
\text { Collection }\end{array}$ & $\begin{array}{c}\text { Last Day of } \\
\text { Lower } \\
\text { Granite } \\
\text { Collection }\end{array}$ & $\begin{array}{c}\text { Total } \\
\text { Collected at } \\
\text { Lower } \\
\text { Granite }\end{array}$ & $\begin{array}{c}\text { Total } \\
\text { Passage } \\
\text { Index at } \\
\text { Lower } \\
\text { Granite }\end{array}$ & $\begin{array}{l}\text { First Day of } \\
\text { McNary } \\
\text { Collection }\end{array}$ & $\begin{array}{c}\text { Last Day of } \\
\text { McNary } \\
\text { Collection }\end{array}$ & $\begin{array}{c}\text { Total } \\
\text { Collected at } \\
\text { McNary }\end{array}$ & $\begin{array}{l}\text { Total } \\
\text { Passage } \\
\text { Index at } \\
\text { McNary }\end{array}$ \\
\hline 83 & RD-su-3 & 91.0 & 18194 & 94 & 159 & 2147 & $\mathrm{NA}^{*}$ & 115 & 151 & 402 & $\mathrm{NA}^{*}$ \\
\hline 85 & RD-R-2 & 93.5 & 23,100 & 100 & 166 & 6403 & 6466 & 112 & 154 & 4962 & 5462 \\
\hline 86 & RA-Y-2 & 92.5 & 40,675 & 98 & 154 & 4703 & 4733 & 111 & 167 & 3501 & 3982 \\
\hline 87 & RA-R-1 & 92.0 & 61,580 & 98 & 129 & 11069 & 11070 & 115 & 154 & 6319 & 7565 \\
\hline 88 & LA-T-2 & 90.0 & 60,631 & 101 & 155 & 17510 & 17510 & 114 & 161 & 6001 & 6001 \\
\hline 89 & R\#-7H-\# & 89.0 & 58,716 & 95 & 154 & $1 3 \longdiv { 3 4 6 }$ & 13346 & 106 & 154 & 3429 & 3813 \\
\hline 90 & \#-7U-\# & 95.0 & 59,869 & 101 & 153 & 14976 & 14976 & 112 & 157 & 3769 & $\overline{3955}$ \\
\hline 83 & RD-T-1 & 95.5 & 24,853 & 113 & 160 & 2904 & $\mathrm{NA}^{*}$ & 122 & 182 & 955 & $\mathrm{NA}^{*}$ \\
\hline 84 & LD-J-1 & 101.0 & 25,555 & 115 & 164 & 3032 & NA* & 128 & 167 & 1573 & $N A^{*}$ \\
\hline 85 & RD-R-3 & 92.5 & 25,600 & 107 & 160 & 4204 & 4264 & $12 \overline{3}$ & 168 & 1139 & 1195 \\
\hline 86 & RD-Y-3 & 86.5 & 43,487 & 97 & 163 & 5921 & 6109 & 115 & 161 & 1693 & $20 \overline{39}$ \\
\hline$\overline{87}$ & LD-R-3 & 90.5 & 56,500 & 114 & 175 & 1956 & 1956 & 124 & 169 & 1550 & 1919 \\
\hline 89 & RA-R-\# & 80.0 & 52,950 & 95 & 179 & 3148 & 3148 & 116 & 177 & 1896 & 1977 \\
\hline 90 & LD-T-\# & $80 . \overline{3}$ & 62,200 & 100 & 166 & 1173 & 1173 & 127 & 177 & 1242 & 1498 \\
\hline 82 & RD-4-1 & 86.0 & 11,072 & 103 & 131 & 1834 & $\mathrm{NA}^{*}$ & 116 & 140 & 995 & $\mathrm{NA}^{*}$ \\
\hline 83 & $\mathrm{RD}-12-1$ & 81.0 & 68,788 & 97 & 147 & 3354 & $\mathrm{NA}^{*}$ & 114 & 140 & 1313 & $\mathrm{NA}^{*}$ \\
\hline 84 & RD-J-3 & 86.5 & 23,840 & 101 & 140 & 2590 & $\mathrm{NA}^{*}$ & 105 & 146 & 2765 & $\mathrm{NA}^{*}$ \\
\hline 85 & LD-R-1 & 95.0 & 34,225 & 103 & 148 & 9433 & 9542 & 112 & 151 & 4769 & 5218 \\
\hline 86 & LD-Y-1 & 95.5 & 44,692 & 95 & 150 & 10589 & 10608 & 104 & 151 & 2906 & 3268 \\
\hline 87 & LD-R-2 & 86.0 & 53,500 & 97 & 125 & 3867 & 3867 & 121 & 166 & 1750 & 2065 \\
\hline 88 & RD-T-4 & 80.0 & 54,500 & 104 & 146 & 5380 & 5380 & 117 & 166 & 1977 & 1977 \\
\hline 89 & L\#-7H-\# & 81.5 & 59,522 & 90 & 135 & 10379 & 10379 & 113 & 148 & 2726 & 3033 \\
\hline 90 & RA-T-\# & 83.0 & 60,750 & 99 & 152 & 12854 & 12854 & 115 & 155 & 3911 & 4095 \\
\hline 83 & RD-T-2 & 88.0 & 26,549 & 99 & 153 & 1047 & $\mathrm{NA}^{*}$ & 122 & 161 & 352 & $\mathrm{NA}^{*}$ \\
\hline 84 & LD-J-3 & 88.0 & 33,934 & 109 & 149 & 2997 & $\mathrm{NA}^{*}$ & 120 & 156 & 1576 & $\mathrm{NA}^{*}$ \\
\hline 85 & RD-R-1 & 86.0 & 39,875 & 104 & 149 & 4324 & 4478 & 118 & 166 & 1599 & $173 t$ \\
\hline 86 & RD-Y-1 & 76.0 & 35,851 & 97 & 154 & 2256 & 2270 & 107 & 140 & 668 & 741 \\
\hline 87 & $\overline{R D}-\mathrm{R}-1$ & 71.0 & 58,400 & 104 & 147 & 1128 & 1128 & 121 & 140 & 565 & 658 \\
\hline 88 & RD-T-1 & 75.0 & 52,300 & 107 & 150 & 1969 & 1969 & 120 & 170 & 932 & 932 \\
\hline 89 & LA-R-\# & 74.0 & 55,250 & 93 & 155 & 2155 & 2155 & 104 & 165 & 1417 & 1538 \\
\hline
\end{tabular}


Table 2 (continued).

\begin{tabular}{|c|c|c|c|c|c|c|c|c|c|c|c|}
\hline Year & $\begin{array}{l}\text { Brand } \\
\text { Code }\end{array}$ & $\begin{array}{c}\text { Median } \\
\text { Release Dạte } \\
\text { (Julian) }\end{array}$ & $\begin{array}{l}\text { Estimated } \\
\text { Number } \\
\text { Released }\end{array}$ & $\begin{array}{c}\text { First Day of } \\
\text { Lower } \\
\text { Granite } \\
\text { Collection }\end{array}$ & $\begin{array}{c}\text { Last Day of } \\
\text { Lower } \\
\text { Granite } \\
\text { Collection }\end{array}$ & $\begin{array}{c}\text { Total } \\
\text { Collected at } \\
\text { Lower } \\
\text { Granite }\end{array}$ & $\begin{array}{c}\text { Total } \\
\text { Passage } \\
\text { Index at } \\
\text { Lower } \\
\text { Granite }\end{array}$ & $\begin{array}{l}\text { First Day of } \\
\text { McNary } \\
\text { Collection }\end{array}$ & $\begin{array}{c}\text { Last Day of } \\
\text { McNary } \\
\text { Collection }\end{array}$ & $\begin{array}{c}\text { Total } \\
\text { Collected at } \\
\text { McNary }\end{array}$ & $\begin{array}{c}\text { Total } \\
\text { Passage } \\
\text { Index al } \\
\text { McNary }\end{array}$ \\
\hline 90 & LA-T-\# & 76.0 & 57,425 & 101 & 152 & 3552 & 3552 & 110 & 157 & 1162 & 1209 \\
\hline 82 & RD-SU-\# & 99.0 & 21,196 & 125 & 166 & 1498 & $\mathrm{NA}^{*}$ & 124 & 158 & 557 & $\mathrm{NA}^{*}$ \\
\hline 83 & RD-T-3 & 77.0 & 43,122 & 93 & 185 & 7217 & $\overline{N A^{*}}$ & 114 & 135 & 2428 & $\mathrm{NA}^{*}$ \\
\hline 87 & LA-J-\# & 91.0 & 40,619 & 101 & 125 & 5019 & 5019 & 120 & 179 & 2716 & 3194 \\
\hline 88 & \#A-I\#-\# & 92.0 & 83,230 & 99 & 154 & 20362 & 20362 & 115 & 155 & 4930 & 4930 \\
\hline 89 & \#D-J-\# & 93.0 & 78,056 & 99 & 157 & 7209 & 7209 & 113 & 159 & 8008 & 8818 \\
\hline 90 & $\# A-A-\#$ & 92.0 & 82,786 & 98 & 135 & 17374 & 17374 & 113 & 157 & 6903 & 7176 \\
\hline 84 & RD-J-1 & 80.5 & 85,644 & 92 & 137 & 4968 & $\mathrm{NA}^{*}$ & 104 & 140 & 6852 & $\overline{\mathrm{NA}^{*}}$ \\
\hline 85 & LD-R-3 & 78.0 & 35,825 & 90 & 135 & 7111 & 7167 & 106 & 149 & 6611 & 6770 \\
\hline 86 & LD-Y-3 & 85.5 & 44,754 & 95 & 142 & 9898 & 9908 & 103 & 151 & 3047 & 3484 \\
\hline 87 & LD-R-4 & 82.0 & 51,350 & 92 & 138 & 5629 & 5629 & 119 & 169 & 2043 & 2388 \\
\hline 88 & LD-T-4 & 82.5 & 53,900 & 98 & 168 & 8956 & 8956 & 118 & 156 & 1441 & 1441 \\
\hline
\end{tabular}

* Passage Index not available from 1982 or 1983 reports by Coastal Zone and Estuarine Studies or from 1984 report by Fish Passage Center. 
Average, minimum, and maximum total daily flows at each of the Lower Granite, Little Goose, Lower Monumental, Ice Harbor, and McNary Dams.

Average, minimum, and maximum daily flows through the spillway at each of the Lower Granite, Little Goose, Lower Monumental, Ice Harbor, and McNary Dams.

Average daily river temperature at Lower Granite, Lower Monumental, Ice Harbor, and McNary Dams (Little Goose data were unavailable).

Average daily turbidity of the water in the forebay of Lower Granite, Lower Monumental, Ice Harbor, and McNary Dams (Little Goose data were unavailable)

As detailed in Section 2.2, it is crucial for the estimation of travel times to adjust recovery numbers for fish that are removed by the smolt transportation program on the river. At certain times of the year, the transportation program accounts for the removal of a substantial percentage of the migrating smolt. The source of data on daily removals of smolt for transportation is the Fish Transportation Oversight Team (FTOT) of NMFS. The relevant removals take place at Lower Granite and Little Goose Dams.

\subsection{Travel Time Estimation Through the Lower Granite to McNarv Reach.}

For studying the relationship between smolt travel times and river conditions, the ideal information would be individual-based. That is, the travel time of each individual smolt through the index reach would be known, and these times could be related to individual traits and the conditions the individuals encountered while navigating the reach. Miniature electronics (i.e. PIT tags) are now making this information-gathering capability possible. Freeze brands, on the other hand, give very limited individual-based information, and then only when the entire group is released all at once at the top of the reach of interest. For releases extended over a number of days, the information obtained from freeze brands is entirely group-based. Consequently, an aggregate measure of the travel times for all the individuals in a group must be used and related to measures-of the prevailing conditions during the time that the group, or at least the bulk of the group, traveled through the index reach.

We use the median of the distribution of the travel times of all the individuals in a brand group as the aggregate or central tendency for the travel time for a group. The mean travel time cannot be computed, as individual travel times are not available. The median travel time through the Lower Granite to McNary index reach is estimated as the difference between the median 
arrival time at McNary and the time of median entry into the index reach at Lower Granite. The median arrival time at McNary is defined as the time when 50 percent of the estimated number of smolts eventually reaching McNary Dam had arrived (i.e. the median of the distribution of smolt arrivals over time). The date of median entry into the index reach at Lower Granite Dam is defined comparably.

\subsubsection{Adiustment Algorithm for Passage Indices}

If no fish were removed by the transportation program and no fish died during passage through the dam, all smolts that arrived at Lower Granite Dam would enter the index reach and continue in-river migration to McNary Dam, and the median arrival time based on collection numbers at Lower Granite could be used as the median entry date into the index reach. However, large numbers of smolts are removed for transportation at Lower Granite and Little Goose dams and there is mortality associated with passage through the dam (i.e. passage through the turbines, bypass system, and spillway). The relevant distribution for comparison to the McNary arrival distribution is the distribution of the actual numbers of fish entering the index reach that remained eligible to be counted in the arrival distribution at McNary, i.e. those that did not die or get removed by the transportation program somewhere in the index reach.

The goal of the adjustment algorithm is to reconstruct the relevant reach entry distribution to the extent possible using the available data. The algorithm is explained in detail below. To summarize, the daily collection numbers at Lower Granite Dam are inflated to estimate the distribution of the total number of fish arriving at the dam. The arrival distribution is then adjusted to estimate the distribution of fish remaining in the river below Lower Granite Dam. A second adjustment corrects for the fish removed from the eligible population at Little Goose. Further adjustments could be made for mortality at Lower Monumental and Ice Harbor dams but, in the absence of transportation at these dams, the effect of such adjustments is to scale the amplitude of the distribution proportionately throughout the range. Because the median is not affected, do not performed the adjustments for the lower reach dams.

The detailed explanation of the algorithm follows:

First, the estimated dally number of smolts collected $\left(N_{c}\right)$ in the bypass system at Lower Granite Dam is taken from the FPC reports. Note that this number is not the number actually sampled. Rather, it is the number sampled expanded to reflect the subsampling rate over time. The estimated number collected is then adjusted by an estimate of the fish guidance efficiency 
(FGE) to estimate the total number of fish entering the powerhouse (bypass or turbines). There is an additional adjustment to compensate for the potential passage through the spillway. These adjustments give an estimate of the total number of fish arriving $\left(N_{a}\right)$ at Lower Granite for that day:

$$
N_{a}=\frac{N_{c}}{F G E\left(1-P_{\text {spill }} S E\right)}
$$

where $P_{\text {spill }}$ is the proportion of the flow passing through the spillway at Lower Granite and FGE is the fish guidance efficiency at Lower Granite, and SE is the spill efficiency. Spill efficiency is the ratio of the proportion of fish that pass through the spillway to the proportion of the flow that is spilled. For example, if a spilı rate of $40 \%$ results in $60 \%$ of the fish passing over the spillway, the spill efficiency is 1.5 . The estimated number arriving at Lower Granite is then adjusted for the fish removed due to mortality in the spillway, turbines, and bypass channel, and those removed by the transportation program. The result is the estimate of the number of fish entering the index reach $\left(N_{e}\right)$; i.e. still migrating in the river below Lower Granite Dam. The equation is:

$$
N_{e}=N_{a}\left\{S E\left(P_{\text {spill }} S_{\text {spill }}\right)+\left(1-P_{\text {spill }} S E\right)\left((1-F G E) S_{\text {turb }}+F G E\left(1-P_{\text {tran }}\right) S_{\text {byp }}\right)\right\}
$$

where in Eq. (2):

$S_{s p i l l}$ is the probability of surviving passage through the spillway at Lower Granite Dam;

$\mathrm{S}_{\text {turb }}$ is the probability of surviving passage through the turbines at Lower Granite Dam;

$\mathbf{P}_{\text {tran }}$ is the proportion of smolts passing through the bypass system at Lower Granite that were removed for transportation to below Bonneville Dam; and

$\mathrm{S}_{\text {byp }}$ is the probability of surviving passage through the bypass system at Lower Granite Dam.

Standard values assumed for the survival probabilities were $85 \%$ through the turbines and $98 \%$ through the spill and bypass system. The standard value for FGE was assumed to be constant through the season and equal to 50\%. The standard value for spill effectiveness was 1.0 (see Table 3). Section 3 includes discussion of the sensitivity of the travel time estimates to different assumed values for the survival probabilities, FGE, spill effectiveness, as well as other parameters. The daily proportions of collected fish removed for transportation were derived 
Table 3. Standard values assumed for parameters in adiustment of passagedistributions for travel time estimation. Standard values were used for all dams,

\begin{tabular}{|cc|}
\hline Parameter & Standard Value \\
\hline FGE & 0.5 \\
$S_{\text {spill }}$ & 0.98 \\
$\mathrm{~S}_{\text {turb }}$ & 0.85 \\
$S_{\text {byp }}$ & 0.98 \\
$T T_{\text {rch }}$ & 4 days \\
$\mathrm{S}_{\text {rch }}$ & 0.80 \\
$\mathrm{SE}$ & 1.0 \\
\hline
\end{tabular}


from FTOT reports of total numbers arriving and numbers bypassed. In the FTOT reports, counts are broken down by species but not by brand codes. Therefore, it is necessary to assume that the proportion of each brand group transported was equal to the proportion of the total for the species.

The result of Eq. 2 is the estimated daily distribution of reach entry, N,. This result is the input for a second adjustment to account for transportation removals and mortality at Little Goose Dam. Daily recovery data are not available from Little Goose Dam. Consequently, it is necessary to approximate indirectly the required adjustments for transportation removals and spill proportions at Little Goose. This was accomplished by lagging the distribution from Lower Granite by a period of days. That is, the entry number for day $i$ derived from Eq. (2) was adjusted for the conditions at Little Goose Dam on day $i+K$, where $K$ is the lag time in days. Our standard value for the lag time for chinook smolts was 4 days, as in the Berggren and Filardo (1993) studies. The effect of changes in the assumed lag time (also called $T T_{r c h}$ for "travel time in the reach") was investigated as part of the sensitivity study reported in Section 3. The form of the adjustment for Little Goose is similar to Eq. (2):

$$
\begin{aligned}
& N_{e}^{\prime}=N_{e} S_{r c h}\left\{S E\left(P_{\text {spill }} S_{s p i l l}\right)_{+}\right. \\
&\left.\left(1-P_{\text {spill }} S E\right)\left((1-F G E) S_{\text {turb }}+F G E\left(1-P_{\text {tran }}\right) S_{\text {byp }}\right)\right\}
\end{aligned}
$$

where in this equation:

$N_{e}^{\prime}$ is the distribution of reach entry for those fish that remained in the river below Little Goose Dam;

$S_{r c h}$ is the probability of surviving through the Lower Granite-to-Little Goose reach;

$P_{\text {spill }}$ is the proportion of the flow passing through the spillway at Little Goose Dam on day $i+4$;

$S_{\text {spill }}$ is the probability of surviving passage through the spillway at Little Goose Dam;

$\mathrm{S}_{\text {turb }}$ is the probability of surviving passage through the turbines at Little Goose Dam;

$P_{\text {tran }}$ is the proportion of smolts passing through the bypass system at Little Goose that were removed to be transported to below Bonneville Dam on day $i+4$; and

$\mathrm{S}_{\text {byp }}$ is the probability of surviving passage through the bypass system at Little Goose Dam. 
The standard value for the survival probability through the Granite-to-Goose reach was 0.80 . For purposes of estimating the median of the passage distribution, however, the actual value used for $S_{r c h}$ is irrelevant. Its only effect on the distribution is to scale each of the daily estimates of $N_{e}^{\prime}$ by a constant amount; the median is the same regardless of the reach survival value. For the other parameters, the same standard values (Table 3) were assumed for Little Goose as for Lower Granite Dam. See Section 3 for studies of sensitivity of the travel time estimates to the assumed values for these parameters.

Equations (1), (2), and (3) result in an estimate of the distribution over time of entry into the index reach for the release group. Because the count on each day represents the accumulated number of fish over the past 24 hours, the median date of passage was obtained by interpolating where the median occurred within the sampling period, relative to the midnight reference point, and assuming uniform passage around the clock. The distribution of arrival at McNary is estimated from numbers sampled just as at Lower Granite (Eq. 1). The form of Eq. 1 implies that the particular value used for FGE at McNary Dam will not affect the estimate of median travel time. The effect of altering the McNary FGE assumption is to scale the amplitude of the distribution. The position of the distribution, and the median in particular, are not changed.

Finally, the median travel time for the group was estimated as the difference between the interpolated median dates of entry into the index reach and arrival at McNary Dam.

\subsubsection{Discussion}

Having adjusted the estimated Lower Granite arrival distribution for removals and mortality at Lower Granite and Little Goose Dams, $N^{\prime}{ }_{e}$ gives the daily distribution of reach entry for those fish that remained in the river below Little Goose Dam. Similarly, using Equation 1 to inflate the collection numbers at McNary gives the daily distribution of arrival at McNary Dam. Summing the distributions over days should give the total number of fish that entered the Little Goose-to-McNary reach and the total number that arrived at the bottom of the reach . Because we do not adjust for mortality at Lower Monumental or Ice Harbor Dams, the total number entering the reach should be equal to or greater than the number arriving at the bottom, and the ratio of the two sums should give an estimate of the survival rate between the two dams. However, using our standard parameter values (including FGE of 0.5 at McNary), the total number arriving at McNary is greater than the number remaining in the river below Little Goose for 35 of the 42 groups. Even using the more realistic figure of 0.75 for McNary FGE, this paradox remains for 16 groups. This result suggests that some commonly-held values for key 
parameters, e.g. FGE, spill effectiveness, or dam and reservoir mortality may be substantially in error.

\subsection{Regression Results}

\subsubsection{Variables}

The independent variable in the multiple regression models is the estimated median travel time of the brand groups through the Lower Granite to McNary index reach (TTIME). The travel time is estimated as described in Section 2.2, assuming the standard values for fish guidance efficiency, spill efficiency, survival probabilities associated with various routes of passage through dams, and the travel time through the Lower Granite to Little Goose reach (Table 3).

Many factors may influence the rate of downstream movement of juvenile salmon. Some factors are biological attributes of the individual fish, most importantly the degree of smoltification, which is related to the fish's readiness to migrate. Other factors are external to the fish, including the flow volumes in the river (especially as they relate to the velocity of the river flow) and other river conditions, such as water temperature and turbidity, and operations at individual dams, such as flow volumes through spillways. Both internal and external variables were considered as predictors of travel time in the regression analyses. Many of the important variables were measured at each of the five different dams in the index reach, i.e. Lower Granite, Little Goose, Lower Monumental, Ice Harbor, and McNary Dams.

Indices of the physiological condition of the smolts were available for a few of the brand groups in recent years (e.g. Rondorf et al, 1989) and these measurements are treated separately and discussed in Section 7. In these regression analyses, however, it is necessary to use surrogate measures of the degree of smoltification that can accompany every marked group. Several such surrogate variables were explored in this analysis. The variables considered were the Julian date of median release from the hatchery (RELDATE), the Julian date of median entry into the index reach (ENTDATE); prior in-river travel time in days from the date of release to median entry into the index reach (TTLGR); and an indicator variable for race to separate spring and summer chinook (RACE). There is also evidence that river temperature is an important factor in stimulating the onset and speed of smoltification (Hoar, 1988; Wedemeyer et al., 1980). River temperature is discussed below as a variable related to river conditions. Hoar (1988) and Wedemeyer et al. (1980) also identified day length as an important factor in smoltification 
development. In this data set, day length gives little information not contained in ENTDATE and therefore was not considered in this analysis (the linear correlation between the Julian date of entry and the day length is 0.995). Rondorf et al. (1988) have shown that yearling chinook and steelhead hatchery groups have exhibited significant increases in ATPase levels after 15 to 20 days of in-river migration, indicating increased smoltification. Brand groups from different release sites in this study must travel widely different distances to arrive at Lower Granite (73 to $465 \mathrm{~km}$ ) and consequently spend different amounts of time in-river before entering the index reach. The TTLGR variable, therefore, was considered as a potential surrogate for degree of smoltification.

The river conditions that were considered relevant to travel time were flow, water temperature, and turbidity. As mentioned above, water temperatures may be related to smoltification. Turbidity may effect the movement of smolts, particularly in the slow moving waters of dam forebays. Daily data on temperature and turbidity at four of the five dams in the index reach were obtained from the Army Corps of Engineers (data were not available from Little Goose Dam). For each dam, a total of six predictor variables was computed from the daily data on temperature and turbidity data. The variables were the average, minimum, and maximum of the daily average temperature and turbidity over the period between the date of median entry into the index reach and the date of median arrival at McNary Dam. This period will be referred to hereafter as the "intermedian period." The self-explanatory names of the variables are AVGTEMP, MAXTEMP, MINTEMP, AVGTURB, MAXTURB, MINTURB.

The flow-related variables considered to be candidates for independent variables were the average (AVGFLOW), maximum (MAXFLOW), and minimum (MINFLOW) of the daily average flows during the intermedian period and the average (AVGSP), maximum (MAXSP), and minimum (MINSP) spill volumes during the intermedian period, These variables were computed (kcfs) for the five dams in the index reach. The spill measures are considered important because of the potential influence of spill rates on the amount of delay the smolt experience in the forebay before they pass through a hydroelectric project.

The complete data set, including measures at all 5 dams in the index reach, is listed in Appendix A. 


\subsubsection{Response Model}

A proper regression analysis includes a priori consideration of the appropriate response model, or form of the regression equation. Careful consideration of the nature of the dependent and independent variables and the relationships between them can suggest transformations of variables that ensure that the relationships are represented appropriately by the equation.

Although using an "incorrect" response model will not induce a correlation that does not exist, using the "correct" form increases the power to detect significant relationships.

If there is a relationship between the time it takes a smolt to travel through a reach of the river and the flow in that reach, it is reasonable to assume that the important characteristic of the flow is the velocity of the water and not its total volume. To model the relationship between flow and the dependent variable of travel time (TTIME) we considered water velocity as represented by the inverse of the flow volume to be an appropriate.measure. According to the storage replacement method developed by the U.S. Army Corps of Engineers, the amount of time it takes for a particle of water to travel through a reservoir is inversely related to flow according to the first-order approximation:

$$
\text { Time } \propto \frac{\text { Reservoir Volume }}{\text { Flow }} .
$$

This relationship suggests that a plausible response model for relating flows to smolt travel times, reflecting the biology of fish migration, is:

$$
\text { TTIME }=\alpha+\beta * \mathrm{FLOW}^{-1}+\varepsilon .
$$

Accordingly, the flow-related variables we used in the regression analyses were the reciprocals of the flow volumes, denoted AVGFLOW ${ }^{-1}$, MINFLOW'-1, and MAXFLOW ${ }^{-1}$. In addition, another flow-related variable was created, called DFLOW'-1, to represent the fluctuation in water volumes during the intermedian period. The $\mathrm{DFLOW}^{-1}$ variable is defined as the difference between MINFLOW ${ }^{-1}$ and MAXFLOW'-1 If faster smolt travel times are associated with large values of $\mathrm{DFLOW}^{-1}$ it is an indication that large changes in flow volumes help speed migrating smolts, perhaps through a "flushing" effect. Berggren and Filardo (1993) used a variable called DFLOW, the difference between the maximum and minimum flows (kcfs), in place of our DFLOW ${ }^{-1}$.

We have no theoretical reason to transform variables such as turbidity, temperature, spill volumes, or the travel time to from release to Lower Granite Dam (TTLGR). These variables 
will enter the model on the original scale of measurement. That is, assuming that a flow variable is included, the form of the model will be:

$$
\operatorname{TTIME}=\alpha+\beta * \mathrm{FLOW}^{-1}+\boldsymbol{\sim}^{\prime} \underset{\sim}{X}+\varepsilon
$$

where $X$ is the vector of covariates and $\gamma$ is the vector of effect parameters.

\subsubsection{Basic Analvsis}

The purpose of the analysis presented in this section is to provide initial regression models that will be used as a starling point for further investigations reported in later sections. For example, the sensitivity of the regression results to the assumptions underlying the estimation of median travel time is investigated in Section 4, and models obtained using predictor variables from all dams in the index reach are the subject of Section 6. It is also instructive to compare the results of our basic analysis to those of Berggren and Filardo (1993).

Our basic regression analysis used predictor variables from only a single index site, Ice Harbor Dam, which is often regarded as the index for all dams in the reach. The dependent variable is the estimated median travel time obtained assuming the standard parameter values in the estimation algorithm. The potential predictor variables are the inverses of the minimum, average, and maximum flow volumes, the difference between the inverses of the minimum and maximum flows, and the minimum, average, and maximum of spill, temperature, and turbidity, all measured at Ice Harbor Dam. Additional potential predictors are the median date of release, the median estimated date of entry into the index reach, and the estimated travel time from release to arrival at Lower Granite Dam. The pair-wise linear correlations between the estimated travel time and all the potential predictor variables are listed in Table 4.

For Ice Harbor to be a valid index for the other dams, the conditions at Ice Harbor (potential predictors) should reflect the conditions at the other dams. Presumably, if two variables are highly correlated to each other then their respective relationships with a third variable will be very similar (i.e. the travel time relationships with Ice Harbor measurements will represent those with measurements at other dams). Table 5 shows the pair-wise linear correlations between the measurements of river conditions at Ice Harbor and the measurements at the other dams. The flow variables are very highly correlated among the dams, especially among the four Snake River dams. The correlations of spill volumes are not as high, especially between the maximum spill measurements at Lower Granite and Ice Harbor. For flow volumes, then, and to a lesser extent spill volume, the measurements at Ice Harbor are reasonable 
Table 4. Pairwise linear correlations ( $r$ ) between estimated median travel time and potential predictor variables in basic repression analvsis. Based on $\mathbf{4 2}$ observations listed in Table 1 ,

\begin{tabular}{|cc|}
\hline Variable & Correlation \\
\hline MINFLOW $^{-1}$ & $0.608^{\prime \prime}$ \\
AVGFLOW & $0.628^{\prime}$ \\
MAXFLOW $^{-1}$ & $0.438^{*}$ \\
DFLOW-1 & $0.565^{*}$ \\
MINSP & $-0.642^{\prime}$ \\
AVGSP & $-0.555^{\prime}$ \\
MAXSP & $-0.388^{\prime}$ \\
MINTEMP & $-0.324 *$ \\
AVGTEMP & -0.126 \\
MAXTEMP & -0.067 \\
MINTURB & 0.119 \\
AVGTURB & 0.093 \\
MAXTURB & 0.241 \\
RELDATE & 0.051 \\
ENTDATE & $-0.461 *$ \\
TTLGR & $-0.456^{\prime}$ \\
\hline
\end{tabular}

* Correlation is significant at the two-sided 0.05 level $\left(P_{\boldsymbol{H}_{\mathbf{0}}}(|\boldsymbol{r}| \geq 0.3041 \mathrm{n}=42)=0.05\right)$ 
21

Table 5. Pairwise correlations between river conditions at Ice Harbor Dam and conditions at other dams. Based on 42 observations listed in Table 1.

\begin{tabular}{|c|c|cccc|}
\hline \multirow{3}{*}{ Condition } & & $\begin{array}{c}\text { Lower } \\
\text { Granite }\end{array}$ & $\begin{array}{c}\text { Little } \\
\text { Goose }\end{array}$ & $\begin{array}{c}\text { Lower } \\
\text { Monumental }\end{array}$ & McNary \\
\hline \multirow{3}{*}{ Flow- } & Minimum & 0.941 & 0.983 & 0.991 & 0.803 \\
& Average & 0.998 & 0.998 & 0.999 & 0.905 \\
& Maximum & 0.950 & 0.979 & 0.993 & 0.729 \\
& Delta Flow ${ }^{-1}$ & 0.912 & 0.976 & 0.984 & 0.636 \\
\hline \multirow{3}{*}{ Spill } & Minimum & 0.763 & 0.710 & 0.890 & 0.922 \\
& Average & 0.882 & 0.880 & 0.937 & 0.884 \\
& Maximum & 0.593 & 0.714 & 0.934 & 0.752 \\
\hline \multirow{3}{*}{ Temperature } & Minimum & 0.421 & NA & 0.785 & 0.504 \\
& Average & 0.731 & NA & 0.902 & 0.695 \\
& Maximum & 0.773 & NA & 0.754 & 0.601 \\
\hline \multirow{3}{*}{ Turbidity } & Minimum & 0.026 & NA & 0.436 & 0.894 \\
& Average & 0.522 & NA & 0.566 & 0.939 \\
& Maximum & 0.772 & NA & 0.704 & 0.867 \\
\hline
\end{tabular}


representations of the conditions at all the Snake River dams. However, Table 5 suggests that the relationships of travel time with temperature and turbidity measured at Ice Harbor are not a reliable index for the other dams. For this reason, the analysis of this section is restricted to models that include flow volumes, spill volumes, and surrogate measures of smoltification.

Both stepwise regression (Sokal and Rohlf, 1981) and best-subsets regression (Snedecor and Cochran, 1980) were used to identify reasonable regression models using the potential variables ENTDATE and TTLGR as surrogates for smoltification and AVGFLOW-1 ${ }^{-1}$ MINFLOW 1, MAXFLOW ${ }^{-1}$, DFLOW'-1 and MINSP, AVGSP, and MAXSP measured at Ice Harbor. Stepwise regression was performed using the MINITAB statistical software package, using the default criteria. That is, variables entered the model if their F-value to enter was greater than 4.0 and were removed from the model at later steps if their F-value dropped below 4.0. Best-subsets regression was also performed using MINITAB. The purpose of best-subsets regression is to find the subset of size $n$ of the potential predictors that result in the highest $R^{2}$ values.

The stepwise procedure selected the variable MINSP first, followed by TTLGR, and then DFLOW $^{-1}$. However, the best subsets regression analysis shows that the model selected by the stepwise procedure is actually the second best 3-variable model according to the $R^{2}$ criterion. The best-subsets regression is summarized in Table 6 . The three best models including 1, 2, 3, or 4 variables are listed, along with the respective values for $R^{2}$ and for Mallow's $C_{p}$ criterion (Neter, Wasserman, and Kutner, 1985, pp. 426-428). Table 6 shows the best 3-variable model, which includes TTLGR, AVGFLOW ${ }^{-1}$, and MAXFLOW ${ }^{-1}$. In using the $C_{p}$ criterion, one seeks to identify subsets of predictor variables for which: (1), the $C_{p}$ criterion is small and (2), the $C_{p}$ value is near the number of predictors in the model. The only model for which both conditions hold is the 4-variable model that includes TTLGR, AVGFLOW-1, MAXFLOW-', and MINSP. This model has $C_{p}=4.1$ and is considered the best possible model for the travel time estimates given the set of potential predictors.

It is clear that there are several 3-and 4-variable regression models of the data that are nearly equal in their explanatory power. The choice of one from among them may depend on the use to which the results are to be put and/or the ease of interpretation. In any case, it is difficult to argue that any particular predictor variable is uniquely valuable by virtue of its inclusion in the model one chooses to work with, when another model in which it is not included has nearly the same explanatory power.

Table 7 gives further results from the best 3- and 4-variable models and for the model selected by the stepwise procedure. The coefficient for TTLGR in all three models suggests that 
Table 6. Summary of results from best-subsets regression and stepwise regression analvses. Potential predictors were surrogates of smoltification and inverse flow volume and spill measured at Ice Harbor Dam. Based on 42 observations listed in Table 1. The model selected by the stepwise procedure is shaded.

(a) 1-variable models.

\begin{tabular}{|ccccc|}
\hline Rank & Variable & $R^{\mathbf{2}}$ & $C_{p}$ & $\mathrm{~S}^{*}$ \\
\hline 1 & MINSP & 41.2 & 37.8 & 2.645 \\
2 & AVGFLOW & 39.4 & 40.1 & 2.686 \\
3 & MINFLOW $^{-1}$ & 37.0 & 43.2 & 2.738 \\
\hline
\end{tabular}

(b) 2-variable models.

\begin{tabular}{|c|c|c|c|c|}
\hline Rank & Variables & $R^{2}$ & $C_{p}$ & S \\
\hline 1 & TTLGR, AVGFLOW-1 & 55.6 & 21.2 & 2.328 \\
\hline 2 & TTLGR, MINSP & 55.1 & 21.8 & 2.340 \\
\hline 3 & TTLGR, MINFLOW ${ }^{-1}$ & 54.5 & 22.7 & 2.357 \\
\hline
\end{tabular}

(c) 3-variable models.

\begin{tabular}{|c|c|c|c|c|}
\hline Rank & Variables & $R^{2}$ & $C_{p}$ & S \\
\hline 1 & TTLGR, AVGFLOW', MAXFLOW' & 65.8 & 10.1 & 2.071 \\
\hline 2 & 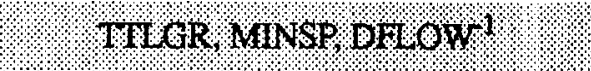 & 622. & $6 \%$ & 2.176 \\
\hline 3 & TTLGR, MINSP, AVGFLOW' & 61.5 & 15.6 & 2.196 \\
\hline
\end{tabular}

(d) 4-variable models.

\begin{tabular}{|ccccc|}
\hline Rank & Variables $^{2}$ & $C_{p}$ & $\boldsymbol{S}^{2}$ \\
\hline 1 & TTLGR, MINSP, AVGFLOW $^{-1}$, MAXFLOW-' & 72.0 & 4.1 & 1.898 \\
2 & TTLGR, AVGSP, AVGFLOW $^{-1}$, MAXFLOW-' & 67.2 & 10.2 & 2.053 \\
3 & TTLGR, MAXSP, AVGFLOW', MAXFLOW-' $^{\prime}$ & 65.9 & 12.0 & 2.096 \\
\hline
\end{tabular}

* Square root of residual mean-square error (MSE). 
I able, Detailed regression results for selected models in basic regression analvsis. Spill and flow volumes measured at I ce Ilarbor Dam. Based on $\mathbf{4 2}$ observations listed in Table 1.

a) Best 4-variable model

\begin{tabular}{|cccccc|}
\hline Variable & Coefficient & Std. Error & p-value' & $R^{2}$ & $\mathbf{S}^{\mathbf{1}}$ \\
\hline Constant & 17.462 & 2.426 & $<0.001$ & & \\
TTLGR & -0.162 & 0.032 & $<0.001$ & & \\
MINSP & -0.081 & 0.028 & 0.007 & & \\
AVGFLOW- 1 & 1011.2 & 214.4 & $<0.001$ & & \\
MAXFLOW-1 & -1220.6 & 328.2 & 0.001 & 72.0 & 1.898 \\
\hline
\end{tabular}

(b) Best 3-variable model

\begin{tabular}{|cccccc|}
\hline Variable & Coefficient & Std. Error & $p$-value* & $R^{2}$ & $\mathbf{S}^{\mathbf{b}}$ \\
\hline Constant & 13.660 & 2.217 & $<0.001$ & & \\
TTLGR & -0.171 & 0.035 & $<0.001$ & & \\
AVGFLOW-1 & 1271.1 & 211.9 & $<0.001$ & & \\
MAXFLOW-1 & -1202.8 & 357.9 & 0.002 & 65.8 & 2.071 \\
\hline
\end{tabular}

(c) Model selected by stepwise procedure

\begin{tabular}{|cccccc|}
\hline Variable & Coefficient & Std. Error & $p$-value & $R^{\mathbf{a}}$ & $S^{\mathbf{b}}$ \\
\hline Constant & 15.863 & 1.372 & $<0.001$ & & \\
TTLGR & -0.141 & 0.036 & $<0.001$ & & \\
MINSP & -0.090 & 0.029 & 0.003 & & \\
DFLOW $^{-1}$ & 213.03 & 79.98 & 0.011 & 62.2 & 2.176 \\
\hline
\end{tabular}

1. Probability (2-tail) of observed coefficient estimate under null hypothesis that parameter is zero.

2. Square root of mean square error (MSE). 
for each additional week that a smolt spends traveling from release site to Lower Granite Dam, it takes around one day less to traverse the Lower Granite to McNary reach. The coefficients for the reciprocal of flow variables must be interpreted jointly in the best 3-and 4- variable models. The negative coefficient for MAXFLOW ${ }^{-1}$ indicates that for a given average flow, greater maximum flows are associated with longer travel times. The difference between the maximum and average flows amounts to a measure of variability in flow. The significance of both the maximum and average flow measures, and their opposite sign are an indication that increased variability of flow is associated with longer travel times.

None of the three regression models in Table 7 gives a particularly good fit to the group released from Dworshak Hatchery in 1986 with brand RA-Y-2. Also, the statistical software flags the group released from McCall Hatchery in 1990 with brand LD-T-\# as having values of the predictor variables that potentially give the observation high influence on the model (i.e. "leverage"; Cook and Weisberg, 1982). The LD-T-\# group took an exceptionally long time to arrive at Lower Granite Dam (62.1) days. Consequently, the group entered the index reach 5 days later than the other two latest groups and 3 weeks to a month later than the bulk of the groups. Omission of this group from the analysis is justifiable on the grounds that the conditions experienced later in the year are substantially different than during the peak of the migration. However, omission of the LD-T-\# group has extremely small effect on the estimated regression coefficients and on the associated standard errors, suggesting no statistical need to omit the group. Omission of the RA-Y-2 group has a larger effect on the regression models, but the group has no readily identifiable characteristic to explain its exceptionally long travel time (20.6 days). In any case, the qualitative results of the best subsets regression are the same when the group is omitted, and we do not feel that the quantitative effects on the regression coefficients is sufficient to justify the removal of the observation.

\subsubsection{Discussion}

The best 3-variable model, including TTLGR, AVGFLOW ${ }^{-1}$, and MAXFLOW $^{-1}$, is very similar to the model identified in the Fish Passage Center analyses (Berggren and Filardo, 1993), which included TTLGR, AVGFLOW ${ }^{-1}$ and DFLOW. However, our best model overall is the 4variable model that includes the same variables as the best 3 -variable model plus the minimum spill volume (MINSP), a variable not considered in the FPC analyses. The importance of MINSP (it is the single variable most highly correlated with estimated travel time) is a distinguishing feature in our basic analysis. 
Spill and flow volumes are generally highly correlated, making it difficult to assess their relative importance in predicting travel time. Experiments manipulating dam operations might be able to resolve the two effects better than is possible with the current data. This is an important question, as remedial measures undertaken to improve smolt travel times could differ depending on which variable is found to be more important.

\section{Section 3: Sensitivitv of Travel Time Estimation to Underlving Assumptions.}

The algorithm for estimating travel time in Section 2.2 is a method to adjust the distribution of daily collections of smolt at Lower Granite Dam to estimate the number of fish that remained in the river below Lower Granite Dam and were subject to eventual detection upon arrival at McNary Dam. The daily distribution of smolts remaining in the river is a composite of three components: those that entered the bypass system and were not removed by the transportation program, those that survived passage through the turbines, and those that survived passage through the spillway. The algorithm makes assumptions regarding several critical parameters (e.g. fish guidance, efficiency and spill effectiveness) to estimate the number of fish passing through each of the three routes. The adjustments made to each of the three components on any given day are not necessarily the same, so that any assumed parameter value that gives more or less weight to a particular component can have an effect on the resulting composite distribution. And, because the median travel time is estimated from the resulting composite distribution, such a parameter can also have a marked effect on the travel time estimate. In this section, we investigate the effect on estimated travel times of altering the assumed parameter values.

\subsection{Methods}

The travel time estimation algorithm (Eqs. 1, 2, and 3) requires assumptions regarding fish guidance efficiency (FGE); the probability of surviving passage though the bypass system,

turbines, and spillway ( $S_{\text {byp }}, S_{\text {turb }}$ and $S_{\text {spill }}$, respectively); the travel time and the probability of surviving passage through the Lower Granite-to-Little Goose reach $\left(T T_{r c h}\right.$ and $S_{r c h}$, respectively); and spill effectiveness (SE). The standard values for the parameters are listed in Table 3. For the sensitivity analysis, our approach was to investigate the sensitivity of the travel time estimates to variations in the assumed value for one of the parameters, while holding all other parameters constant at their standard values. Seven brand groups, listed in Table 8, were selected to illustrate the effects of varying parameter values in detail. The groups were chosen to be representative of a wide variety of years, release sites, and release conditions. Most of the 
Table 8. Brand croups used in the study of the sensitivitv of travel time estimates to assumed uarameter values.

\begin{tabular}{|clccllr|}
\hline Year & Brand & Strain & Start & Finish Source & Release & Number \\
\hline $\mathbf{8 6}$ & RA-Y-2 & sp & 02 Apr & 03 Apr Dworshak & NFork Clear-water & 40,675 \\
87 & RA-R-1 & sp & 02 Apr & 02 Apr Dworshak & Dworshak & 61,580 \\
86 & RD-Y-3 & su & 24 Mar & 31 Mar McCall & S Fork Salmon & 43,487 \\
85 & LD-R-1 & sp & 31 Mar & 10 Apr Rapid River & Rapid River & 34,225 \\
89 & L\#-7H-\# & sp & 15 Mar & 30 Mar Rapid River & Rapid River & 59,522 \\
90 & LA-T-\# & sp & 17 Mar & 17 Mar Sawtooth & Sawtooth & 57,425 \\
84 & RD-J-1 & sp & 20 Mar & 21 Mar Rapid River & Hells Canyon & $\mathbf{8 5 . 6 6 4}$ \\
\hline
\end{tabular}


sensitivity results reported in this section deal with these seven groups, while certain points are illustrated using all 42 hatchery release groups.

For each of the seven parameters listed in Table 3, the adjustment algorithm of Section 2.2 was applied to the seven representative groups using a series of different values. The sensitivity analysis for FGE used values of $0.2,0.4,0.5,0.6,0.8$ and 1.0. In addition, modeling of FGE as a function of time of year (Julian date) was also investigated. The equation used for the relationship between FGE and Julian date $(j)$ is derived from the results of Swan et al (1986; 1990), which suggest FGE increases as the season progresses. The equation is:

$$
F G E=\left\{\begin{array}{c}
0.3 \text { if } j<90 \\
-0.1+j / 225 \text { if } 90<j<180 \\
0.7 \text { if } j>180
\end{array}\right.
$$

This equation is illustrated in Figure 2. The FGE is constant at its minimum level (0.3) before day 90 (approximately April 1) and increases linearly to its maximum value (0.7) on day 180 (approximately July 1), thereafter it remains at 0.7. The results of Swan et al $(1986 ; 1990)$ suggest that the relationship is more complicated than a simple linear increase, but the effects on estimation of travel time can be characterized by the linear approximation. The equation was applied at all relevant dams, i.e. Lower Granite, Little Goose, and McNary.

For spillway and bypass survival, the values $0.9,0.925,0.95,0.975$, and 1.0 were used in the sensitivity analysis. Turbine survival values were $0.8,0.85,0.9,0.95$, to 1.0 . The sensitivity analysis for Lower Granite-to-Little Goose travel time ( $T T_{r c h}$, or lag) used values of $0,2,4,6$, 8 , and 10 days, while the analysis for survival probability in that reach used $0.2,0.4,0.6,0.8$, and 1 .O. Finally, spill effectiveness values of $0.75,1.0,1.25,1.5,1.75$, and 2.0 were investigated.

The results of Wilson et al (1991) suggest that the spill effectiveness at Lower Granite is not 1.0 , but rather a function of the proportion of the flow that is spilled. Their results suggest that the spill effectiveness is approximately 2.0 when $20 \%$ of the flow is spilled and 1.5 when $40 \%$ is spilled. In addition to the suite of values listed above applied as constant spill effectiveness, a sensitivity test was conducted modeling daily spill effectiveness as a function of the proportion of water spilled that day. The function we used is a cubic polynomial that passes near the points suggested by Wilson et al $(1991)$ and through the points $(0,0)$ and $(1,1)$. (Obviously, the proportion of fish passing through the spillway must be $0 \%$ when there is no spill and $100 \%$ when all the water is spilled). The function, illustrated in Figure 3, is:

$$
\mathrm{SE}=2.583 \mathrm{~s}-3.250 s^{2}+1.667 s^{3}
$$

where $s$ is the proportion of the flow that is spilled. 


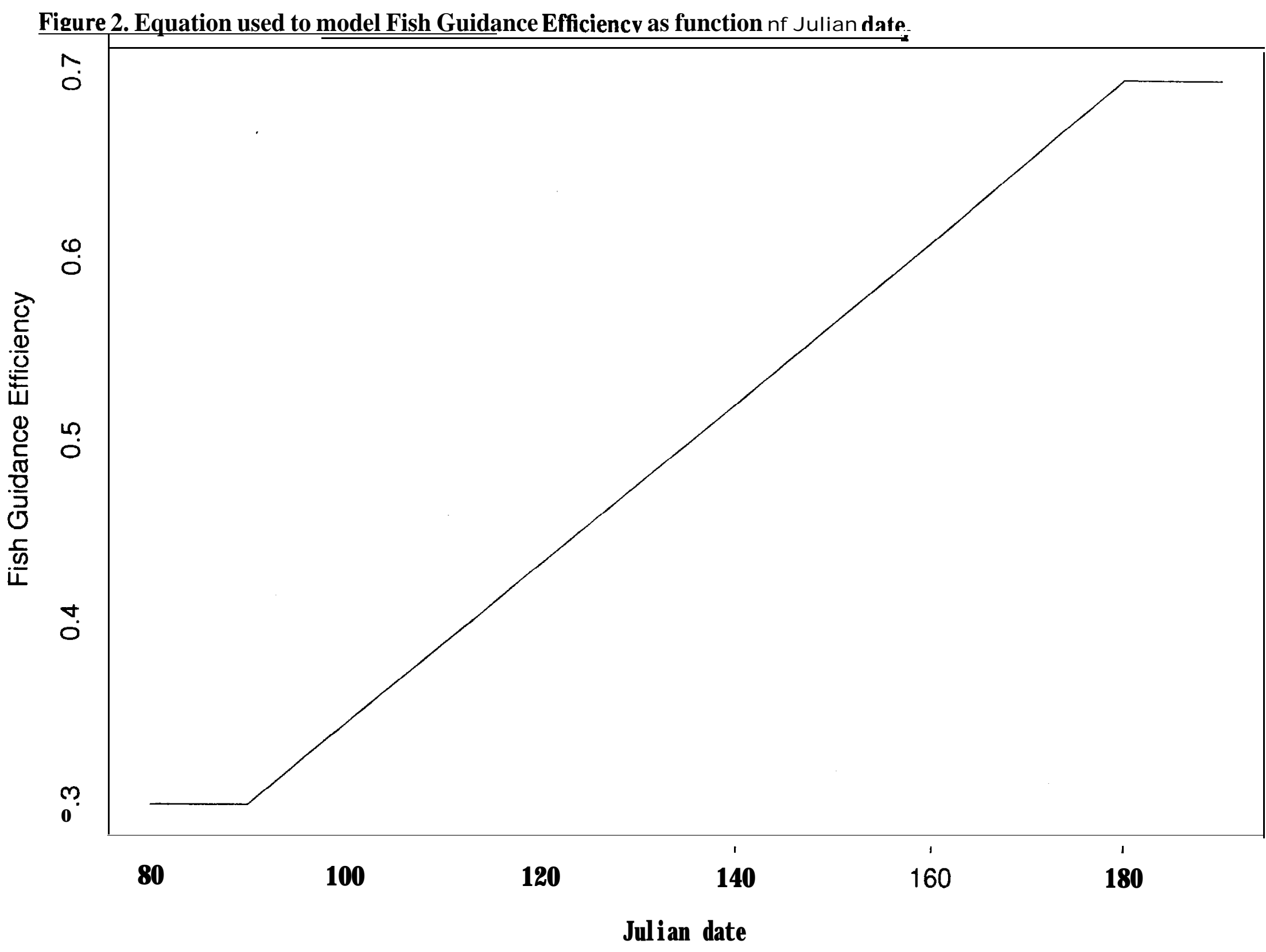


Figure 3. Eauation used to model Spill Effectiveness as a function of the proportion of flow spilled at Lower Granite Dam. Derived from estimates presented in Wilson et al (1991).

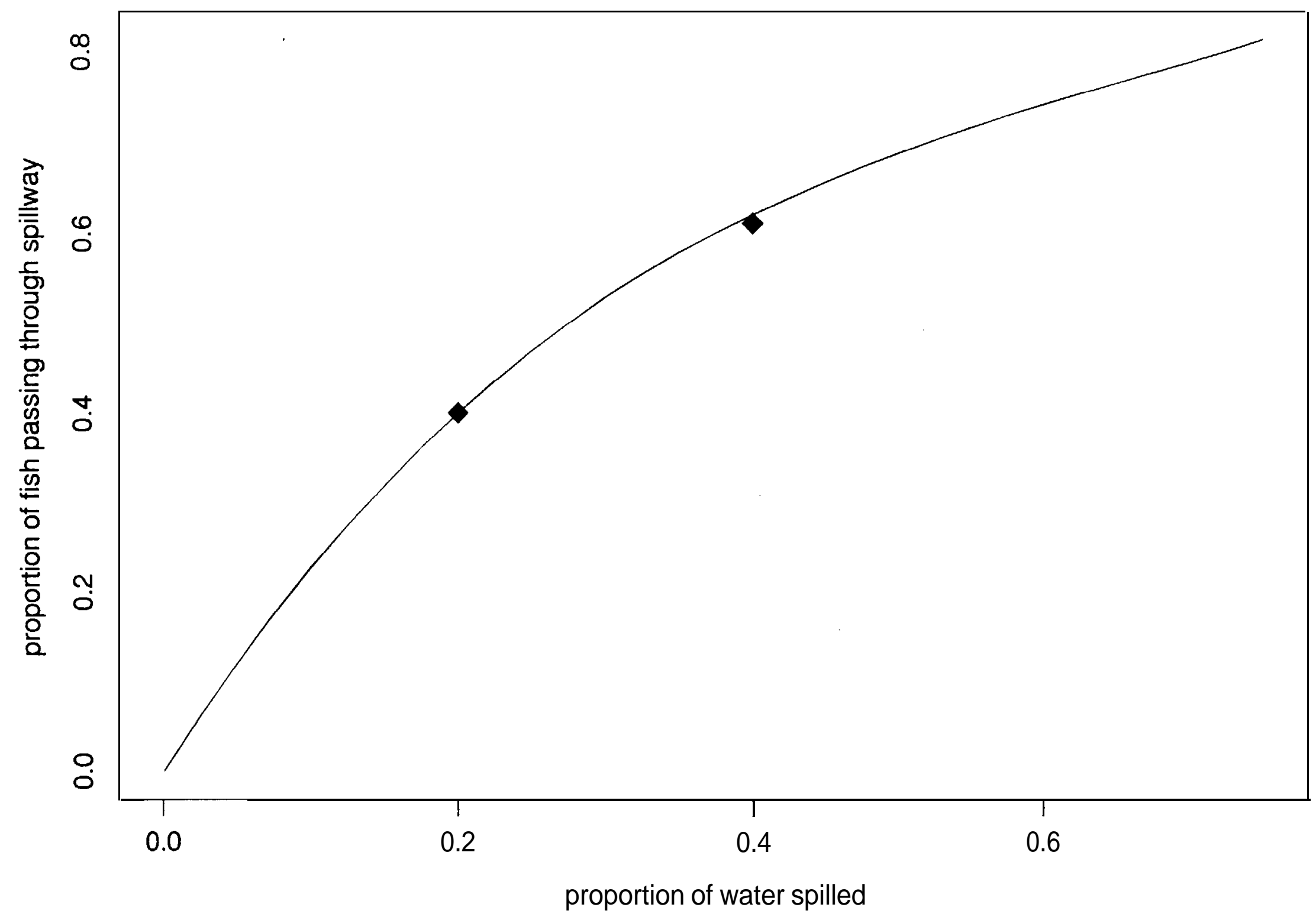




\section{$\underline{3.2}$ Results}

The results of the sensitivity analysis for the 7 representative groups are listed in Table 9 . The first row of the table gives the travel time estimates for the seven sample groups under the standard assumed values for the parameters (Table 3). For the estimates in each of the subsequent rows, the value of one of the parameters is varied from the standard, while all the others are held at the their standard values. For instance, the row labeled "FGE $=0.8$ " uses the value 0.8 for the fish guidance efficiency at each dam (Lower Granite, Little Goose and McNary) involved in the estimation algorithm, while the standard values are used for the other

parameters: $S_{\text {spill }}=0.98, S_{\text {turb }}=0.85, S_{\text {bypass }}=0.98, T T_{r c h}=4$ days, $S_{r c h}=0.8$, and $\mathrm{SE}=1.0$.

For each parameter, plots are presented for each of the 7 brand groups, showing the travel time estimate on the y-axis and the parameter value on the x-axis. The range of the $y$-axis is the same for all plots for a particular parameter, but the ranges vary from parameter to parameter. The range will be noted as each figure is introduced below. Additional graphics are used to illuminate the effects of altering the fish guidance efficiency parameter.

\section{Fish guidance efficiency}

Figure 4 shows plots of estimated travel time versus assumed value of FGE for the seven representative brand groups. The range of the y-axis is 10 days. Changes in the FGE value have negligible effect on the travel time estimate for four of the seven groups. The estimate of TTIME for the 1986 RA-Y-2 group is changed little in the FGE range of 0.2 to 0.8 , but is drastically different (actually negative) for FGE $=1.0$. For the 1985 LD-R-1 and 1986 RD-Y-3 groups there is more variability in the travel time estimates. The TTIME estimate for the LD-R1 group steadily increases as FGE increases, although the opposite trend occurs for the RD-Y-3 group.

Figures 5(a), 5(b), and 5(c) illustrate the situation for three of the groups to show how increasing FGE can have no effect on the travel time estimate for some groups, increase the estimate for some groups, and decrease the estimate for still others. The upper plot in each of the figures shows the distributions of estimated daily numbers of fish departing in-river from Lower Granite Dam resulting from three different assumed values for FGE at Lower Granite Dam (Eq. 2). The lower plot shows the spill history at Lower Granite for the period that the fish were passing the dam. 
Table 9. Summarv of travel time sensitivitv analvsis. Travel times for 7 representative brand groups under a varietv of assumed parameter values,

\begin{tabular}{|c|c|c|c|c|c|c|c|}
\hline Parameter & $\begin{array}{c}1984 \\
\text { RD-J-1 }\end{array}$ & $\begin{array}{c}1985 \\
\text { LD-R- } 1\end{array}$ & $\begin{array}{c}1986 \\
\text { RA-Y-2 }\end{array}$ & $\begin{array}{c}1986 \\
\text { RD-Y-3 }\end{array}$ & $\begin{array}{c}1987 \\
\text { RA-R- } 1\end{array}$ & $\begin{array}{c}1989 \\
\text { L\#-7H-\# }\end{array}$ & $\begin{array}{c}1990 \\
\text { LA-T-\# }\end{array}$ \\
\hline Standard' & 7.89 & 13.92 & 20.57 & 10.78 & 12.35 & 13.82 & 11.08 \\
\hline $\mathrm{FGE}=0.2$ & 8.11 & 13.56 & 20.62 & 12.02 & 12.40 & 13.56 & 11.08 \\
\hline $\mathrm{FGE}=0.4$ & 7.98 & 13.76 & 20.59 & 11.56 & 12.38 & 13.73 & 11.08 \\
\hline$F G E=0.6$ & 7.79 & 14.16 & 20.53 & 10.00 & 12.32 & 13.92 & 11.08 \\
\hline $\mathrm{FGE}=0.8$ & 7.48 & 16.40 & 20.03 & 2.39 & 12.15 & 14.15 & 11.08 \\
\hline $\mathrm{FGE}=\mathrm{f}(\mathrm{DATE})^{2}$ & 7.89 & 14.13 & 20.92 & 12.34 & 12.96 & 13.83 & 11.18 \\
\hline$S_{\text {spill }}=0.9$ & 7.91 & 13.93 & 20.58 & 11.21 & 12.35 & 13.82 & 11.08 \\
\hline$S_{\text {spill }}=0.925$ & 7.90 & 13.92 & 20.58 & 11.08 & 12.35 & 13.82 & 11.08 \\
\hline$S_{\text {spill }}=0.95$ & 7.90 & 13.92 & 20.57 & 10.94 & 12.35 & 13.82 & 11.08 \\
\hline$S_{\text {spill }}=0.975$ & 7.89 & 13.92 & 20.57 & 10.80 & 12.35 & 13.82 & 11.08 \\
\hline$S_{\text {spill }}=1.0$ & 7.89 & 13.91 & 20.57 & 10.67 & 12.35 & 13.82 & 11.08 \\
\hline $\boldsymbol{S}_{\text {turb }}=0.8$ & 7.87 & 13.94 & 20.56 & 10.55 & 12.35 & 13.84 & 11.08 \\
\hline$S_{\text {turb }}=0.9$ & 7.91 & 13.89 & 20.58 & 11.06 & 12.36 & 13.81 & 11.08 \\
\hline$S_{\text {turb }}=0.95$ & 7.93 & 13.87 & 20.58 & 11.31 & 12.36 & 13.79 & 11.08 \\
\hline$S_{t u r b}=1.0$ & 7.95 & 13.85 & 20.59 & 11.53 & 12.36 & 13.78 & 11.08 \\
\hline$S_{\text {byp }}=0.9$ & 7.90 & 13.87 & 20.57 & 10.76 & 12.36 & 13.80 & 11.08 \\
\hline$S_{b y p}=0.925$ & 7.90 & 13.89 & 20.57 & 10.76 & 12.36 & 13.81 & 11.08 \\
\hline$S_{b y p} \doteq 0.95$ & 7.90 & 13.90 & 20.5 & 10.77 & 12.35 & 13.81 & 11.08 \\
\hline$S_{\text {byp }}=0.975$ & 7.89 & 13.91 & 20.57 & 10.78 & 12.35 & 13.82 & 11.08 \\
\hline$S_{b v p}=1.0$ & 7.89 & 13.93 & 20.57 & 10.78 & 12.35 & 13.83 & 11.08 \\
\hline
\end{tabular}


Table 9 (cont).

\begin{tabular}{|l|ccccccc|}
\hline Parameter & $\begin{array}{c}1984 \\
\text { RD-J- } 1\end{array}$ & $\begin{array}{c}1985 \\
\text { LD-R- }\end{array}$ & $\begin{array}{c}1986 \\
\text { RA-Y-2 }\end{array}$ & $\begin{array}{c}1986 \\
\text { RD-Y-3 }\end{array}$ & $\begin{array}{c}1987 \\
\text { RA-R- } 1\end{array}$ & $\begin{array}{c}1989 \\
\text { L\#-7H-\# }\end{array}$ & $\begin{array}{c}1990 \\
\text { LA-T-\# }\end{array}$ \\
\hline$T T_{r c h}=0$ & 7.78 & 14.74 & 20.62 & 11.31 & 12.42 & 13.02 & 11.12 \\
$T T_{r c h}=2$ & 7.76 & 14.27 & 20.55 & 11.08 & 12.42 & 13.48 & 11.08 \\
$T T_{r c h}=6$ & 7.85 & 13.46 & 20.55 & 10.74 & 12.28 & 13.70 & 11.05 \\
$T T_{r c h}=8$ & 7.88 & 13.07 & 20.53 & 10.90 & 12.21 & 13.52 & 11.08 \\
$T_{r c h}=10$ & 7.88 & 13.22 & 20.52 & 11.09 & 12.19 & 13.52 & 11.08 \\
$\mathrm{~S}_{r c h}=0.2$ & 7.89 & 13.92 & 20.57 & 10.78 & 12.35 & 13.82 & 11.08 \\
$\mathrm{~S}_{r c h}=0.4$ & 7.89 & 13.92 & 20.57 & 10.78 & 12.35 & 13.82 & 11.08 \\
$S_{r c h}=0.6$ & 7.89 & 13.92 & 20.57 & 10.78 & 12.35 & 13.82 & 11.08 \\
$S_{r c h}=1.0$ & 7.89 & 13.92 & 20.57 & 10.78 & 12.35 & 13.82 & 11.08 \\
$\mathrm{SE}=0.75$ & 8.37 & 13.94 & 20.51 & 11.43 & 12.33 & 13.69 & 11.00 \\
$S E=1.25$ & 7.30 & 13.88 & 20.65 & 10.28 & 12.38 & 13.98 & 11.19 \\
$\mathrm{SE}=1.50$ & 6.62 & 13.81 & 20.74 & 8.92 & 12.40 & 14.17 & 11.33 \\
$S E=1.75$ & 5.55 & 13.69 & 20.52 & 7.38 & 12.43 & 14.41 & 11.56 \\
$S E=2.00$ & 1.65 & 13.44 & 25.33 & 11.28 & 12.46 & 14.69 & 12.14 \\
$S E=\mathrm{f}(\%$ spill) & 8.17 & 13.76 & 20.78 & 11.47 & 13.41 & 13.72 & 10.95 \\
\hline
\end{tabular}

1. $F G E=0.5, S_{\text {sill }}=0.98, S_{\text {furb }}=0.85, S_{\text {bypass }}=0.98, T T_{r c h}=4, S_{r c h}=0.80, S E=1.0$.

2. See Eq. 4 and Figure 2.

3. See Eq. 5 and Figure 3. 


\section{Figure 4. Plots of estimated travel time versus assumed fish guidance efficiencv value for 7 representative.groups.}
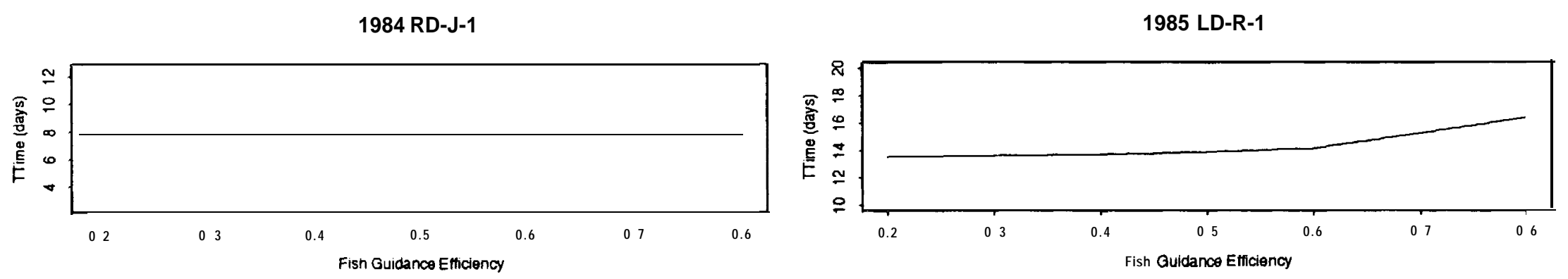

1986 RA-Y-2
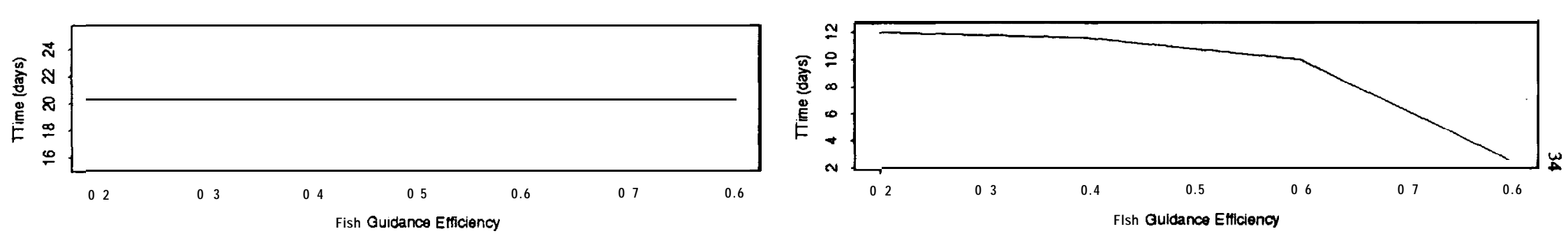

1987 RA-R-I

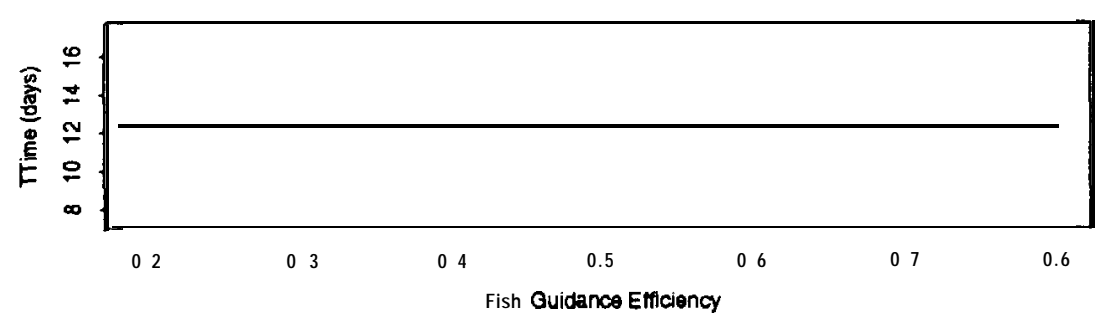

1989 L \#-7H-\#

1990 LA-T-\#
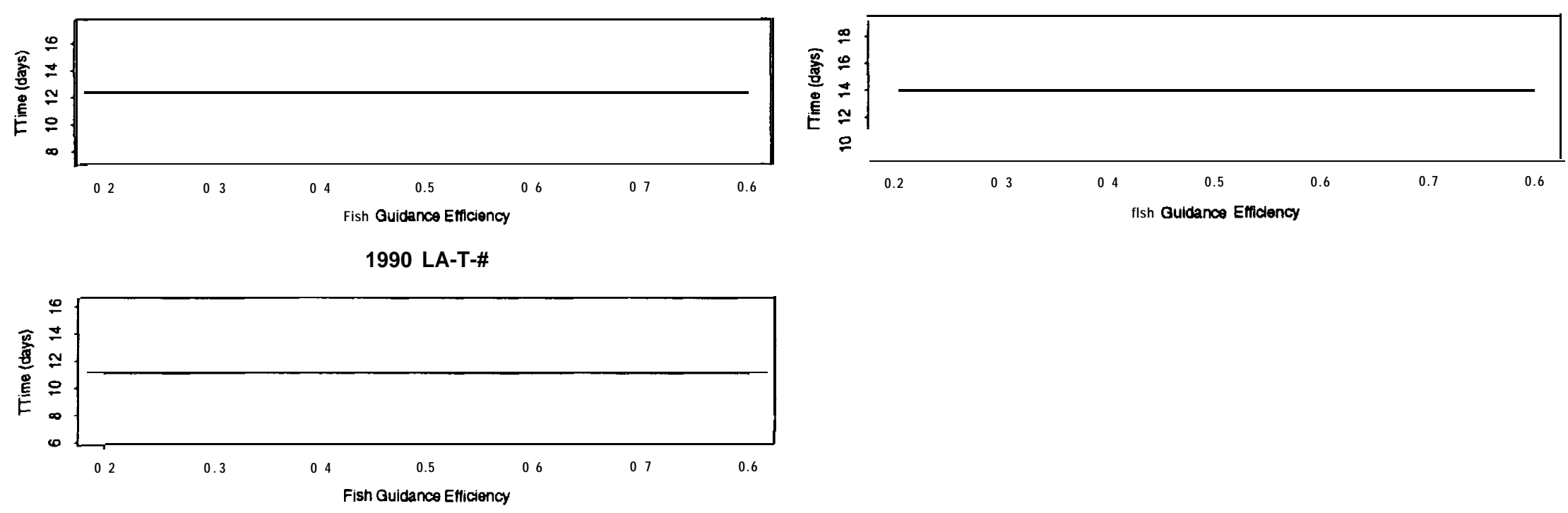
Figure 5(a).Estimated Lower Granite deuarture distributions and derived travel time from Lower Granite to McNary using various assumed values of FGE and Lower Granite spill volumes for 1986 group RD-Y-3.

\section{RD-Y-3 passage distribution}

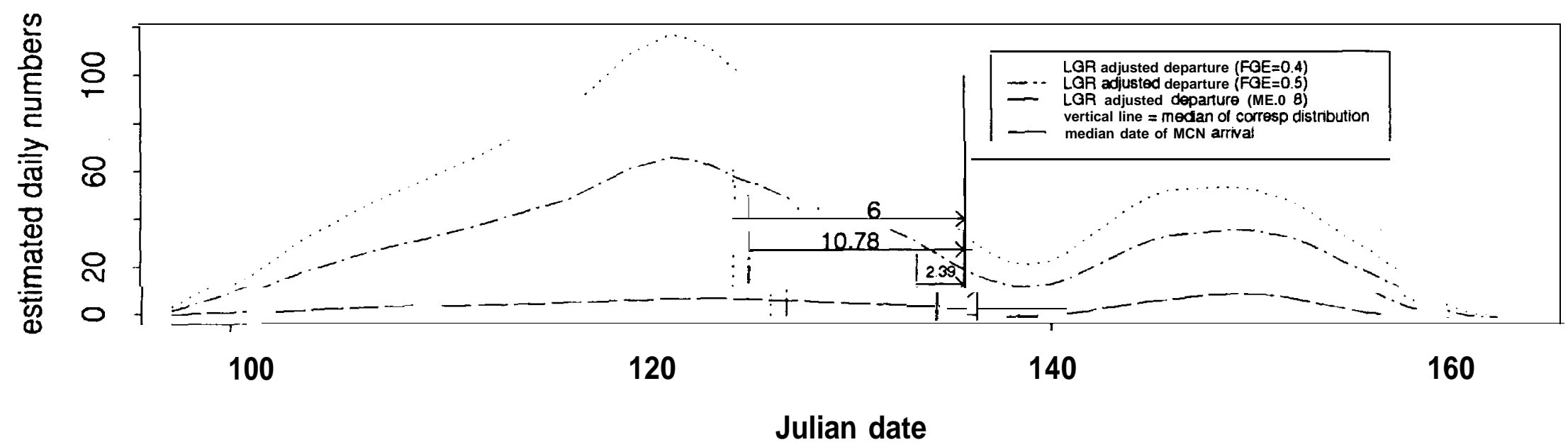

Spill Volume at Lower Granite Dam

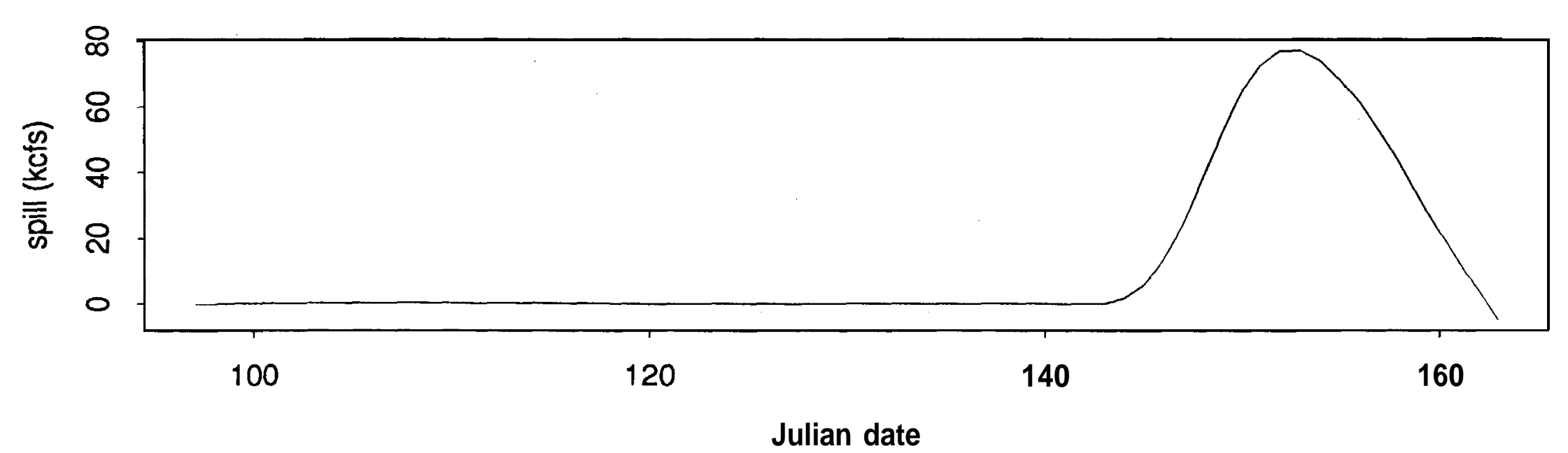


Figure 5(b). Estimated Lower Granite departure distributions and derived travel time from Lower Granite to McNarv using various assumed values of FGE and Lower Granite spill volumes for 1983 group RD-SU-3.

\section{RD-SU-3 passage distribution}

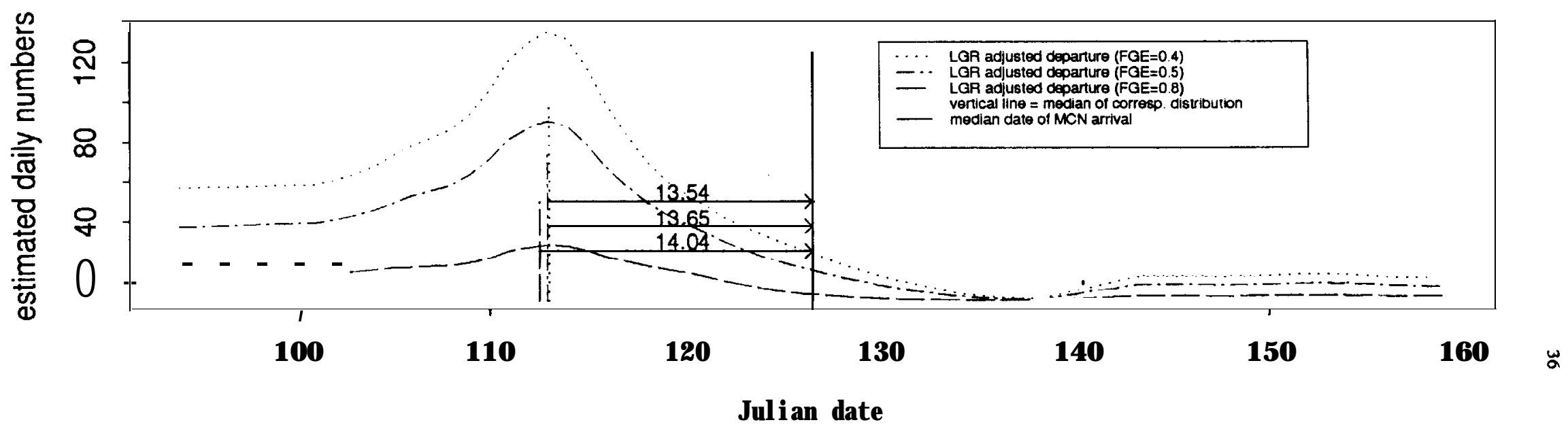

\section{Spill Volume at Lower Granite Dam}

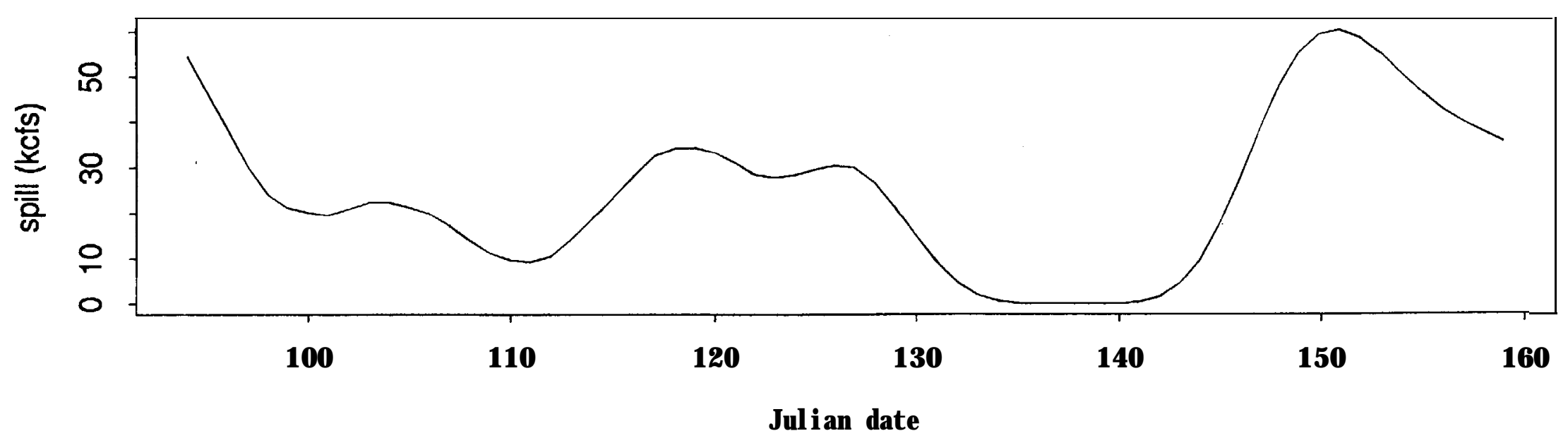


Figure 5(c). Estimated Lower Granite departure distributions and derived travel time from Lower Granite to McNary using various assumed values of FGE and Lower Granite spill volumes for 1988 group RD-T-I,

\section{RD-T-1 passage distribution}

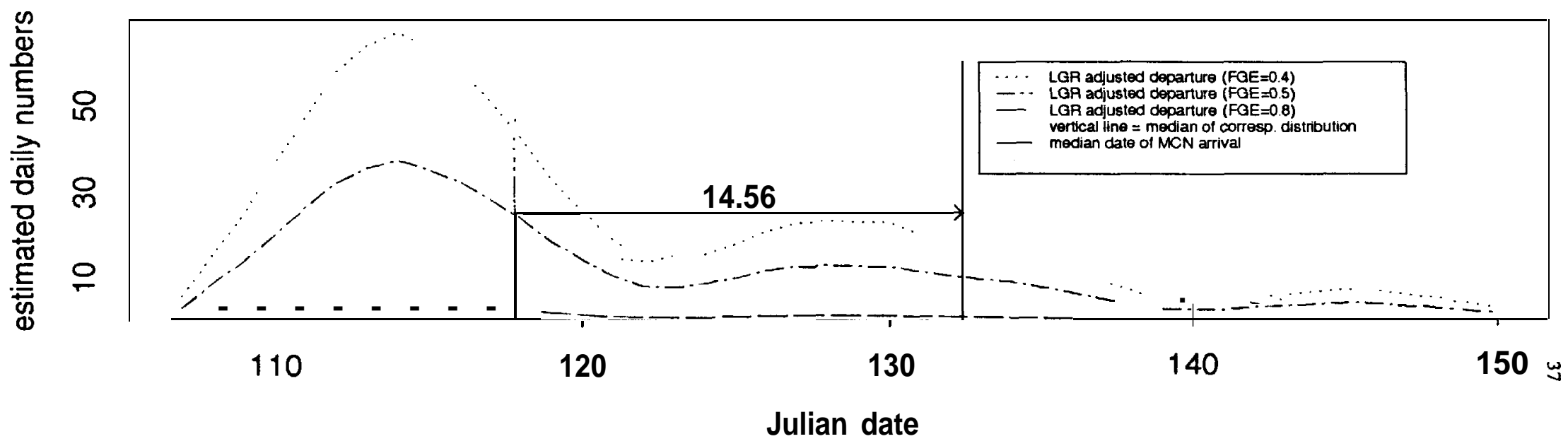

Spill Volume at Lower Granite Dam

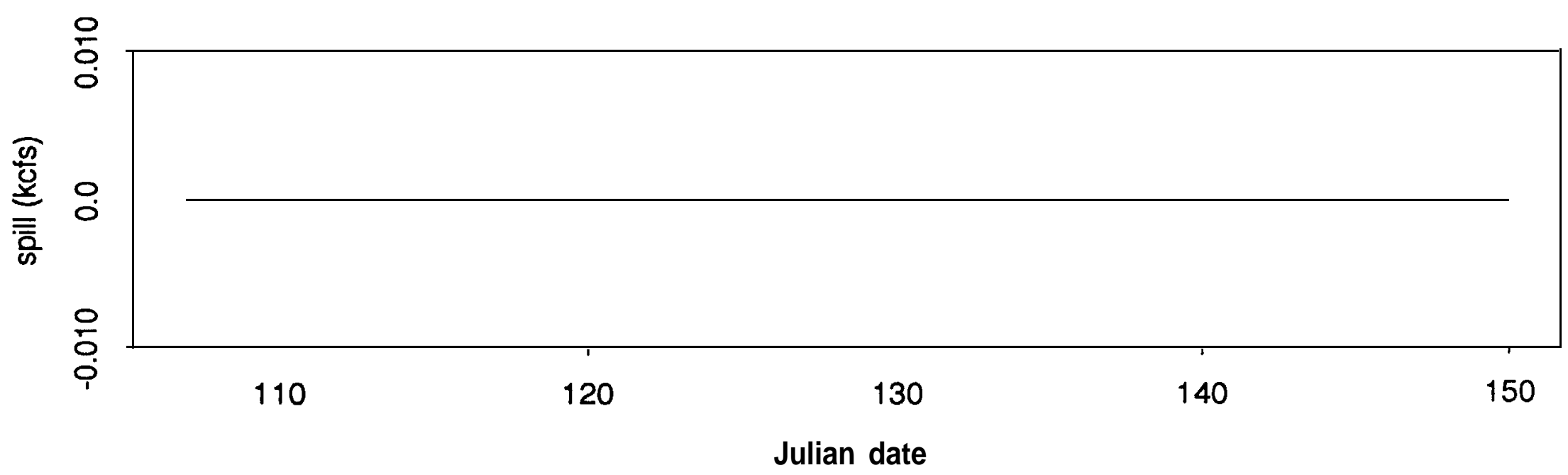


Figure 5(a) illustrates the effect of changing the FGE assumption on the travel time estimate for the RD-Y-3 branded group in 1986. This group had a strong peak in the numbers arriving at Lower Granite in late April/early May (around Julian day 121) and a lesser peak in late May/early June (around day 152). No water was being spilled at the time of the first peak, but the second peak coincided with a period of spill. The juxtaposition of the arrival distribution and the spill distribution results in appreciable differences in the estimated travel time for the group as the assumed value of FGE is altered.

Because a very large proportion of the fish that enter into the bypass system are removed by the transportation program at Lower Granite Dam, most of the fish remaining in-river below the dam passed through either the spillway or the turbines. Thus, there are two main components of the adjusted departure distributions: the number of fish that passed the dam through the spillway, and the number that passed through the turbines. As the assumed value of FGE increases, the estimated number passing through the turbines decreases (the estimated number going through the turbines is (l-FGE) times the estimated number entering the powerhouse). The estimated spillway passage remains constant regardless of the FGE, so the relative importance of the spill component of the departure distribution increases as the FGE increases. This phenomenon can be seen in Figure 5(a), where the first peak, when there was no spill, essentially disappears as the assumed FGE approaches 1.0 (implying that almost all fish are removed for transportation), while the second peak, corresponding in time with a period of spill, is not depressed nearly as much. Thus the weight of the distribution is shifted to the right, resulting in a later estimated median date of entry into the reach, and a shorter estimated travel time (the estimated median date of arrival at McNary is not affected by the change in assumed FGE).

Figure 5(b) shows the comparable plots for the RD-SU-3 branded group in 1983. This group had a single strong peak in passage at Lower Granite Dam right around Julian day 112. The highest spill volumes occurred at the beginning and end of the period of passage, so the effect of increasing FGE (more fish removed for transportation) is to depress the adjusted departure distribution more in the middle of passage period than in the tails. The left-hand tail is heavier than the right, so the median shifts to the left and the estimated travel time increases as the assumed FGE increases. However, because the single peak dominates the distribution, the shift in the median is slight.

Figure 5(c) shows the plots for the RD-T-1 branded group in 1988. This group had a strong peak around Julian day 115 and another lesser peak about two weeks later. Because there was no 
spill at all during the time of passage of this group, the departure distributions represent primarily the estimated number of fish passing through the turbines, and the effect of changing the assumed value for FGE is to scale the distribution uniformly throughout the range. The relative shape does not change, and the median is unaffected. Thus, changing the assumed value of FGE has no effect whatsoever on the estimated travel time of this group.

In summary, the travel time estimate derived from the algorithm in Section 2 is sensitive to the assumed value of FGE only in the presence of spill. The sensitivity that is seen is the result of changes in the relative importance of the spillway and turbine passage components in the estimated departure distribution. The effect of FGE on travel time is not systematic. It depends entirely on the juxtaposition of the distributions of fish arrival and spill conditions at Lower Granite Dam. If there is no spill, the travel time estimate is the same regardless of the assumed FGE value. When there is spill, the effect of an increase in the assumed value of FGE can be either an increase or a decrease in the estimated travel time. There is no way to predict the effect of for any particular group.

Figure 6 illustrates the results when FGE was modeled as a function of the Julian date (Equation 7). For each of the 42 hatchery release groups, the travel time estimated using the function for FGE is plotted against the travel time under the standard assumptions. For 39 of the 42 groups, the estimated travel time was greater using the function than under the standard. In 8 cases, the difference was greater than a day. In addition, the average travel time over all 42 groups was greater using the FGE function than for any of the constant FGE values. If FGE truly increases over the course of the migration season, as suggested by the results of Swan et al (1986; 1990), our results suggest that travel times are underestimated if it is assumed in the estimation algorithm that FGE is constant throughout the season, regardless of the assumed constant value of FGE.

\section{Spillway survival}

Plots of estimated travel time versus assumed spillway survival are shown in Figure 7. The range of the y-axis is 0.6 days. For six of the seven groups the effect of varying spillway survival is negligible. There is a small effect on the estimate for the RD-Y-3 group in 1986, but all estimates were within a range of 0.6 days. 


$$
\text { E }
$$


Figure 7. Plots of estimated travel time versus assumed spillway survival value for 7 representative groups.
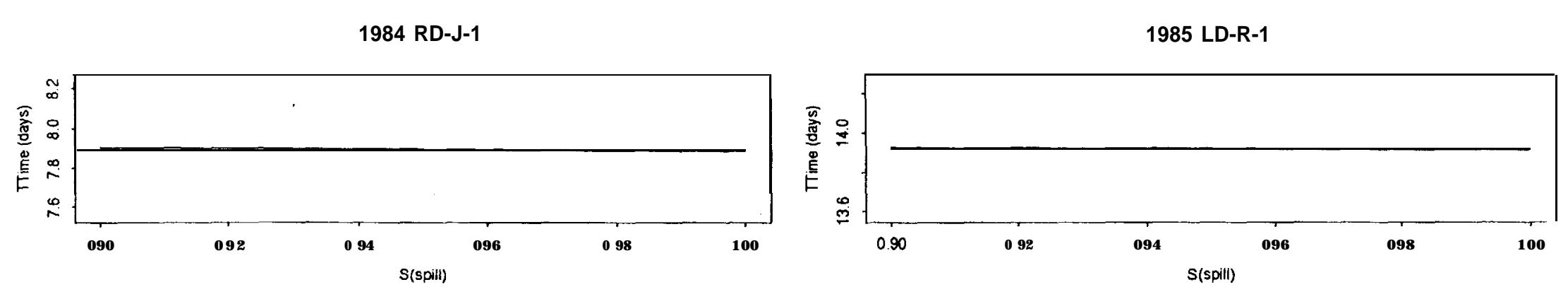

1986 RA-Y-2

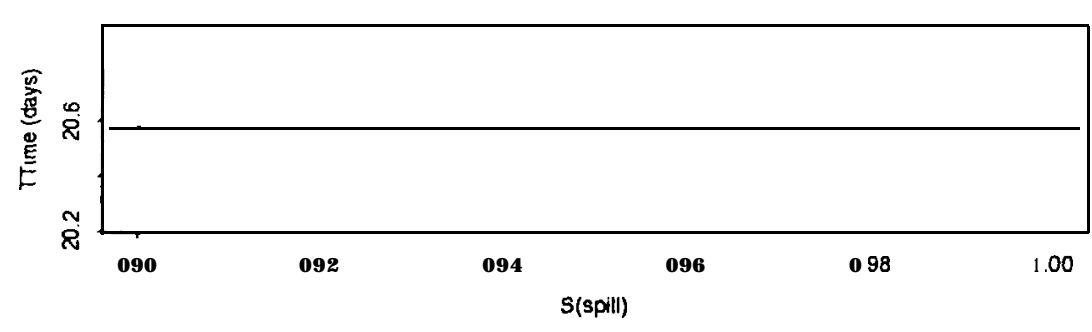

1986 RD-Y-3

1987 RA-R-I

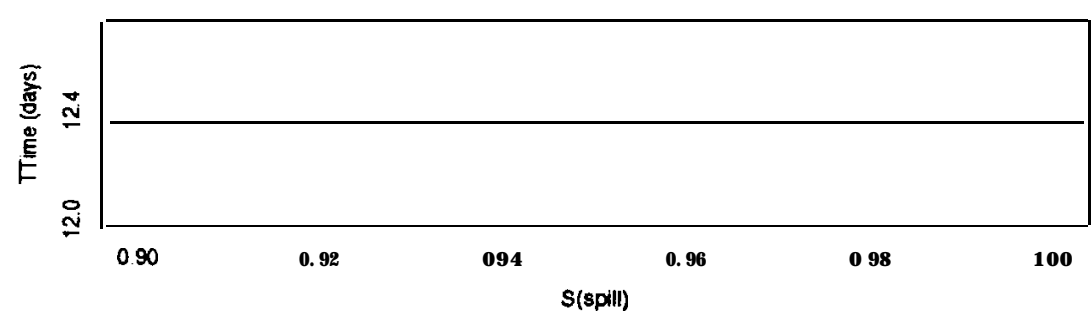

1990 LA-T-\#
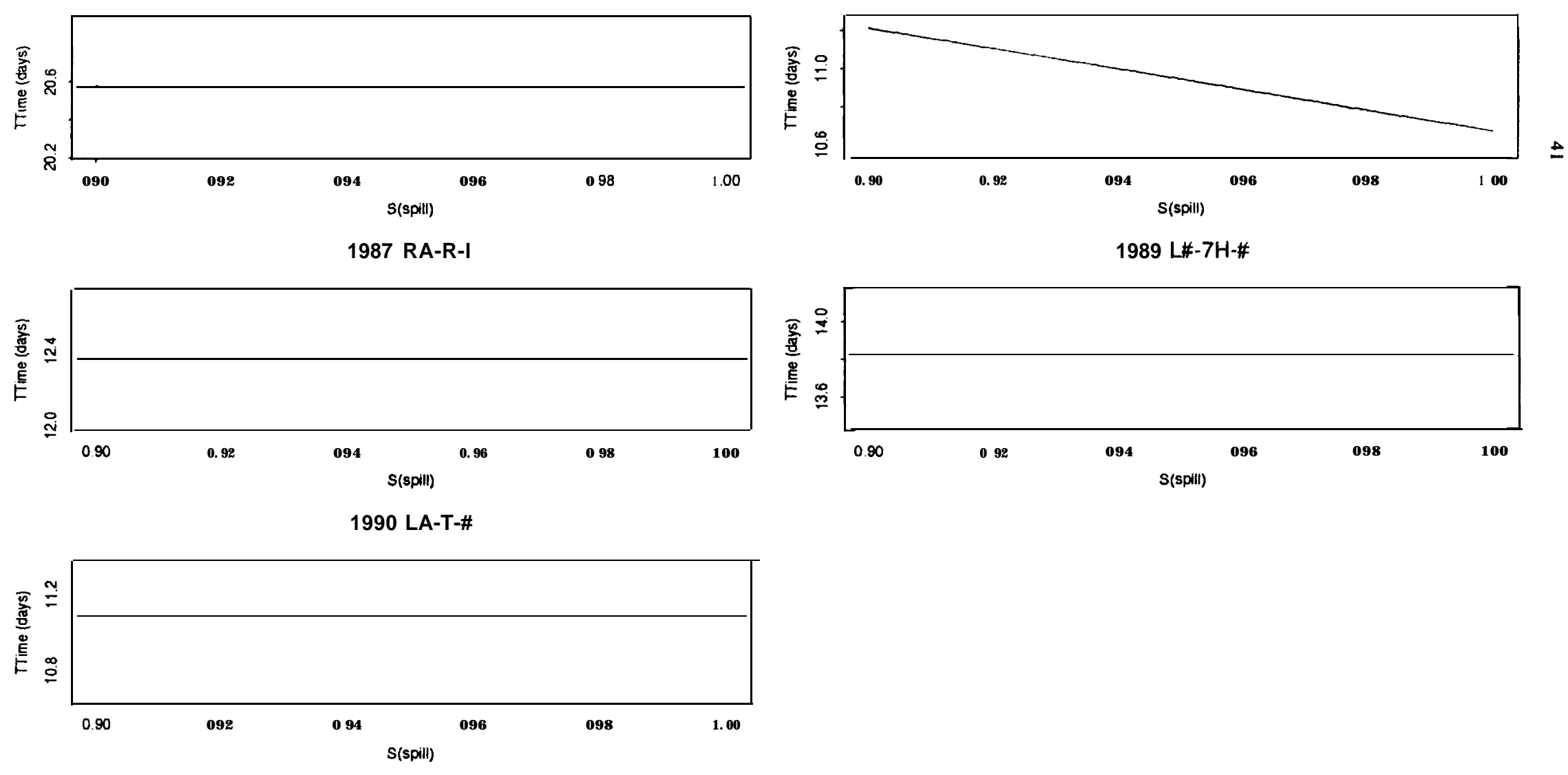

1989 L\#-7H-\#

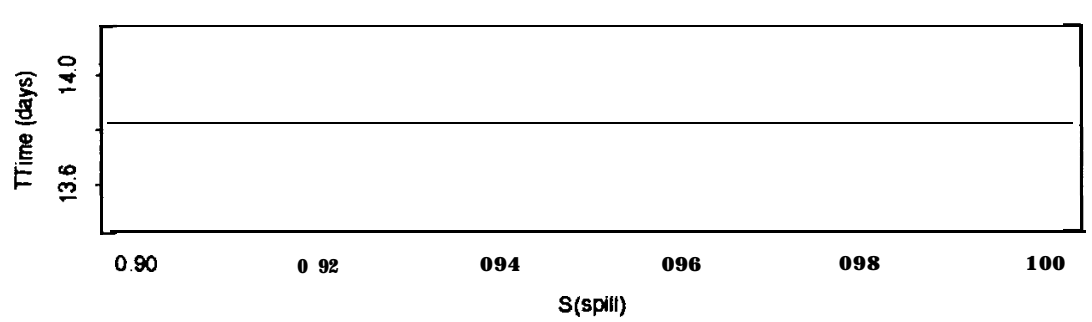




\section{Turbine survival}

Figure 8 shows the plots of estimated travel time versus assumed turbine survival. The range of estimated travel times on the $y$-axis of the figure is 1 day. The 1986 RD-Y-3 group again is the only group for which there is any discernible effect. The range of estimated travel times is again less than a day.

\section{Bypass survival}

The plots of estimated travel time versus assumed bypass survival are shown in Figure 9. The range of estimated travel times on the y-axis of the figure is 1 day. Varying bypass survival in the range $(0.9,1.0)$ has no effect of travel time estimates.

\section{Travel time from Lower Granite to Little Goose}

Figure10 shows plots of estimated travel time versus the assumed travel time from Lower Granite to Little Goose for the seven representative groups. The range of estimated travel times on the $y$-axis of the figure is 1.5 days. This parameter governs the adjustment of the distribution for transportation removals at Little Goose Dam. For four of the groups there is negligible effect, while for the 1986 RD-Y-3 and 1989 L\#-7H-\# groups the range of the travel time estimate is less than a day. The range is slightly greater for the 1985 LD-R-1 group, though the range of travel time estimates for the most likely range of $T T_{r c h}$ (3 to 6 days) is quite small.

\section{Survival from Lower Granite to Little Goose}

The plots of estimated travel time versus assumed survival in the Lower Granite-to-Little Goose reach show that the assumed value for this parameter has absolutely no effect on the estimated travel time between Lower Granite to $\mathrm{McNary}$ Dams. The effect of varying the $S_{r c h}$ parameter is simply to change the scale of the estimated departure distribution, while the shape of the distribution is unchanged. In particular, the median of the distribution does not change.

\section{Spill effectiveness}

The plots in Figure1 1 show the effect of varying the value of spill effectiveness (SE) on the travel time estimates for the seven representative groups. The range of estimated travel times on the y-axis of the figure is 7 days. Changes in the assumed SE have negligible effect on four of the seven groups. The travel time estimate for the 1986 RA-Y-2 group is changed little in the 
Figure 8. Plots of estimated travel time versus assumed turbine survival value for 7 representative groups.
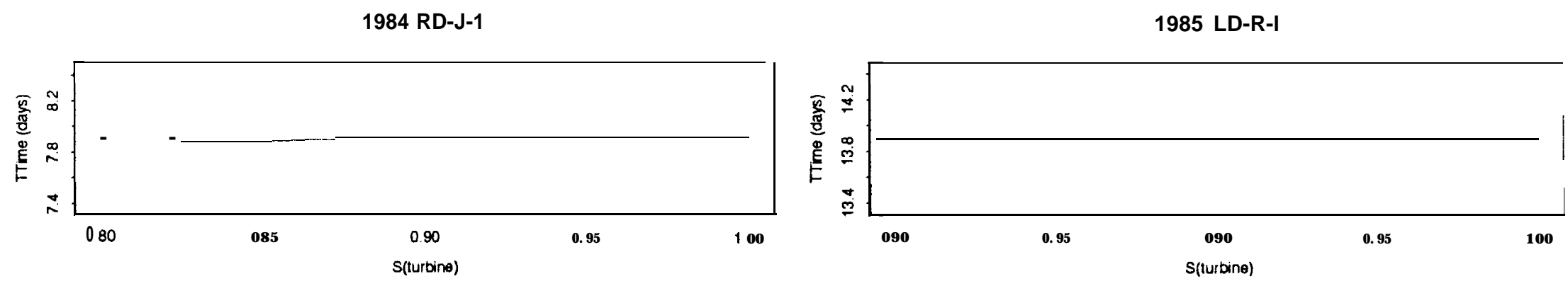

1986 RA-Y-2
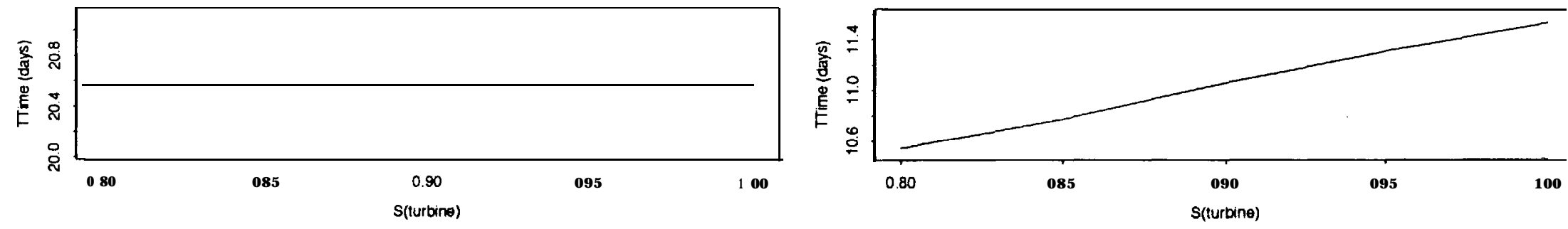

1987 RA-R-1
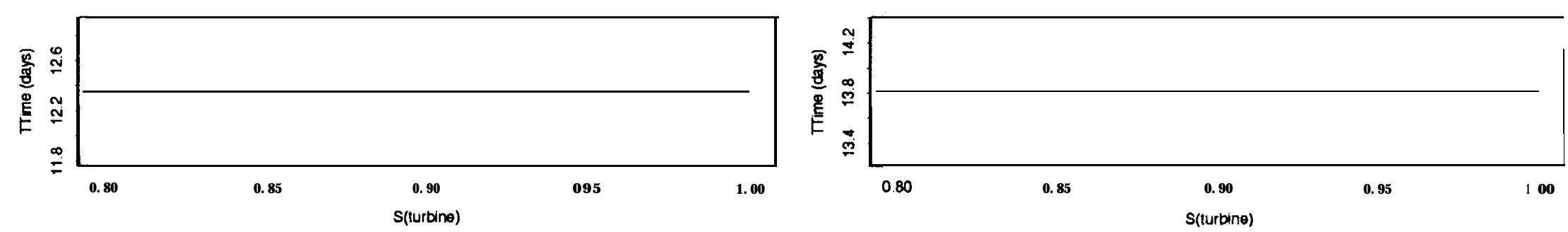

1990 LA-T-\#

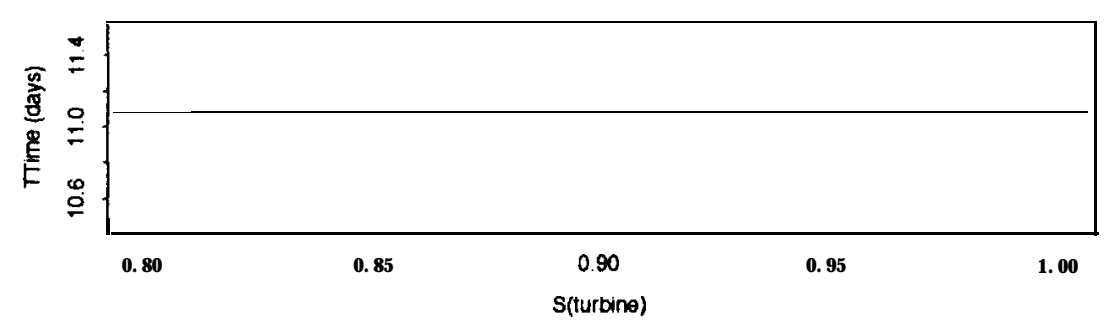


Figure 9. Plots of estimated travel time versus assumed bvpass survival value for 7 representative groups.

1984 RD-J-1

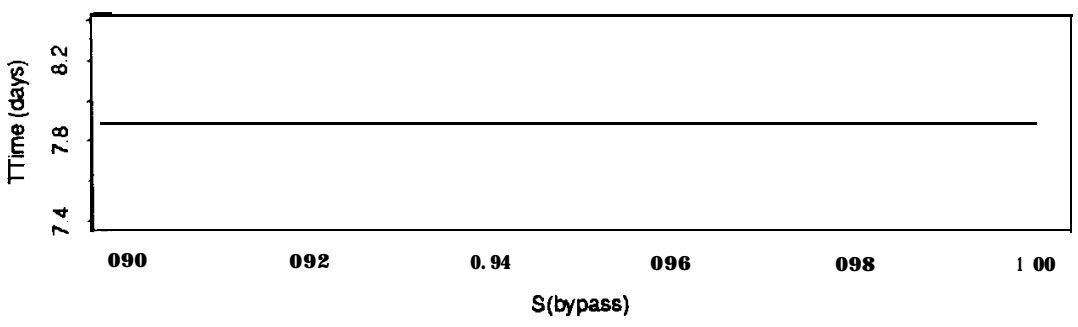

1986 RA-Y-2

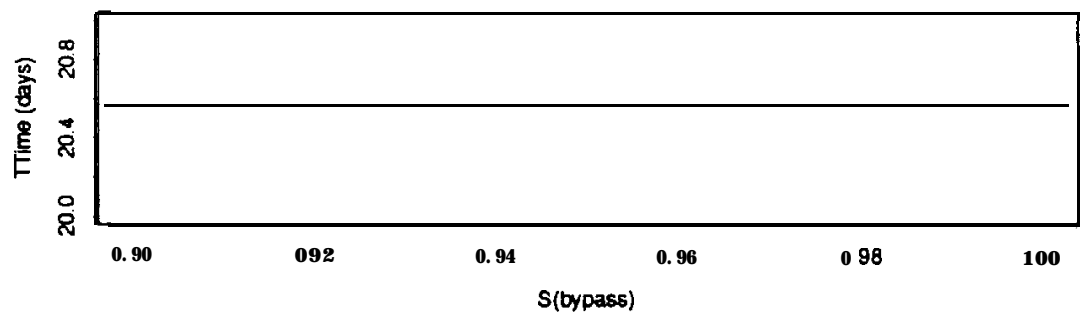

1987 RA-R-1

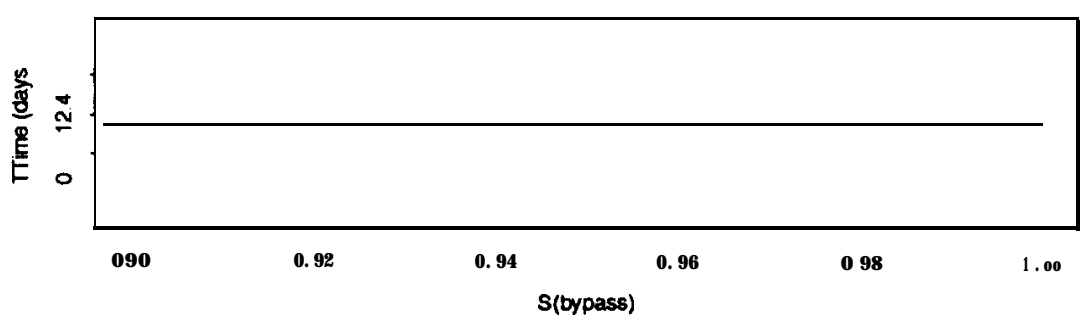

1990 LA-T-\#

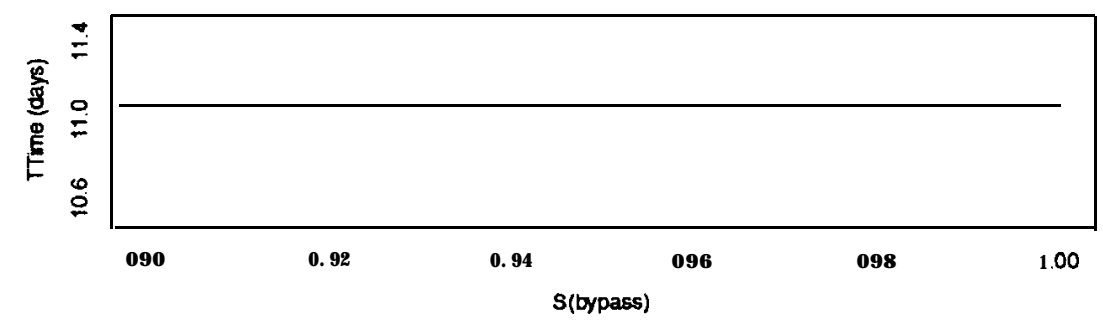

1985 LD-R-1

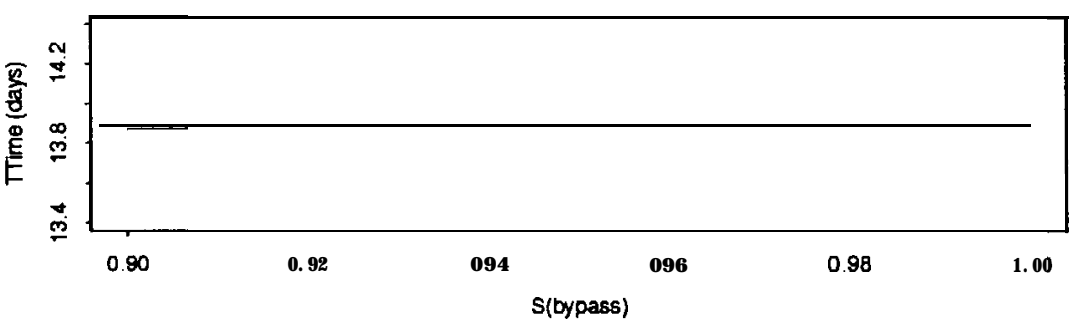

1986 RD-Y-3

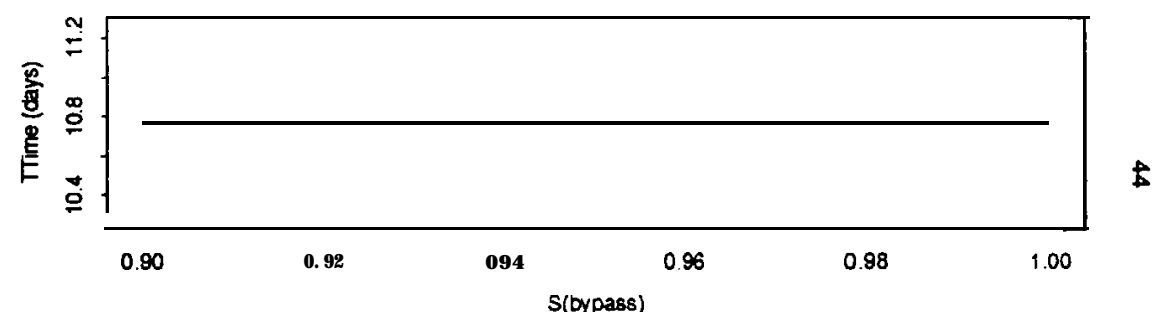

1989 L\#-7H-\#

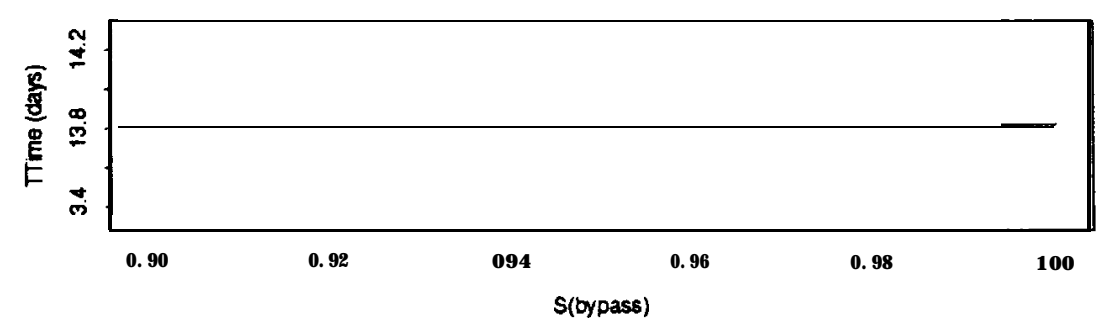


Figure 10. Plots of estimated travel time versus assumed value of travel time between Lower Granite to Little Goose Dams for 7 representative grouds.

1985 LD-R-1
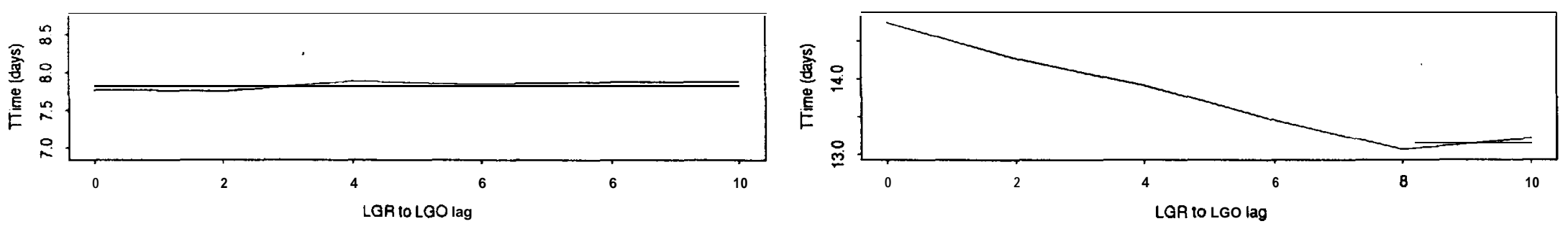

1988 RA-Y-2

1986 RD-Y-3
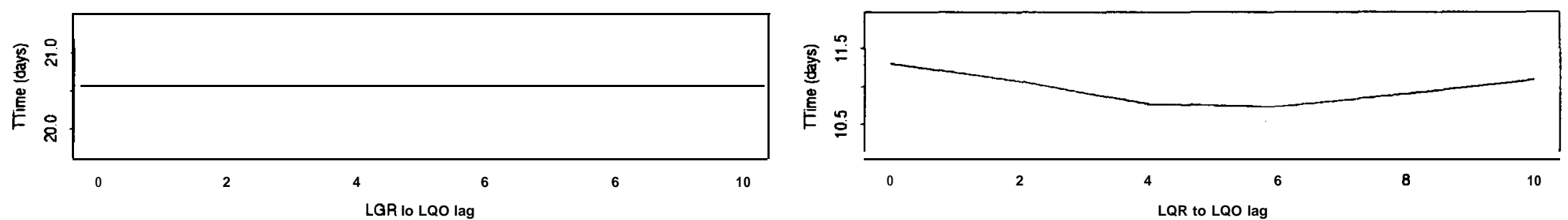

1987 RA-R-1

1989 L\#-7H-\#
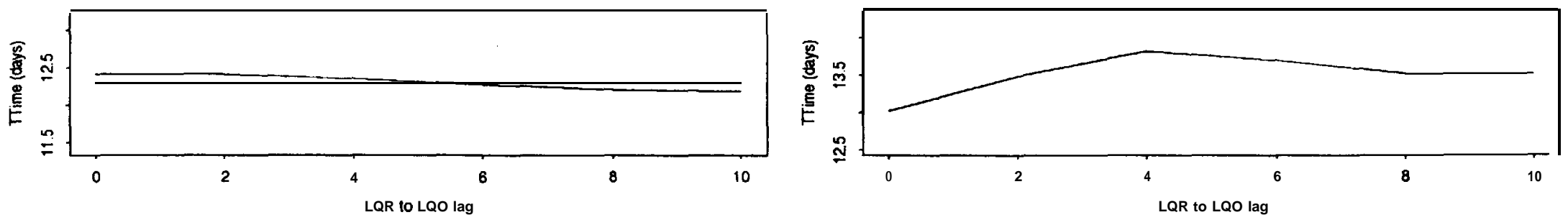

1990 LA-T-\#

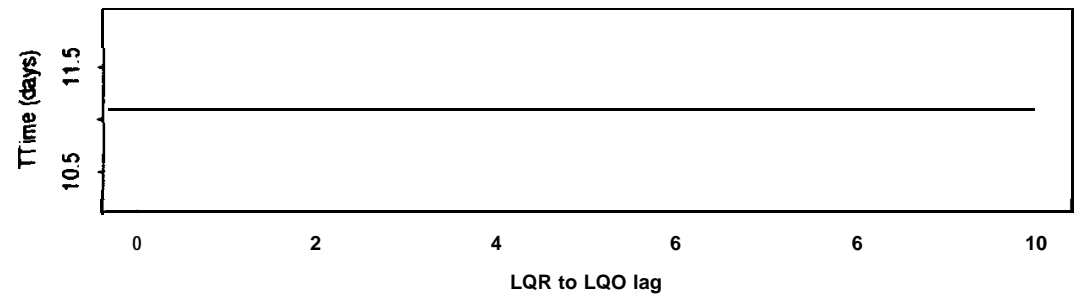


Figure 11. Plots of estimated travel time versus assumed value of spill effectiveness for 7 representative groups.

1984 RD-J-1

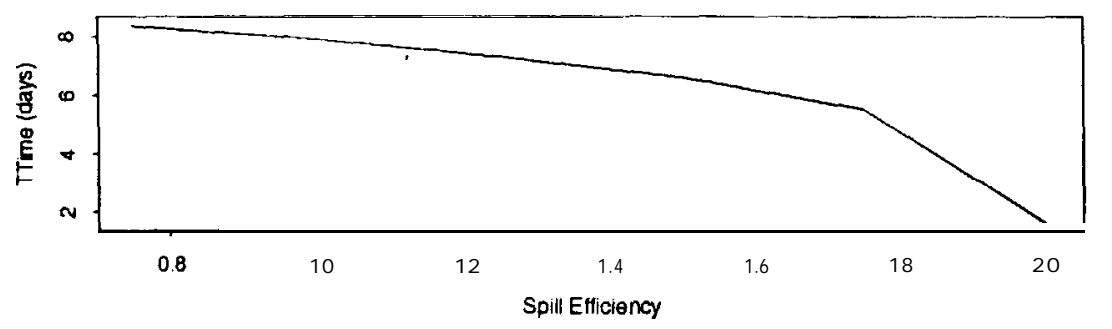

1986 RA-Y-2

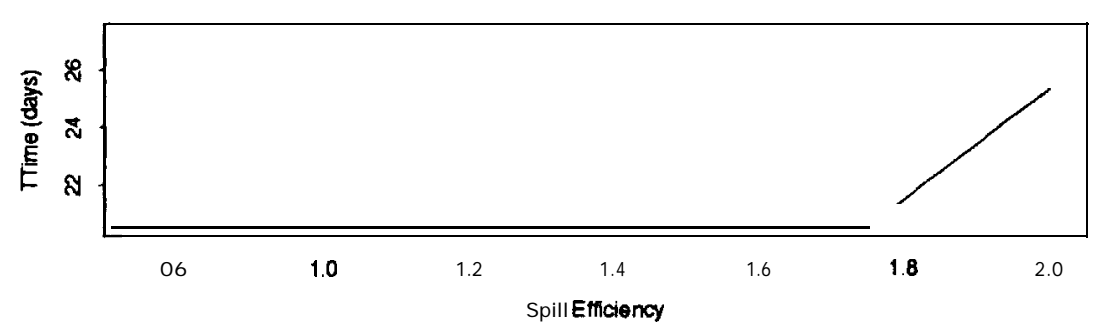

1987 RA-R-1

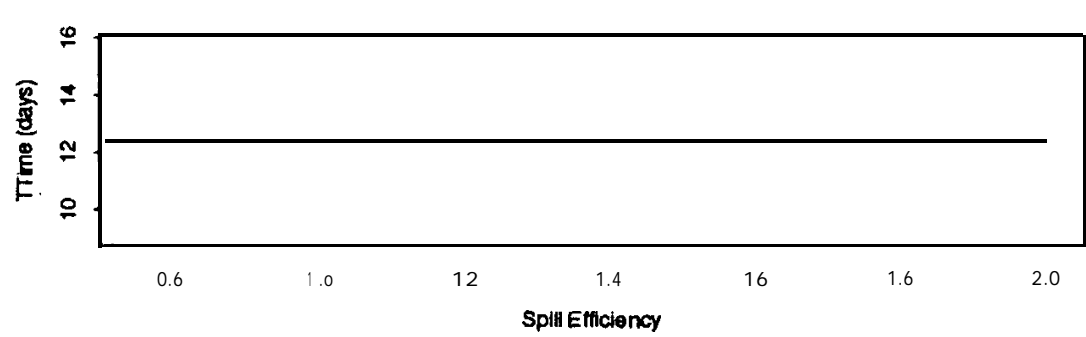

1990 LA-T-\#

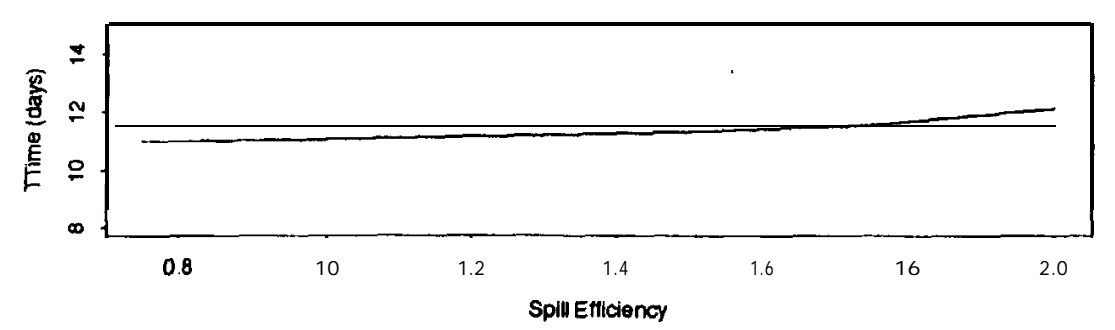

1985 LD-R- 1

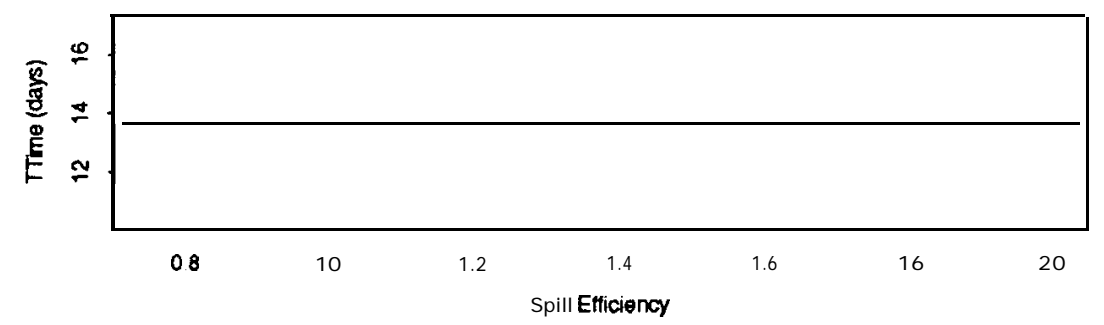

1986 RD-Y-3

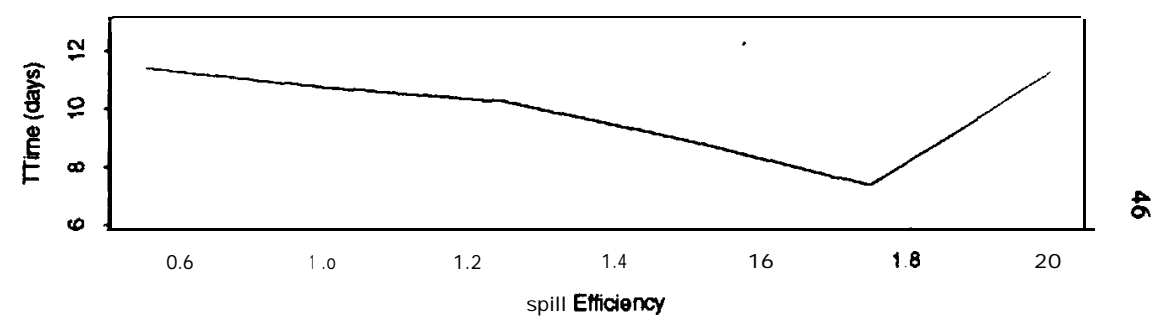

1989 L\#-7H-\#

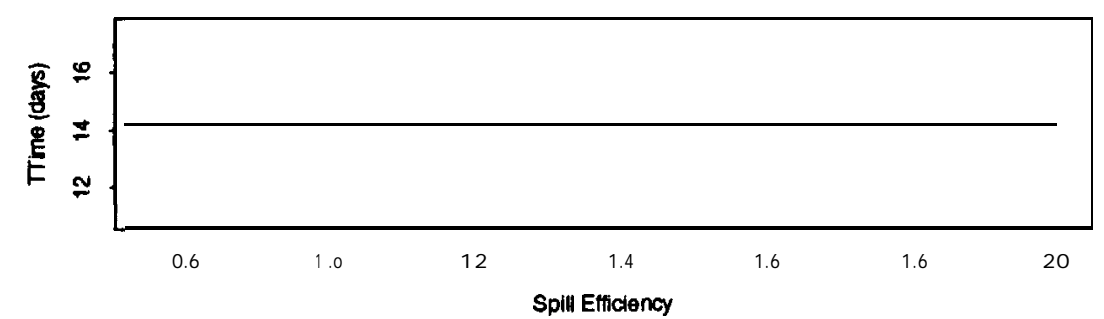


range for SE of 0.75 to 1.75 , but is almost 5 days greater when SE equals 2.0. For the 1984 RD$\mathrm{J}$ - 1 group there is an almost 7 day range in the estimated travel times using different values of SE. The estimate gradually decreases as the value of SE increases. The effect on the estimate for the 1986 RD-Y-3 group is not uniform. The travel time estimate is nearly the same for the two extreme values of 0.75 and 2.0 , but is as much as 4 days shorter for intermediate values.

The spill effectiveness parameter was varied simultaneously for both Lower Granite and at McNary Dams. The assumed value of SE affects both the estimated departure distribution from Lower Granite and the estimated arrival distribution at McNary. As with the FGE sensitivity investigation, if there is no spill, the effect of varying SE is to scale the estimated distributions, but not to change their shapes or the location of the medians. However, for all seven groups there was at least a small amount of spill at one dam or the other, so we see effects on the travel time estimates for all groups. Also, as with the FGE, the effect of SE on the estimate depends entirely on the juxtaposition of the distributions of fish collected at the two dams and the distribution of spill operations, and there is no way to predict the effect on any particular group's estimated travel time. Examining the results for the various constant values of SE, the sensitivity of the travel time estimate is seen to be potentially great, but unpredictable. Using the model of $\mathrm{SE}$ as a function of spill proportion (Eq. 6), the estimate travel times for the 7 groups are changed little from the standard value of $\mathrm{SE}=1$.O.

\subsection{Discussion}

The algorithm for estimating travel tunes based on medians of smolt passage distributions (Eqs, 1, 2, 3) is a complicated, non-linear function of survival rates through various passage routes, fish guidance efficiency, and spill effectiveness. For many of the parameters there is little information on which to base estimates, so we are forced to use educated guesses at the appropriate values. This section has examined the sensitivity of the resulting travel time estimates to differing values of the assumed parameters to assess the potential error if our educated guesses at the "standard values" prove to be incorrect.

The Lower Granite Dam departure distribution, or distribution of smolts remaining in-river below the dam, is a composite of three components: fish passing through the spillway, fish passing through the turbines, and fish entering the bypass channel and then returned to the river. Typically, the latter component is small because almost all smolts that enter the bypass system are removed by the transportation program. Thus, the departure distribution is usually the result of interplay between the distributions of turbine and spillway passage. Combinations of river 
conditions and assumed parameter values that change the relative importance of the components can change the shape of the departure distribution and consequently affect the estimated median travel time.

Our investigations show that the two parameters that have the largest potential effect on the travel time estimate are Fish Guidance Efficiency (FGE) and Spill Effectiveness (SE). However, the effect of FGE is realized only when there is spill at Lower Granite and the effect of SE is realized only when there is spill at either Lower Granite or McNary during the passage of the release group in question. The effect is unpredictable, and can be a positive or negative bias in the estimated travel time, depending entirely on the coincidence of the arrival distributions at Lower Granite and McNary Dams and the spill schedules at Lower Granite, Little Goose, and McNary Dams.

Because of the relatively large influence of the FGE and SE variables on the estimated travel times of the 7 representative groups, the sensitivity analyses for those two variables were expanded to include all 42 of the hatchery release groups used in the regression analyses. The results are summarized in Table 10. The table shows the minimum and maximum values obtained for the estimated travel time of each group using three ranges of parameter values; constant FGE between 0.3 and 0.7, constant FGE between 0.2 and 0.8 and constant SE between 0.75 and 2.00. Over the ranges studied, estimated travel times are more sensitive to the assumed SE value. Eleven of the 42 groups have estimated travel times ranging more than 2 days as SE is changed from 0.75 to 2.00. Eight groups have differences of 2 or more days over the FGE range of 0.2 to 0.8 , while only four have ranges that large over the smaller FGE range of 0.3 to 0.7 .

The unpredictability of the magnitude and direction of the effect suggests that there is no systematic bias on the travel time estimates incurred by using an "incorrect" value for FGE or $\mathrm{SE}$ in the estimation algorithm, but that appreciable variability might be introduced into any subsequent analyses of the estimated travel times.

Unfortunately, because of its complicated, nonlinear nature, is impossible to quantify the variability incurred by the adjustment procedure in a single number, such as a standard error, that could be used in weighted regressions (see Section 5). 
Table 10. Ranges of estimated travel times for varving assumutions for Fish Guidance Efficiency and Spill Effectiveness, Shaded cells mark ranges of travel times greater tban one dav for FGE and greater than two davs for $\mathrm{SE}$.

\begin{tabular}{|c|c|c|c|c|c|c|c|c|}
\hline \multirow[b]{2}{*}{ Year } & \multirow[b]{2}{*}{$\begin{array}{l}\text { Brand } \\
\text { Code }\end{array}$} & \multirow{2}{*}{$\begin{array}{l}\text { Travel Time } \\
\text { (standard } \\
\text { parameters) }\end{array}$} & \multicolumn{2}{|c|}{$\begin{array}{c}\text { FGE ranging from } \\
0.3 \text { to } 0.7\end{array}$} & \multicolumn{2}{|c|}{$\begin{array}{l}\text { FGE ranging from } \\
0.2 \text { to } 0.8\end{array}$} & \multicolumn{2}{|c|}{$\begin{array}{l}\text { SE ranging from } \\
0.75 \text { to } 2.00\end{array}$} \\
\hline & & & Min & $\operatorname{Max}$ & Min & $\operatorname{Max}$ & Min & Max \\
\hline 83 & RD-SU-3 & 13.651 & 13.438 & 13.899 & 13.345 & 14.042 & $76,50 \%$ & $987 \% 9$ \\
\hline 85 & RD-R-2 & 12.072 & 12.007 & 12.262 & 11.989 & 12.573 & 11.884 & 12.101 \\
\hline 86 & RA-Y-2 & 20.570 & 20.457 & 20.630 & 20.034 & 20.630 & 20.506 & 25.33 \\
\hline 87 & RA-R- I & 12.353 & 12.264 & 12.391 & 12.153 & 12.403 & & 12.459 \\
\hline 88 & LA-T-2 & 18.236 & 18.236 & 18.236 & 18.236 & 18.236 & $18.236^{332}$ & 18.236 \\
\hline 89 & R\#-7H-\# & 11.340 & 10.860 & 11.592 & 9438 & 11592 & 11.244 & 11.902 \\
\hline 90 & \#-7U-\# & 16.656 & 16.617 & 16.673 & 16.568 & 16.678 & 16.592 & 17.300 \\
\hline 83 & RD-T-1 & 8.033 & 7043 & 9577 & 671 & $10 \% 58$ & 7.512 & 8.857 \\
\hline 84 & LD-J-1 & 8.292 & 8.157 & 8.752 & 8.087 & 8.752 & 6.793 & 8.753 \\
\hline 85 & RD-R-3 & 13.107 & 12.388 & 14629 & 12,200 & 16802 & 12.759 & 14.242 \\
\hline 86 & RD-Y-3 & 10.777 & 8241 & 11856 & 2389 & 12083 & $1381 \%$ & 11700 \\
\hline 87 & LD-R-3 & 10.716 & 10.624 & 10.756 & 10.508 & 10.764 & 10.714 & 10.796 \\
\hline 89 & RA-R-\# & 10.565 & 10.338 & 10.842 & 10.226 & 10.920 & 10.092 & 10.652 \\
\hline 90 & LD-T-\# & 10.390 & 10.389 & 10.391 & 10.389 & 10.392 & 10.127 & 11.399 \\
\hline 82 & RD-4-1 & 9.562 & 8742 & 10.224 & 77884 & 1025 & 8946 & $110 \%$ \\
\hline 83 & RD-12-1 & 11.377 & 11.113 & 11.664 & 10.984 & 11.838 & $1 \% 40$ & $11.68 \%$ \\
\hline 84 & RD-J-3 & 10.280 & 9.889 & 10.597 & 9.889 & 10.814 & 9870 & 20982 \\
\hline 85 & LD-R- 1 & 13.917 & 13.642 & 14798 & 13557 & 16402 & 13.436 & 13.974 \\
\hline 86 & LD-Y- 1 & 14.632 & 14.615 & 14.662 & 14.609 & 14.685 & 14.285 & 14.650 \\
\hline 87 & LD-R-2 & 10.844 & 10.789 & 10.867 & 10.721 & 10.874 & 10.838 & 10.873 \\
\hline 88 & RD-T-4 & 16.698 & 16.698 & 16.698 & 16.698 & 16.698 & 16.698 & 16.698 \\
\hline 89 & L\#-7H-\# & 13.821 & 13.642 & 14.029 & 13.560 & 14.151 & 13.688 & 14.685 \\
\hline 90 & RA-T\#\# & 12.247 & 12.247 & 12.247 & 12.246 & 12.247 & 12.199 & 12.519 \\
\hline 83 & RD-T-2 & 7.330 & 6761 & 8368 . & 6463 & 9897 & 2127 & 9408 \\
\hline 84 & LD-J-3 & 12.495 & ii. 201 & 12.889 & 12080 & 13210 & 12386 & 14846 \\
\hline 85 & RD-R-1 & 12.927 & 12.748 & 13.145 & 12.669 & 13.348 & 11.192 & 13.100 \\
\hline 86 & RD-Y- 1 & 9.093 & 8.756 & 9.183 & 8182 & 9209 & 7.690 & 9.208 \\
\hline 87 & RD-R- 1 & 8.997 & 8.882 & 9.046 & 8.738 & 9.062 & 8.913 & 9.359 \\
\hline 88 & RD-T- 1 & 14.564 & 14.564 & 14.564 & 14.564 & 14.564 & 14.564 & 14.564 \\
\hline 89 & LA-R-\# & 0.904 & 10.820 & 11.013 & 10.782 & 11.091 & 10.886 & 10.988 \\
\hline 90 & LA-T-\# & 11.084 & 11.084 & 11.084 & 11.084 & 11.084 & 11.001 & 12.135 \\
\hline 82 & RD-SU-\# & 4.111 & 3913 & 6782 & 3846 & 8289 & $39914 \%$ & 8264 \\
\hline 83 & RD-T-3 & 13.481 & 13.007 & 13.007 & 12.835 & 13.689 & 17.88 & 22134 \\
\hline 87 & LA-J-\# & 12.205 & 12.169 & 12.220 & 12.124 & 12.225 & 12.186 & 12.308 \\
\hline 88 & \#A-I\#-\# & 19.915 & 19.915 & 19.915 & 19.915 & 19.915 & 19.915 & 19.915 \\
\hline 89 & \#D-J-\# & 12.059 & 12.027 & 12.080 & 12.011 & 12.073 & 12.023 & 12.269 \\
\hline 90 & \#A-A-\# & 15.883 & 15.880 & 15.889 & 15.879 & 15.897 & 15.862 & 16.067 \\
\hline 84 & RD-J-1 & 7.891 & 7.653 & 8.206 & 7.484 & 8.206 & 1.654 & 8.372 . \\
\hline 85 & LD-R-3 & 15.378 & 15.234 & 15.555 & 15.172 & 15.660 & 15.338 & 15.692 \\
\hline 86 & LD-Y-3 & 12.561 & 12.541 & 12.604 & 12.534 & 12.652 & 12.453 & 12.590 \\
\hline 87 & LD-R-4 & 10.734 & 10.662 & 10.759 & 10.531 & 10.767 & 10.710 & 10.856 \\
\hline 88 & LD-T-4 & 18.184 & 18.184 & 18.184 & 18.184 & 18.184 & 18.184 & 18.184 \\
\hline
\end{tabular}


Section 4: Sensitivity of R epression R esults

In this section we report the results from three studies of the sensitivity of the basic regression results (Section 2.3). In the first two studies, we varied the values of key underlying parameters and then recomputed two portions of the analysis. First, we re-applied the stepwise regression and best-subsets regression techniques to determine the effect of varying parameters on the models selected. Secondly, we selected a particular set of independent variables and applied them to the data arising from each set of parameter assumptions, to determine the effect of varying parameters on the regression coefficients. Because the travel time estimates were shown not to be sensitive to changes in assumed values for spillway survival, bypass survival, turbine survival, and survival and travel time in the Lower Granite to Little Goose reach, we chose to restrict our investigation to the effects on the regression model of changing values of Fish Guidance Efficiency (FGE) and Spill Effectiveness (SE). The third sensitivity study involved the omission of the data for single years, one year at a time, to determine whether any particular year had undue influence on the analytical results.

\subsection{Sensitivitv of Selected Regression M odels to Underlving Assumptions}

The travel times of the 42 hatchery releases (Table 1) were estimated under of variety of sets of assumed values for the underlying parameters and the stepwise and best-subsets regression analyses were performed on each resulting data set. As in the basic analyses of Section 2.3, Ice Harbor Dam data were used as indices of the data from other dams and the potential predictor variables were ENTDATE and TTLGR as surrogates for smoltification and AVGFLOW ${ }^{-1}$, MINFLOW $^{-1}$, MAXFLOW-', DFLOW ${ }^{-1}$ and MINSP, AVGSP, and MAXSP. Stepwise regression was performed using the MINITAB statistical software package, with variables entering the model if their F-value to enter was greater than 4.0 and being removed from the model at later steps if their F-value dropped below 4.0. Best-subsets regression was also performed using MINITAB. The purpose of best-subsets regression is to' find the subsets of size $n$ of the potential predictors that result in the highest $R^{2}$ values.

Table 11 summarizes the results from stepwise regression, while Table 12 shows the best 3variable model under each set of parameter values and Table 13 shows the best 4 -variable models. In each table, the variables included in the model are indicated with an " $\mathrm{X}$ " and the $R^{2}$ values for the models are given. The top row of each table shows the selected model when the standard parameter values are used. Each subsequent row shows the selected models when the value of one of the key parameters is set to the value indicated. The values $0.2,0.3,0.4,0.6,0.7$, 
Table 11. Models selected bv stepwise repression algorithm under varving assumptions for Fish Guidance Efficiency and Spill Effectiveness. Steuwise procedure applied using data from Ice Harbor dam only. Selected variables are indicated with "X".

\begin{tabular}{|c|c|c|c|c|c|c|c|c|c|}
\hline \multirow{2}{*}{$\begin{array}{l}\text { Parameter } \\
\text { Values }\end{array}$} & \multirow[b]{2}{*}{ TTLGR } & \multicolumn{4}{|c|}{ Ice Harbor Flow } & \multicolumn{3}{|c|}{ Ice Harbor Spill } & \multirow{2}{*}{$R^{2}$} \\
\hline & & Min & Avg & Max & DFLOW $^{-1}$ & M i n & Avg & Max & \\
\hline Standard' & X & & X & X & & X & & & 70.4 \\
\hline $\mathrm{FGE}=0.2$ & X & & & & X & X & & & 66.2 \\
\hline $\mathrm{FGE}=0.3$ & $X$ & X & & & & $\mathrm{X}$ & & & 62.2 \\
\hline $\mathrm{FGE}=0.4$ & $x$ & & & & $\mathrm{X}$ & $\mathrm{X}$ & & & 62.7 \\
\hline FGE $=0.6$ & $x$ & & $x$ & $x$ & & $x$ & & & 69.4 \\
\hline $\mathrm{FGE}=0.7$ & $\mathrm{X}$ & & $\mathrm{X}$ & $\mathrm{X}$ & & X & & & 67.6 \\
\hline $\mathrm{FGE}=0.8$ & X & X & & & & $\mathrm{X}$ & & & 45.7 \\
\hline FGE $=f(D A T E)^{2}$ & $\mathrm{X}$ & & $\mathrm{X}$ & $\mathrm{X}$ & & $\mathrm{X}$ & & & 68.6 \\
\hline SE $=0.75$ & X & & & & $X$ & X & & & 61.5 \\
\hline $\mathbf{S E}=1.25$ & $\mathrm{X}$ & & $\mathrm{X}$ & $\mathrm{X}$ & & $\mathrm{X}$ & & & 70.4 \\
\hline $\mathbf{S E}=1.50$ & $\mathrm{X}$ & & & & $\mathrm{X}$ & $\mathrm{X}$ & & & 65.1 \\
\hline $\mathrm{SE}=1.75$ & $\mathrm{X}$ & & & & $\mathrm{X}$ & & & & 65.8 \\
\hline$S E=2.00$ & $x$ & & & & $\mathrm{X}$ & $x$ & $\mathrm{X}$ & & 70.6 \\
\hline SE $=f(\% \text { spill })^{3}$ & $\mathrm{x}$ & $\mathrm{x}$ & & & & & & & I 59.7 \\
\hline
\end{tabular}

1. $F G E=0.5 S_{\text {sill }} 0.98, S_{\text {turb }}=0.85, S_{\text {bypass }}=0.98, T T_{r c h}=4, S_{r c h}=0.80, S E=1.0$.

2. See Equation 7 and Figure 2.

3. See Equation 8 and Figure 3. 
Table 12. Models selected bv best-subsets repression algorithm under varving assumptions for Fish Guidance Efficiency and spill Effectiveness. Variables in best 3-variable models using data from Ice Harbor dam onlv are indic ated bv "X".

\begin{tabular}{|c|c|c|c|c|c|c|c|c|c|}
\hline \multirow{2}{*}{$\begin{array}{l}\text { Parameter } \\
\text { Values }\end{array}$} & \multirow[b]{2}{*}{ TTLGR } & \multicolumn{4}{|c|}{ Ice Harbor Flow } & \multicolumn{3}{|c|}{ Ice Harbor Spill } & \multirow{2}{*}{$R^{2}$} \\
\hline & & Min & Avg & $\operatorname{Max}$ & DFLOW $^{-1}$ & Min & Avg & $\operatorname{Max}$ & \\
\hline Standard $^{1}$ & $\mathrm{x}$ & & $\mathrm{x}$ & $\mathrm{x}$ & & & & & 64.1 \\
\hline $\mathrm{FGE}=0.2$ & $\mathrm{x}$ & & $\mathrm{x}$ & $\mathrm{x}$ & & & & & 66.6 \\
\hline $\mathrm{FGE}=0.3$ & $\mathrm{x}$ & & $\mathrm{x}$ & $\mathrm{x}$ & & & & & 66.3 \\
\hline $\mathrm{FGE}=0.4$ & $\mathrm{x}$ & & $\mathrm{X}$ & $\mathrm{X}$ & & & & & 65.7 \\
\hline $\mathrm{FGE}=0.6$ & $\mathrm{x}$ & & $\mathrm{x}$ & $\mathrm{x}$ & & & & & 65.2 \\
\hline $\mathrm{FGE}=0.7$ & $\mathrm{X}$ & & $\mathrm{x}$ & $\mathrm{x}$ & & & & & 64.1 \\
\hline $\mathrm{FGE}=0.8$ & $\mathrm{x}$ & & $\mathrm{x}$ & $\mathrm{x}$ & & & & & 59.3 \\
\hline$F G E=f(D A T E)^{2}$ & $\mathrm{x}$ & & $\mathrm{x}$ & $\mathrm{x}$ & & & & & 62.9 \\
\hline$S E=0.75$ & $\mathrm{X}$ & & $\mathrm{x}$ & $\mathrm{x}$ & & & & & 64.7 \\
\hline$S E=1.25$ & $\mathbf{X}$ & & $\mathrm{X}$ & $\mathrm{x}$ & & & & & 66.0 \\
\hline$S E=1.50$ & $\mathrm{X}$ & & & & $\mathrm{X}$ & $\mathrm{x}$ & & & 65.1 \\
\hline$S E=1.75$ & $\mathrm{x}$ & & & & $\mathrm{X}$ & & & $\mathrm{X}^{*}$ & 67.3 \\
\hline$S E=2.00$ & & & & & $\mathrm{x}$ & $\mathrm{x}$ & $\mathrm{X}^{*}$ & & 61.5 \\
\hline$S E=\mathrm{f}(\% \text { spill })^{3}$ & $\mathrm{x}$ & & $\mathrm{x}$ & $\mathrm{x}$ & & & & & 66.0 \\
\hline
\end{tabular}

* Variable not significant at $P=0.05$ significance level.

1. $F G E=0 . S_{\text {sill }} \notin .98, S_{\text {turb }}=0.85, S_{\text {bypass }}=0.98, T T_{r c h}=4, S_{r c h}=0.80, S E=1.0$.

2. See Equation 7 and Figure 2.

3. See Equation 8 and Figure 3. 
Table 13. Models selected bv best-subsets repression algorithm under varving assumptions for Fish Guidance Efficiencv. and Spill Effectiveness. Variables in best 4-variablemodels using data from Ice Harbor dam onlv are indicated bv "X".

\begin{tabular}{|c|c|c|c|c|c|c|c|c|c|}
\hline \multirow{2}{*}{$\begin{array}{c}\text {, Parameter } \\
\text { Values }\end{array}$} & \multicolumn{5}{|c|}{ Ice Harbor Flow } & \multicolumn{3}{|c|}{ Ice Harbor Spill } & \multirow{2}{*}{$R^{2}$} \\
\hline & TTLGR M & $\mathrm{i} n$ & Avg & Max & DFLOW $^{-1}$ & Min & Avg & Max & \\
\hline Standard' & $\mathrm{X}$ & & $\mathrm{x}$ & $\mathrm{x}$ & & $\mathrm{X}$ & & & 70.4 \\
\hline $\mathrm{FGE}=0.2$ & $\mathrm{X}$ & & $\mathrm{X}$ & $\mathrm{X}$ & & $\mathrm{x}$ & & & 72.3 \\
\hline $\mathrm{FGE}=0.3$ & $\mathrm{X}$ & & $\mathrm{X}$ & $\mathrm{X}$ & & $\mathrm{X}^{*}$ & & & 71.9 \\
\hline $\mathrm{FGE}=0.4$ & $\mathrm{X}$ & & $\mathrm{X}$ & $\mathrm{X}$ & & $\mathrm{X}^{*}$ & & & 71.3 \\
\hline $\mathrm{FGE}=0.6$ & $\mathrm{x}$ & & $\mathrm{x}$ & $\mathrm{x}$ & & $\mathrm{x}$ & & & 69.4 \\
\hline $\mathrm{FGE}=0.7$ & $\mathrm{x}$ & & $\mathrm{x}$ & $\mathrm{x}$ & & $\mathrm{X}^{*}$ & & & 67.6 \\
\hline $\mathrm{FGE}=0.8$ & $\mathrm{X}$ & & $\mathrm{X}$ & $\mathrm{X}$ & & $\mathrm{X}^{*}$ & & & 61.7 \\
\hline FGE $=f(D A T E)^{2}$ & $\mathrm{x}$ & & $\mathrm{x}$ & $\mathrm{X}$ & & $\mathrm{x}$ & & & 68.6 \\
\hline $\mathrm{SE}=0.75$ & $\mathrm{x}$ & & $\mathrm{x}$ & $\mathrm{x}$ & & $\mathrm{x}$ & & & 70.9 \\
\hline $\mathbf{S E}=1.25$ & $\mathrm{x}$ & & $\mathrm{x}$ & $\mathrm{x}$ & & $x$ & & & 70.4 \\
\hline SE $=1.50$ & $\mathrm{x}$ & & $\mathrm{x}$ & $\mathrm{x}$ & & $\mathrm{x}$ & & & 71.0 \\
\hline $\mathbf{S E}=1.75$ & $\mathrm{x}$ & $\mathrm{x}$ & & & & $\mathrm{x}$ & $\mathrm{x}$ & & 75.4 \\
\hline SE $=2.00$ & $x$ & & & & $\mathrm{X}$ & $\mathrm{Tx}$ & $X$ & & 70.6 \\
\hline $\mathbf{S E}=f(\% \text { spill })^{3}$ & $\mathrm{x}$ & & $\mathrm{x}$ & $\mathrm{x}$ & & $\mathrm{x}$ & & & 72.5 \\
\hline
\end{tabular}

* Variable not significant at $P=0.05$ significance value.

1. $F G E \quad 0.5,=S_{\text {sill }} 0.98, S_{\text {turb }}=0.85, S_{\text {bypass }}=0.98, T T_{r c h}=4, S_{r c h}=0.80, S E=1.0$.

2. See Equation 7 and Figure 2.

3. See Equation 8 and Figure 3. 
and 0.8 are used for FGE; 0.75, 1.25, $1.50,1.75$, and 2.00 for SE. In addition, there are results for travel time estimates based on FGE as a function of Julian date (see Eq. 7) and on SE as a function of the spill proportion (Eq. 8).

The composition of the model selected by the stepwise procedure is not consistent between parameter sets, either in the number of variables in the model or in their identity. It is difficult to detect patterns in the variables selected, though with parameter sets "close" to the standard set (e.g. when FGE is set at 0.6 or 0.7 where the standard is OS), the same model is selected as with the standard set. The variables in this commonly-selected model are TTLGR, AVGFLOW'-1, MAXFLOW' ${ }^{-1}$ and MINSP. Another model frequently selected includes the three variables 'ITLGR, DFLOW'-1, and MINSP; quite similar to the standard model.

The best-subsets models, in contrast, are very consistent. The same 3-variable and 4variable models are selected regardless of the value of FGE. However, with some of the FGE values, MINSP is not significant at the $\boldsymbol{p}=0.05$ significance level in the 4 -variable model. The same best models are chosen for the lower values of spill effectiveness, but as the value for SE increases, the relative importance of the spill volume variables increases, resulting in the spill measures being included in the best models.

\subsection{Sensitivitv of Regression Eauations to Underlving Assumptions}

For simplicity, we present results on the sensitivity of the coefficients in the best 2-variable model from Section 2.3.3, that is, the model that includes only TTLGR and AVGFLOW ${ }^{-1}$. The results for this model are representative of the sensitivity of other models we investigated. Table 14 gives the results of the analysis of sensitivity to changing values of FGE and SE. The first row of the table repeats the coefficient estimates, their standard errors and 2-sidedp-values and the overall $R^{2}$ obtained using the travel time estimates from the standard assumed values. Each subsequent row presents the regression results using the travel time estimates with the indicated value for the key parameter. The values $0.2,0.4,0.6$, and 0.8 are used for FGE; 0.75, 1.25, $1 \mathrm{SO}$, 1.75, and 2.00 for SE. In addition, there are results for travel time estimates based on FGE as a function of Julian date (see Eq. 7) and on SE as a function of the spill proportion (Eq. 8).

The estimated regression coefficients and their levels of significance are fairly insensitive to the value of FGE. For TTLGR, the range of coefficients is -0.126 to -0.146 and the variable is highly significant regardless of the FGE. The range of the AVGFLOW ${ }^{-1}$ coefficient is also about $10 \%$ (602.9 to 667.3 ), and it remains highly significant. The $R^{2}$ values for the regression 
Table 14. Summarv of analvsis of sensitivitv of regression to underlving parameters. Coefficient estimates, standard errors, and R-sauared under a varietv of assumed parameter values. P-values are 2-sided.

\begin{tabular}{|l|ccc|ccc|c|}
\hline \multirow{2}{*}{ Parameter } & \multicolumn{3}{|c|}{ TTLGR } & \multicolumn{3}{|c|}{ AVGFLOW } & \\
\cline { 2 - 7 } & $\hat{\beta}$ & S.e $(\hat{\beta})$ & $p$-value & $\hat{\beta}$ & s.e $(\hat{\beta})$ & $p$-value & $R^{2}$ \\
\hline Standard' & -0.141 & 0.037 & $<0.001$ & 647.630 & 118.065 & $<0.001$ & 55.6 \\
FGE=0.2 & & & & & & & \\
FGE=0.4 & -0.146 & 0.038 & $<0.001$ & 667.283 & 117.728 & $<0.001$ & 57.1 \\
FGE=0.6 & -0.143 & 0.038 & $<0.001$ & 651.753 & 117.995 & $<0.001$ & 55.9 \\
FGE=0.8 & -0.136 & 0.037 & $<0.001$ & 616.261 & 116.880 & $<0.001$ & 53.9 \\
FGE=f(DATE) & -0.134 & 0.046 & 0.006 & 602.919 & 147.033 & $<0.001$ & 41.7 \\
& -0.126 & 0.039 & 0.002 & 642.966 & 121.792 & $<0.001$ & 51.4 \\
SE = 0.75 & -0.143 & 0.038 & $<0.001$ & 631.796 & 119.228 & $<0.001$ & 54.4 \\
SE = 1.25 & -0.137 & 0.037 & co.001 & 647.096 & 117.254 & $<0.001$ & 55.6 \\
SE = 1.50 & -0.137 & 0.039 & 0.001 & 651.542 & 121.160 & $<0.001$ & 54.4 \\
SE = 1.75 & -0.206 & 0.051 & $<0.001$ & 652.468 & 171.032 & $<0.001$ & 47.2 \\
SE = 2.00 & -0.238 & 0.063 & $<0.001$ & 492.064 & 203.058 & 0.020 & 37.2 \\
SE = f(\%spill) & -0.142 & 0.038 & $<0.001$ & 659.559 & 121.249 & $<0.001$ & 55.2 \\
\hline *Range & -0.126 & & & 492.064 & & & 37.2 \\
& -0.238 & & & 667.630 & & & 57.1 \\
\hline
\end{tabular}

1. $F G E=0.5, S_{\text {sill }}=0.98, S_{\text {turb }}=0.85, S_{\text {bypass }}=0.98, T T_{r c h}=4, S_{r c h}=0.80, S E=1.0$.

2. See Eq. 7 and Figure 2.

3. See Eq. 8 and Figure 3. 
equation are nearly equal for all values of FGE except 0.8 . At that value, the percentage of variability explained by the independent variables is 41.7 , compared to about $55 \%$ for the other values.

The regression equation is insensitive to the value of SE in the range 0.75 to 1.50 , but there are large differences using the extreme values of 1.75 and 2.00 for $\mathrm{SE}$. At $\mathrm{SE}=1.75$, the coefficient for TTLGR is changed by nearly $50 \%$ from the standard value while the AVGFLOW${ }^{1}$ coefficient stays about the same. For $\mathrm{SE}=2.00$, both coefficients are greatly altered and the $R^{2}$ of the model goes down sharply, from $55 \%$ to $37 \%$. In addition, the significance of the AVGFLOW $^{-1}$ variable changes from less than 0.001 to 0.020 .

\section{3 "Leave-One-Year-Out" Sensitivity}

There is a common approach to the analysis of sensitivity of a regression model called "leave-one-out" diagnostics (Cook and Weisberg, 1982), in which the influence of each single observation is investigated by recomputing the regression equation many times, each time omitting a single observation from the full data set. Figure 12 shows a plot of the estimated travel time using the standard parameter values versus the inverse of the average flow at Ice Harbor Dam. The plotting character in the figure is the last digit of the year of the observation, and the regression line is fitted through all 42 points. While this is far from a perfect representation of the multi-dimensional space of the multiple regression, the clustering of points for many year's observations (especially 1984, 1987 and 1988) suggests that the leave-one-out approach will not be very informative in this case; when a particular observation is omitted, there are others from the same year in nearly the same position that will tend to maintain the regression line's slope. In this case, it is interesting to investigate the effects on the regression equation of omitting all the observations for a given year. This we have called the "leave-oneyear-out" approach. The results of the approach are reported in Table 15. It is apparent that the observations from 1988 and 1990, the years of lowest flow in the study, exert much influence on the fit of the regression equation. When both the 1988 and 1990 observations are in the model, the equation is relatively stable. When the 1988 observations are omitted, the coefficients are not changed greatly, but the overall fit of the model is worsened, reflected in the $R^{2}$ value, and in the $p$-value for MAXFLOW ${ }^{-1}$. Omitting the 1990 observations has little effect on the significance levels of the coefficients or on the $R^{2}$ value, but has substantial effect on the coefficients themselves. 


\section{Figuli}

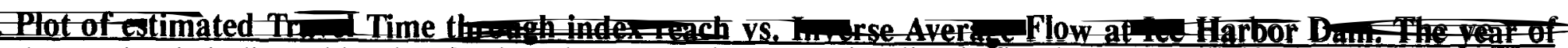
observation is indicated bv the plotting character. The repression line is fitted through all 42 observations.

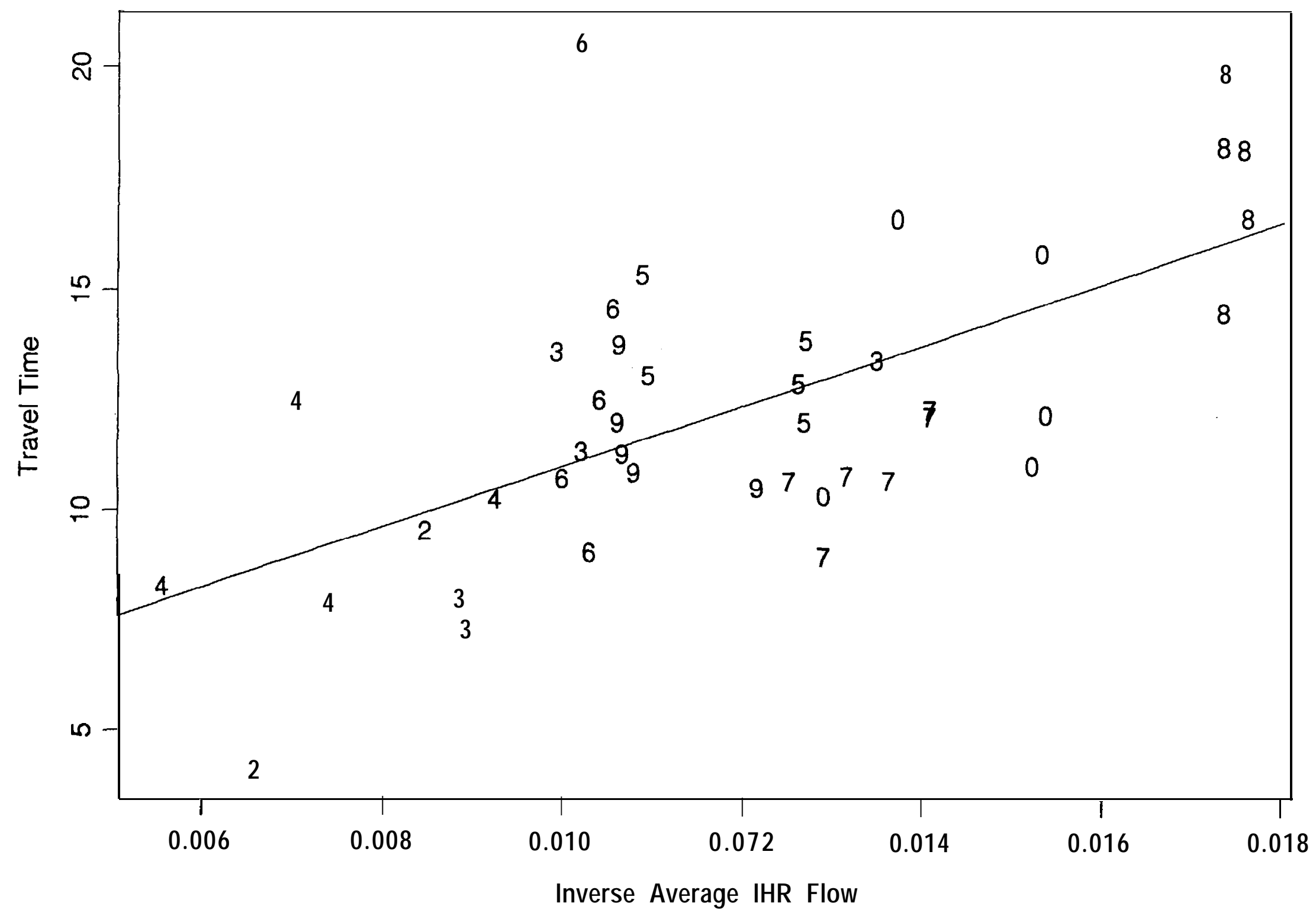


Table 15. Summarv of analvsis of sensitivitv of regression to vear-bv-year omission of observations. Coefficient estimates. standard errors, and $\mathbf{R}^{2}$ for model with indicated vear omitted. P-values are 2-sided.

\begin{tabular}{|c|c|c|c|c|c|c|c|c|c|c|}
\hline \multirow{2}{*}{$\begin{array}{c}\text { Year } \\
\text { Omitted }\end{array}$} & \multicolumn{3}{|c|}{ TTLGR } & \multicolumn{3}{|c|}{ AVGFLOW' } & \multicolumn{3}{|c|}{ MAXFLOW $^{-1}$} & \multirow[b]{2}{*}{$R^{2}$} \\
\hline & $\hat{\beta}$ & s.e $(\hat{\beta})$ & p-value & $\hat{\beta}$ & s.e $(\hat{\beta})$ & p-value & $\hat{\beta}$ & $\operatorname{s.e}(\hat{\beta})$ & $p$-value & \\
\hline None & -0.171 & 0.035 & $<0.001$ & 1271.1 & 211.9 & $<0.001$ & -1202.8 & 357.9 & 0.002 & 65.8 \\
\hline 1982 & -0.166 & 0.033 & $<0.001$ & 1220.6 & 206.2 & $<0.001$ & -1247.1 & 344.6 & 0.001 & 64.2 \\
\hline 1983 & -0.173 & 0.036 & $<0.001$ & 1297.2 & 236.8 & $<0.001$ & -1275.9 & 392.2 & 0.003 & 65.2 \\
\hline 1984 & -0.174 & 0.035 & $<0.001$ & 1219.3 & 219.9 & $<0.001$ & -1056.7 & 386.3 & 0.010 & 64.8 \\
\hline 1985 & -0.185 & 0.036 & $<0.001$ & 1302.4 & 214.0 & co.001 & -1233.3 & 362.1 & 0.002 & 69.7 \\
\hline 1986 & -0.140 & 0.033 & $<0.001$ & 1279.6 & 182.4 & $<0.001$ & -1127.2 & 309.9 & 0.001 & 73.6 \\
\hline 1987 & -0.175 & 0.038 & $<0.001$ & 1225.7 & 225.5 & co.001 & -1023.1 & 396.9 & 0.015 & 68.8 \\
\hline 1988 & -0.166 & 0.039 & $<0.001$ & 1201.1 & 351.8 & 0.002 & -1123.9 & 476.0 & 0.024 & 48.2 \\
\hline 1989 & -0.182 & 0.039 & $<0.001$ & 1307.3 & 223.0 & co.001 & -1262.4 & 374.4 & 0.002 & 67.8 \\
\hline 1990 & -0.168 & 0.042 & $<0.001$ & 1391.0 & 257.1 & $<0.001$ & -1537.8 & 506.1 & 0.005 & 66.4 \\
\hline Range & $\begin{array}{c}-0.140 \\
\text { to } \\
-0.185\end{array}$ & & & $\begin{array}{c}1201.1 \\
\text { to } \\
1391.0\end{array}$ & & & $\begin{array}{c}-1023.1 \\
\text { to } \\
-1537.8\end{array}$ & & & $\begin{array}{c}48.2 \\
\text { to } \\
73.6\end{array}$ \\
\hline
\end{tabular}




\subsection{Discussion}

The lack of spill at Ice Harbor Dam in the low-flow year of 1988, combined with the influence of the observations seen in the leave-one-year-out analysis, explains to a large extent the insensitivity of the regression equation to changes in the FGE value. In Section 3.2, we showed that the travel time estimates are not changed by changing values in FGE when there is no spill. Thus, the 1988 observations are anchored into their influential position as seen in Figure 12. As the spill efficiency value approaches its extreme value of 2.0, on the other hand, travel time estimates in the left hand side of the plot (high flows and high spills), are altered more than points in the right-hand tail (see Table 9), overpowering the anchoring effect of the 1988 observations and causing the sensitivity to extreme values of SE exhibited in Table 14.

It must be emphasized that conclusions drawn from the analysis of sensitivity of the regression equation are conditional on the 42 observations to which the equations were fit, and cannot be extrapolated to other data sets, for example data sets that might be collected in the future. In particular, there is no guarantee that any future data set will feature a set of anchoring points like our 1988 observations, and the resulting regression equation can be much more unstable than observed here.

\section{Section 5: Effects of Sampling Precision on Regression Relationships: Weighted Regression.}

In the regression analyses of the previous sections, all the observations were given equal weight in the fitting of the model, ignoring differences in the reliability of the estimated median travel times between brand groups. Alternatively, the regressions can be recomputed using unequal weights on the observations, giving greater weight to brand groups whose travel time is more precisely estimated.

The precision of estimation is measured by the variance of the estimator. As an approximation to the variances of the travel time estimates used in the regression estimates, consider an estimate of average travel time based on the difference in mean passage at McNary and Lower Granite Dams. That is, suppose we had the estimate

$$
\hat{\mathbf{1}}=\bar{P}_{M C}-\bar{P}_{L G}
$$

where $P_{M C}$ is the sample mean date of arrival at McNary Dam and $\bar{P}_{L G}$ the sample mean date of entry into the index reach. The variance of this estimate would be (assuming independent samples): 


$$
\sigma_{\uparrow}^{2}=\frac{\sigma_{M C}^{2}}{n_{M C}}+{ }_{{ }^{0}}^{2}{ }_{L G}
$$

where $\sigma^{2}{ }_{M C}$ and $\sigma^{2}{ }_{L G}$ are the variances in passage time at McNary and Lower Granite Dams, respectively, and $n_{M C}$ and $n_{L G}$ are the sample sizes on which the sample means are based. Assuming that the variances in passage times at the two dams are equal, the variance of the estimated average travel time is:

$$
\sigma^{2}\left(\frac{1}{n_{M C}}+\frac{1}{n_{L G}}\right)=\sigma^{2}\left(\frac{n_{M C}+n_{L G}}{n_{M C} n_{L G}}\right)
$$

Thus, if the estimate $\hat{T}$ were used in a regression analysis, reasonable weights for the observations would be:

$$
W=\frac{n_{M C} n_{L G}}{n_{M C}+n_{L G}}
$$

The variance of the sample median is asymptotically proportional to the variance of the mean (Lehmann, 1983). Thus, the relative variances of travel time estimates based on the medians are approximately equal to those based on the means and weights defined by Equation (10) are appropriate for the analysis of the median-based data. In the method described in Section 2, the median passage dates are estimated from samples with size equal to the total number of fish actually sampled at each of the dams, i.e. the "Number Sampled" in the FGE recovery reports (Figure 1), as opposed to the "Number Collected." The basic regression models in Section 2.3 were recomputed using weights on the observations defined by Equation (10), substituting the total number of freeze branded fish sampled at McNary for $\boldsymbol{n}_{\boldsymbol{M C}}$ and total number of freeze branded fish sampled at Lower Granite, adjusted for transportation removals, for $\boldsymbol{n}_{\boldsymbol{L}}$, respectively. The total number sampled for each of the 42 observations are listed in Table 16, along with the resulting weights, normalized so that the largest weight is equal to 1 .O.

The results of the weighted regressions are shown in Table 17 and can be compared to the unweighted results in Table 7 (the coefficients from the unweighted analyses are included in Table 17). The noteworthy effects of weighting the observations are (1) the magnitude of the slopes of all flow variables (AVGFLOW'-1, MAXFLOW'-1, and DFLOW'-1) are decreased and (2) measures related to the variability of the flow are not as highly significant. The variable DFLOW ${ }^{1}$ reflects the variability of the flow, as does MAXFLOW'-1, when added to a model that already includes AVGFLOW'-1. 
Table 16. Total number sampled (see Figure 1) at Lower Granite and McNary Dams for each of 42 brand groups and resulting weights for weighted repression.

\begin{tabular}{|c|c|c|c|c|}
\hline Year & $\begin{array}{l}\text { Brand } \\
\text { Code }\end{array}$ & $\begin{array}{c}\text { Total } \\
\text { Sampled } \\
\text { Lower } \\
\text { Granite }\end{array}$ & $\begin{array}{c}\text { Total } \\
\text { Sampled } \\
\text { McNary }\end{array}$ & $\begin{array}{c}\text { Regression } \\
\text { Weight }\end{array}$ \\
\hline 83 & RD-SU-3 & 335 & 142 & 0.161 \\
\hline 85 & RD-R-2 & 384 & 378 & 0.307 \\
\hline 86 & RA-Y-2 & 479 & 372 & 0.338 \\
\hline 87 & RA-R-l & 659 & 358 & 0.374 \\
\hline 88 & LA-T-2 & 502 & 555 & 0.425 \\
\hline 89 & R\#-7H-\# & 1410 & 211 & 0.296 \\
\hline 90 & \#-7U-\# & 372 & 254 & 0.243 \\
\hline 83 & RD-T-1 & 444 & 290 & 0.283 \\
\hline 84 & LD-J-1 & 196 & 153 & 0.139 \\
\hline 85 & RD-R-3 & 185 & 86 & 0.095 \\
\hline 86 & RD-Y-3 & 508 & 171 & 0.206 \\
\hline 87 & LD-R-3 & 90 & 114 & 0.081 \\
\hline 89 & RA-R-\# & 55 & 48 & 0.041 \\
\hline 90 & LD-T-\# & 54 & 91 & 0.055 \\
\hline 82 & RD-4-1 & 159 & 144 & 0.122 \\
\hline 83 & RD-12-1 & 617 & 536 & 0.462 \\
\hline 84 & RD-J-3 & 302 & 262 & 0.226 \\
\hline 85 & LD-R-1 & 593 & 362 & 0.362 \\
\hline 86 & LD-Y-1 & 1073 & 295 & 0.373 \\
\hline 87 & LD-R-2 & 194 & 98 & 0.105 \\
\hline 88 & RD-T-4 & 116 & 189 & 0.116 \\
\hline 89 & L\#-7H-\# & 1026 & 165 & 0.229 \\
\hline 90 & RA-T-\# & 196 & 215 & 0.165 \\
\hline 83 & RD-T-2 & 182 & 113 & 0.112 \\
\hline 84 & LD-J-3 & 230 & 156 & 0.150 \\
\hline 85 & RD-R-1 & 216 & 124 & 0.127 \\
\hline 86 & RD-Y-1 & 226 & 65 & 0.081 \\
\hline 87 & RD-R-1 & 56 & 33 & 0.033 \\
\hline 88 & RD-T-1 & 47 & 88 & 0.049 \\
\hline 89 & LA-R-\# & 304 & 67 & 0.088 \\
\hline 90 & LA-T-\# & 76 & 96 & 0.068 \\
\hline 82 & RD-SU-\# & 87 & 93 & 0.072 \\
\hline 83 & RD-T-3 & 1123 & 1386 & 1.000 \\
\hline 87 & LA-J-\# & 289 & 155 & 0.163 \\
\hline 88 & \#A-I\#-\#\# & 479 & 451 & 0.374 \\
\hline 89 & \#D-J-\# & 856 & 381 & 0.425 \\
\hline 90 & \#A-A-\# & 512 & 557 & 0.430 \\
\hline 84 & RD-J-1 & 557 & 653 & 0.485 \\
\hline 85 & LD-R-3 & 574 & 465 & 0.414 \\
\hline 86 & LD-Y-3 & 981 & 285 & 0.356 \\
\hline 87 & LD-R-4 & 261 & 116 & 0.129 \\
\hline 88 & LD-T-4 & 217 & 131 & 0.132 \\
\hline
\end{tabular}


Table 17. Results of weighted repressions for selected models from "basic analysis" Section 2.3.3). Observation weights based on number of smolt sampled at Lower Granite and McNary Dams,

(a) Best 4-variable model

\begin{tabular}{|c|c|c|c|c|}
\hline Variable & Coefficient & Std. Error & p-value' & $\begin{array}{l}\text { Coef. in } \\
\text { unweighted } \\
\text { analysis }^{2}\end{array}$ \\
\hline constant & 16.100 & 2.737 & $<0.001$ & 17.462 \\
\hline TTLGR & -0.151 & 0.046 & 0.002 & -0.162 \\
\hline MINSP & -0.095 & 0.033 & 0.007 & -0.081 \\
\hline AVGFLOW' & 715.2 & 217.6 & 0.002 & 1011.2 \\
\hline MAXFLOW ${ }^{-1}$ & -720.5 & 348.1 & 0.046 & -1220.6 \\
\hline
\end{tabular}

(b) Best 3-variable model

\begin{tabular}{|cccc|c|}
\hline Variable & Coefficient & Std. Error & $p$-value & $\begin{array}{c}\text { Coef. in } \\
\text { unweighted } \\
\text { analysis }\end{array}$ \\
\hline constant & 12.784 & 2.712 & $<0.001$ & 13.660 \\
TTLGR & -0.180 & 0.049 & 0.001 & -0.171 \\
AVGFLOW $^{-1}$ & 972.4 & 216.7 & $<0.001$ & 1271.1 \\
MAXFLOW $^{-1}$ & -704.4 & 380.1 & 0.072 & -1202.8 \\
\hline
\end{tabular}

(c) Model selected by stepwise procedure

\begin{tabular}{|c|c|c|c|c|}
\hline Variable & Coefficient & Std. Error & p-value' & $\begin{array}{l}\text { Coef. in } \\
\text { unweighted } \\
\text { analysis' }\end{array}$ \\
\hline Constant & 17.296 & 1.495 & $<0.001$ & 15.863 \\
\hline TTLGR & -0.152 & 0.050 & 0.004 & -0.141 \\
\hline MINSP & -0.121 & 0.033 & 0.001 & -0.090 \\
\hline DFLOW $^{-1}$ & 114.48 & 75.42 & 0.137 & 213.03 \\
\hline
\end{tabular}

1. Probability (2-tail) of observed coefficient estimate under null hypothesis that parameter is zero.

2. See Table 7. 
In the context of the weighted regression, one observation becomes extremely influential; the difference between the weighted and unweighted analyses is almost entirely due to the extremely large weight given to the 1983 RD-T-3 group, which has more than twice the weight of any other observation. If the RD-T-3 group is given a weight of 0.5 , for example, the slopes for AVGFLOW ${ }^{-1}$ and MAXFLOW ${ }^{-1}$ in the best 3-variable model are 1082.2 and -895.7, respectively. If the observation is given zero weight., the slopes are 1264.7 and -1213.9 , respectively, almost unchanged from the unweighted analysis.

This attempt at weighting observations in our analysis according to the relative precision with which the travel time is estimated has shown that the regression results can be very sensitive to the relative weights. The extreme influence exerted by a single observation shows that the weights must be selected carefully. Exact measures of precision would assure that the proper weights were applied. Unfortunately, the distribution-adjustment algorithm used to estimate travel times from brand recapture data (Section 2.2) does not permit such measures.

\section{Section 6: Repression Analvsis Using Independent Variables From All Dams,}

\section{$\underline{6.1 \text { Introduction }}$}

The basic regression models developed in Section 2.3 and further investigated in Sections 4 and 5 were developed using surrogate smoltification measurements and river condition variables measured at Ice Harbor Dam only. Table 5 presented correlations between Ice Harbor measurements and those at other dams, and indicated that Ice Harbor provides an excellent index of the flow volumes at all the other dams, but is less reliable as an index of spill volumes. The correlations among temperature and turbidity measurements across dams indicated that there is no single reliable index for these variables. Accordingly, temperature and turbidity were not considered as potential predictors in the development of the models of the previous sections. The purpose of this section is to explore the potential usefulness of the additional available variables, measured at all the dams, as predictors of travel time.

\subsection{All-Dam Analysis}

A large stepwise regression procedure was performed using all the previously-identified variables as potential explanatory variables. That is, the surrogate smoltification variables were considered, along with the flow, spill, temperature, and turbidity data from all five of the dams in 
64

Table 18. Descriptive statistics for variables used in regression analyses. Statistics are for the 42 release groups listed in Table 1. and used in the repression analyses.

\begin{tabular}{|lcccc|}
\hline & $\begin{array}{c}\text { Median } \\
\text { Release Date } \\
\text { (Julian) }\end{array}$ & $\begin{array}{c}\text { Median } \\
\text { (Julian) }\end{array}$ & $\begin{array}{c}\text { Travel } \\
\text { Time } \\
\text { (Days) }\end{array}$ & $\begin{array}{c}\text { Days } \\
\text { to } \\
\text { LGR }\end{array}$ \\
\hline Mean & 864.4 & 117.72 & 12.379 & 31.28 \\
Std. Dev. & 7.30 & 8.78 & 3.408 & 9.70 \\
Minimum & 71.00 & 103.50 & 4.111 & 14.59 \\
Maximum & 101.00 & 142.43 & 20.570 & 62.09 \\
\hline
\end{tabular}

\begin{tabular}{|c|c|c|c|c|c|c|c|c|c|c|c|c|c|}
\hline & \multicolumn{13}{|c|}{ Measurements at Lower Granite } \\
\hline & \multicolumn{3}{|c|}{ FLOW $^{-1}$} & \multirow[b]{2}{*}{ DFLOW $^{-1}$} & \multicolumn{3}{|c|}{ SPILL (kcfs) } & \multicolumn{3}{|c|}{ Temperature } & \multicolumn{3}{|c|}{ Turbidity } \\
\hline & Min. & Avg. & Max. & & Min. & Avg. & Max. & Min. & Avg. & Max. & Min. & Avg. & Max. \\
\hline Mean & .0164 & .0119 & .0093 & 0.0070 & 3.09 & 8.62 & 16.67 & 49.23 & 51.47 & 53.19 & 1.61 & 2.54 & 5.16 \\
\hline Std. Dev. & .0059 & .0031 & .0018 & 0.0047 & 8.33 & 15.18 & 24.98 & 2.48 & 1.48 & 1.52 & 0.89 & 0.75 & 1.01 \\
\hline Minimum & .0063 & .0055 & .0050 & 0.0010 & 0.00 & 0.00 & 0.00 & 39.00 & 48.27 & 50.00 & 0.20 & 1.30 & 1.70 \\
\hline Maximum & .0270 & .0173 & .0129 & 0.0162 & 38.37 & 58.61 & 80.89 & 56.00 & 56.91 & 58.00 & 3.10 & 3.92 & 5.00 \\
\hline
\end{tabular}

\begin{tabular}{|c|c|c|c|c|c|c|c|c|c|c|c|c|c|}
\hline & \multicolumn{13}{|c|}{ Measurements at Little Goose } \\
\hline & \multicolumn{3}{|c|}{ FLOW $^{-1}$} & \multirow[b]{2}{*}{ DFLOW $^{-1}$} & \multicolumn{3}{|c|}{ SPILL (kcfs) } & \multicolumn{3}{|c|}{ Temperature } & \multicolumn{3}{|c|}{ Turbidity } \\
\hline & Min. & Avg. & Max. & & Min. & Avg. & Max. & Min. & Avg. & Max. & Min. & Avg. & Max. \\
\hline Mean & .0166 & .0118 & .0093 & .0074 & 3.23 & 9.82 & 15.76 & $\mathrm{NA}$ & NA & $\overline{N A}$ & $\mathrm{NA}$ & $\mathrm{NA}$ & $\mathrm{NA}$ \\
\hline Std. Dev. & .0056 & .0030 & .0018 & .0045 & 8.61 & 17.67 & 26.46 & NA & NA & NA & NA & NA & NA \\
\hline Minimum & .0064 & .0055 & .0050 & .0009 & 0.00 & 0.00 & 0.00 & NA & NA & NA & NA & NA & NA \\
\hline Maximum & .0264 & .0172 & .0127 & .0159 & 46.45 & 64.42 & 88.45 & NA & NA & NA & NA & NA & NA \\
\hline
\end{tabular}

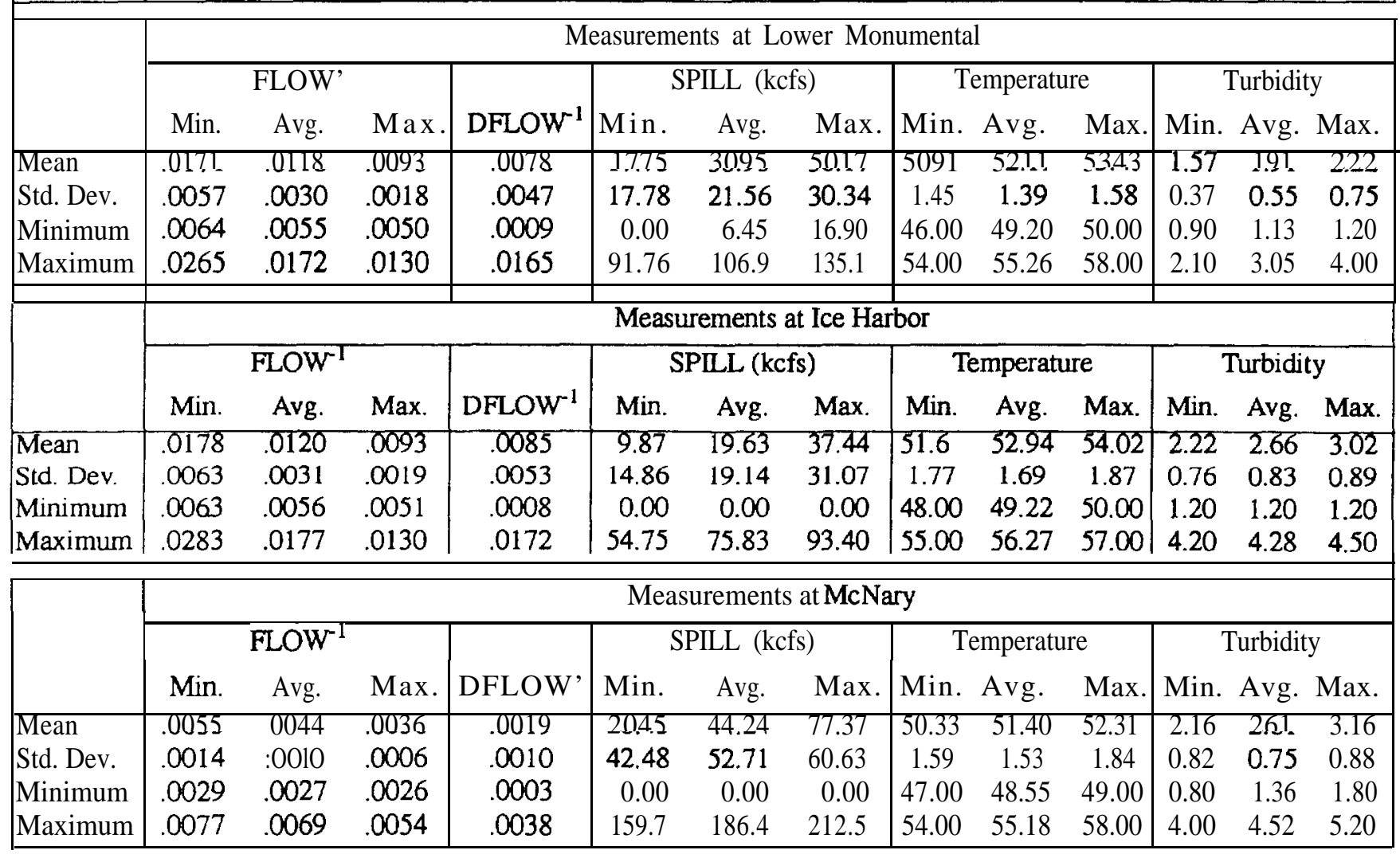


Table 19. Pairwise correlations between Travel Time through index reach and 62 continuous predictor variables. Correlations based on all 42 brand groups listed in Table 1 ,

\begin{tabular}{|lll|}
\hline $\begin{array}{c}\text { Median } \\
\text { Release Date } \\
\text { (Julian) }\end{array}$ & $\begin{array}{c}\text { Median } \\
\text { Entry Date } \\
\text { (Julian) }\end{array}$ & $\begin{array}{c}\text { Days } \\
\text { to } \\
\text { LGR }\end{array}$ \\
\hline 0.051 & $-0.461^{*}$ & $-0.456^{*}$ \\
\hline
\end{tabular}

\begin{tabular}{|c|c|c|c|c|c|c|c|c|c|c|c|c|c|}
\hline & \multicolumn{3}{|c|}{ FLOW $^{-1}$} & \multirow[b]{2}{*}{ DFLOW $^{-1}$} & \multicolumn{3}{|c|}{ SPILL (kcfs) } & \multicolumn{3}{|c|}{ Temperature } & \multicolumn{3}{|c|}{ Turbidity } \\
\hline & Min. & Avg. & Max. & & Min. & Avg. & Max. & Min. & Avg. & Max. & Min. & Avg. & Max. \\
\hline Lower Granite & $0.620 *$ & $0.625^{*}$ & $0.500 *$ & $0.573^{*}$ & $-0.468 *$ & $-0.491^{*}$ & $-0.425^{*}$ & -0.200 & -0.250 & -0.074 & $0.325 *$ & $0.510^{*}$ & $0.444^{*}$ \\
\hline Little Goose & $0.629 *$ & $0.632 *$ & $0.510^{*}$ & $0.574^{*}$ & $-0.380 *$ & $-0.427^{*}$ & $-0.391^{*}$ & & - & - & --- & --- & $\cdots$ \\
\hline Lower Monumental & $0.623 *$ & $0.625^{*}$ & $0.457^{*}$ & $0.576^{*}$ & $-0.652^{*}$ & $-0.622^{*}$ & $-0.507^{*}$ & -0.285 & -0.217 & -0.052 & 0.231 & $0.332^{*}$ & 0.292 \\
\hline Ice Harbor & $0.608 *$ & $0.628 *$ & $0.438^{*}$ & $0.565^{*}$ & $-0.642 *$ & $-0.555 *$ & $-0.388 *$ & $-0.324^{*}$ & -0.126 & -0.067 & 0.119 & 0.093 & 0.241 \\
\hline McNary & $0.535 *$ & $0.670^{*}$ & $0.619 *$ & $0.398 *$ & $-0.602 *$ & $-0.586^{*}$ & $-0.588 *$ & 0.050 & 0.022 & 0.105 & 0.021 & 0.196 & $0.305^{*}$ \\
\hline
\end{tabular}

* Correlation is significant at the two-sided 0.05 level $\left(P_{H_{0}}(|r| \geq 0.3041 n=42)=0.05\right)$. 
the index reach. Since data are used from all the dams at once in this set of analyses, we have deemed this the "All-Dam Analysis."

The complete set of 63 variables used in the regression analyses is listed in Appendix 1. The variables are summarized with descriptive statistics in Table 18, including mean, standard deviation, minimum, and maximum. In addition, the pairwise linear correlations between each of the 62 continuous predictor variables (i.e. excluding the discrete RACE) and TTIME are listed in Table 19. On a pairwise basis, TTIME is significantly correlated with all the flow and spill variables from all the dams $(P(|r| \geq 0.3041 n=42, \rho=0.0)=0.05)$. Travel time through the index reach is also significantly correlated pair-wise with all three turbidity measures at Lower Granite and average turbidity at Lower Monumental, maximum turbidity at McNary, minimum temperature at Ice Harbor, the median date of entry into the index reach, and with the navel time from release to Lower Granite (TTLGR). In general, TTIME has the strongest pairwise correlations with the flow variables.

The results for the stepwise regression using the full set of 42 brand groups are summarized in Table 20. The variables selected were TTLGR, AVGFLOW-1, MINFLOW'-1, MAXFLOW $^{-1}$, and MAXTEMP measured at McNary Dam, MINSP measured at Ice Harbor, and AVGTEMP measured at Lower Granite. All predictors were highly significant ( $p$ value $<0.001$ ) except AVGTEMP at Lower Granite ( $p$-value $=0.024)$.

As with the basic regressions of Section 2.3, the group released in 1990 from McCall Hatchery with tag code LD-T-\#, was flagged by MINITAB as an observation whose X-values give it potentially large influence on the model (i.e. "leverage"; Cook and Weisberg, 1982). The observation was removed from the data set and the regression equation was recomputed, and again as with the basic regressions there was little change in regression coefficients, significance, or the overall $R^{2}$ value. There is no need to remove the observation from the data set.

Despite the inclusion of several more variables than in the basic regressions, the exceptionally long travel time of the group released from Dworshak Hatchery with code RA-Y-2 is not fit well. The observation was omitted and the regression recomputed, with small effect on the coefficient estimates, but the coefficients had considerably smaller standard errors and correspondingly smaller significance levels. Without biological or practical evidence for support, however, there is no statistical justification for omitting the observation, and the larger standard errors must be accepted. 
67

Table 20. Results of stepwise regression analvsis using full suite of potential predictor variables, All-Dam analysis.

\begin{tabular}{|cccccc|}
\hline Variable & Coefficient & Std. Error & p-value' & $R^{2}$ & $\mathbf{S}^{2}$ \\
\hline constant & 14.448 & 9.779 & 0.149 & \\
TTLGR & -0.175 & 0.030 & $<0.001$ & \\
Lower & & & & \\
Granite & -0.696 & 0.295 & 0.024 & \\
AVGTEMP & & 0.024 & $<0.001$ & \\
$\begin{array}{c}\text { Ice Harbor } \\
\text { MINSP }\end{array}$ & -0.131 & 0.262 & 0.003 & \\
$\begin{array}{c}\text { McNary } \\
\text { MAXTEMP }\end{array}$ & 0.836 & 450.3 & 0.003 & \\
$\begin{array}{c}\text { McNary } \\
\text { MINFLOW }\end{array}$ & -1417.7 & 1091 & $<0.001$ & \\
$\begin{array}{c}\text { McNary } \\
\text { AVGFLOW' }\end{array}$ & 4740 & 1392 & 0.003 & 82.6 \\
$\begin{array}{c}\text { McNary } \\
\text { MAXFLOW }\end{array}$ & -4479 & & & \\
\hline
\end{tabular}

1. Probability (2-tail) of observed coefficient estimate under null hypothesis that parameter is zero.

2. Square root of mean square error (MSE). 


\subsection{Individual-Dam Analysis}

Our goal in Section 6 is to determine whether there is any added explanatory power to be gained from variables that were not considered as potential predictors of travel time in our basic regressions (Section 2). In light of this goal, interpretation of the all-dam analysis taken as a whole is difficult. In particular, the high degree of multicollinearity among the potential predictor variables means that for any particular reasonable model that is chosen, there are several others essentially just as good. No unique importance can be ascribed to any particular variable that happens to be in a chosen model when another model that does not include the variable has equal explanatory power.

The desire for an "index" dam to represent all dams in the reach is motivated by the multicollinearity in the data; one wishes a model based on a restricted set of variables that conveys essentially the same information as the monolithic all-dam analysis. However, the spill, temperature, and especially turbidity variables are not highly correlated among dams, and it is worthwhile to look at the regressions on a dam-by-dam basis. For these reasons, a second phase of analyses was undertaken in which separate best-subset regressions were performed for each individual dam, using the flow, spill, temperature, and turbidity data from only one dam at a time. This is referred to as the "Individual-Dam" analysis.

The results from the Individual-Dam phase of best-subsets regressions are presented in Table 2 1. For each dam, the two 4-variable models with the largest values of $R^{2}$ are listed. Each regression model in the table is based on the full set of 42 observations. The TTLGR variable is selected in every model. The variables AVGFLOW ${ }^{-1}$ and MAXFLOW ${ }^{-1}$ are also selected in most models, usually in tandem. (The third best model for the McNary Dam includes, TTLGR, MINSP, and the two inverse flow measures. In addition, the best 5-variable model at McNary includes TTLGR, MINSP, and the inverses of all three flow variables, minimum, average, and maximum, and all the covariates are significant). The minimum spill volumes are also significant at the three lower dams of the reach. The turbidity measures at several of the dams are also found to be significantly correlated with travel times. Turbidity measures appear in pairs in the models for Ice Harbor and for McNary.

Once again, the LD-T-\# release from McCall in 1990 was flagged as having potentially large influence on all five regression equations, but the omission of the observation actually proved to have little effect on the models. And once again, none of the models fit the 1986 RAY-2 release from Dworshak Hatchery well. The effect of leaving this observation in the model is to inflate standard error estimates and to decrease significance. However, there is no statistical or biological evidence supporting its omission from the model. 
69

Tab \& 21. eP1 t ofbest-subsets regressions using full suite of Dote ti a $I_{D}$ edict $r$ variables. Individual-Dam analvsis. Two best 4-variable models for each dam,

(a) Lower Granite Dam

\begin{tabular}{|c|c|c|c|c|c|c|c|c|c|c|}
\hline & \multicolumn{3}{|c|}{ FLOW' } & \multicolumn{3}{|c|}{ SPILL } & \multicolumn{3}{|c|}{ TURBIDITY } & \multirow[b]{2}{*}{$R^{2}$} \\
\hline T T L G & $\mathrm{MIN}$ & AVG & MAX & MIN & $\mathrm{AVG}$ & MAX & MIN & $\mathrm{AVG}$ & MAX & \\
\hline$X$ & $X$ & & & $X^{*}$ & & & $X$ & & & 63.6 \\
\hline $\mathrm{X}$ & & $X$ & $X$ & & & & $X^{*}$ & & & 63.3 \\
\hline
\end{tabular}

(b) Little Goose Dam

\begin{tabular}{|c|c|c|c|c|c|c|c|c|c|c|}
\hline & \multicolumn{3}{|c|}{ PLOW' } & \multicolumn{3}{|c|}{ SPILL } & \multicolumn{3}{|c|}{ TURBIDITY } & \\
\hline TTLGR & MIN & AVG & MAX & MIN & AVG & MAX & MIN & AVG & MAX & $R^{2}$ \\
\hline$X$ & & $X$ & $X$ & & $X^{*}$ & & & & & 63.4 \\
\hline $\mathrm{X}$ & & $\mathrm{X}$ & $\mathrm{X}$ & & & $\mathrm{X}^{*}$ & & & & 63.1 \\
\hline
\end{tabular}

(c) Lower Monumental Dam

\begin{tabular}{|c|c|c|c|c|c|c|c|c|c|c|}
\hline & \multicolumn{3}{|c|}{ FLOW' } & \multicolumn{3}{|c|}{ SPILL } & \multicolumn{3}{|c|}{ TURBIDITY } & \multirow[b]{2}{*}{$R^{2}$} \\
\hline TTLGR & MIN & AVG & MAX & MIN & AVG & MAX & MIN & AVG & MAX & \\
\hline$X$ & & & $X$ & $X$ & & & & $X$ & & 70.6 \\
\hline $\mathrm{X}$ & & $\mathrm{X}$ & $\mathrm{X}$ & $\mathrm{X}$ & & & & & & 69.0 \\
\hline
\end{tabular}

(d) Ice Harbor Dam

\begin{tabular}{|c|ccc|ccc|ccc|c|}
\hline & \multicolumn{3}{|c|}{ FLOW $^{-1}$} & \multicolumn{3}{c|}{ SPILL } & \multicolumn{3}{c|}{ TURBIDITY } & \\
\hline TTLGR & MIN & AVG & MAX & MIN & AVG & MAX & MIN & AVG & MAX & $R^{2}$ \\
\hline $\mathrm{X}$ & & & & $\mathrm{X}$ & & & & $\mathrm{X}$ & $\mathrm{X}$ & 72.5 \\
$\mathrm{X}$ & & $\mathrm{X}$ & $\mathrm{X}$ & $\mathrm{X}$ & & & & & & 70.4 \\
\hline
\end{tabular}

(e) McNary Dam

\begin{tabular}{|c|ccc|ccc|ccc|c|}
\hline & \multicolumn{3}{|c|}{ FLOW' } & \multicolumn{3}{c|}{ SPILL } & \multicolumn{3}{c|}{ TURBIDITY } & \\
\hline TTLGR & MIN & AVG & MAX & MIN & AVG & MAX & MIN & AVG & MAX & $R^{2}$ \\
\hline X & & & & X & & & $X$ & & $X$ & 74.1 \\
X & & & & & X & & X & X & 72.0 \\
\hline
\end{tabular}

* Variable not significant at the $P=0.05$ significance level. 


\subsection{Discussion}

The all-dam and individual-dam analyses corroborate the results of the basic analysis of Section 2.3 in identifying TTLGR, AVGFLOW ${ }^{-1}$, and MAXFLOW'-1 as important variables in regression models of travel time. The flow variables usually appear together in the models, corroborating the finding of the basic analysis that longer travel times are associated with increased ranges of flows during the period of migration in the reach. The individual-dam analysis provides more resolution on the relationship between travel time and spill volumes. The analysis shows that the relationship is not significant at the upper reach dams (Lower Granite and Little Goose) but is significant for the dams of the lower reach, where water is spilled routinely as a smolt passage strategy.

Finally, the expanded regression investigations of this section show that turbidity measures at several dams are also significantly related to travel times. For the lower dams, turbidity measures appear in pairs, and suggest that shorter travel times are associated with clearer water and that longer travel times are associated with increased variability in turbidity during the migration period. For example, the estimated slopes for the average and maximum turbidity in the best model for Ice Harbor (-6.1 and 5.7, respectively), indicate that for a given average turbidity, greater maximum turbidity is associated with longer travel times.

\section{Section 7: Value of Surrogate Measures of Smoltification.}

The most commonly occurring independent variables of the stepwise and best-subsets regression analyses are the inverse minimum flow volumes $\left(\mathrm{MINFLOW}^{-1}\right)$ and the median travel time from release until entry into the index reach (TTLGR). The TTLGR variable has been proposed as a surrogate measurement of the brand group's degree of smoltification. The negative correlation between TTLGR and travel time means that increased time in-river before entering the index reach (and, presumably, increased smoltification) is correlated with decreased travel time. Assuming that the degree of smoltification is directly related with the amount of time inriver, the correlation between TTLGR and travel time is assumed to reflect the influence of the degree of smoltification on the travel time measure.

In this section we discuss the appropriateness of TTLGR as a measure of smoltification. We try to answer the question of whether the importance of TTLGR in the regression analyses equates to the importance of smoltification status in predicting travel time. We begin with some general comments, followed with an attempt to quantitatively separate the various potential influences on TTLGR to assess the degree to which it actually measures smoltification. (Because 
the other variables proposed as surrogates for smoltification, RELDATE and ENTDATE are not important in the regression analyses, we will not use this space to discuss their strengths and weaknesses as measures of smoltification).

\subsection{General Comments}

The level of smolt development exhibited by yearling spring and summer chinook has been shown to be an important factor affecting migratory behavior. Research conducted by NMFS provided experimental evidence that developmentally advanced (more smolted) yearling spring chinook migrated from Dworshak National Fish Hatchery to Lower Granite Dam significantly faster than less developed counterparts (Giorgi 1990; Giorgi et al. 1991). Beeman et al (1990) used a multivariate approach to assess the effects of flow and smolt development (as indexed by gill ATPase activity) on smolt travel time in both the Snake and Columbia rivers. Results from their study indicated that for yearling chinook, gill ATPase was a significant variables explaining a large portion of the variability in observed travel times in both rivers.

Like the present investigation, some studies have conducted multivariate analyses when direct measures of smolt development are not available. They have employed surrogate variables in attempt to capture the effects of smoltification. Berggren and Filardo (1993) suggested that TTLGR was a useful surrogate. They found TTLGR to be a significant factor explaining a portion of the estimated yearling chinook travel time through the Snake River dam from Lower Granite Dam to McNary Dam. In our analysis we also found TTLGR to be a significant variable. The rationale is that over time more fish advance through the transitional stages of the parr/smolt transformation, thus fish with the longest travel times to Lower Granite Dam are presumed to exhibit higher levels of smolt development. Rondorf et al. (1985) presented evidence in support of this conclusion.

However, the surrogate variable TTLGR may reflect additional mechanisms and may not capture the full influence of smolt development, since smolt travel time to LGR is influenced by other factors as well. The distance from each hatchery site to the dam, and the tributary discharge volumes experienced by each marked group certainly influence smolt travel time to LGR. Furthermore, hatchery and tributary temperatures can change annually. Temperature affects the rate of smolt development (Folmar and Dickhoff, 1980; Wedemeyer et al. 1980), which in turn can affect travel time to LGR (Giorgi 1990). As a consequence, it is plausible that in a warm spring smolt development will proceed more quickly and result in shorter travel times to LGR. All the mechanisms in concert affect the observed travel time to Lower Granite Dam. 
Thus, the surrogate variable can capture some of the effects of each of these mechanisms, but cannot wholly and accurately characterize the effects of any single mechanism.

\subsection{Direct Measurements of Smolt Development}

For hatchery-released groups of freeze-branded chinook smolts, there is very little data on direct measurements (e.g. gill ATPase activity) of the degree of smoltification. Since 1988, researchers with the United States Fish and Wildlife Service (USFWS) have sampled freezebranded groups of juvenile salmonids for indicators of smoltification development at various sites on the Snake and Columbia rivers (Rondorf, et al, 1989; Beeman et al., 1990, 1991). The indicators are $\mathrm{Na}^{+}-\mathrm{K}^{+}$ATPase activity in the gill and condition factor. Each release group was sampled from the hatchery 4 weeks, 2 weeks, and immediately prior to release, and then again at the early, middle and late portions of the migrations past Lower Granite and McNary dams. The samples at the dams were timed to occur at approximately the times of the $25 \mathrm{th}, 50 \mathrm{th}$, and 75 th percentiles of the migration past the dam. Thus, the middle sample at Lower Granite corresponds approximately with the date of median entry into the Lower Granite to McNary reach, and the other samples are usually about a week before and after the middle sample. Sampling is by destructive means and the smolts sampled are assumed to be representative of the fish from the brand group passing the dam at the time of the sample.

Over the years 1988-1990, 11 of the hatchery groups used in our regression analyses (Table 1) have been included in the smoltification studies, providing a limited opportunity to investigate relationships between travel time and direct measurements of smoltification development. We have performed correlation and regression analyses combining the measurements from these studies with the flow data and our estimates of Lower Granite to McNary travel time.

Table 22 gives the mean ATPase activity measured at Lower Granite Dam for the 11 brand groups included in both our regression analyses and in the smoltification studies. Condition factor has been omitted because it was reported for less than half of these groups. Table 23 summarizes the pairwise linear correlations between the estimated travel time through the Lower Granite to Little Goose reach (TTIME) and the estimated travel time from release to Lower Granite Dam (TTLGR) with the measurements of ATPase activity. None of the pairwise correlations is significant at the 0.05 level. In the linear regression analysis, the dependent variable TTIME was regressed on the inverse minimum flow at Ice Harbor and on the mean 
Table 22. Direct measurements of smolt condition for selected hatcherv brand groups.Samplemeans for fish sampled at time of release and at Lower Tranite Dam at three times during the passage of the groups.Data from Rondorf et al(1989). and beeman et al $(1990,1991)$.

\begin{tabular}{|c|c|c|c|c|c|c|c|c|}
\hline \multirow[b]{2}{*}{ Brand } & \multirow[b]{2}{*}{ Hatchery } & \multirow[b]{2}{*}{ TTIME $^{1}$} & \multirow[b]{2}{*}{ TTLGR $^{2}$} & \multirow[b]{2}{*}{ ENTDATE $^{3}$} & \multicolumn{4}{|c|}{ Gill $\mathrm{Na}^{+}-\mathrm{K}^{+}$ATPase } \\
\hline & & & & & Release & Early & Mid & Late \\
\hline \multicolumn{9}{|c|}{1988 Releases } \\
\hline LA-T-2 & Dworshak & 18.24 & 21.77 & 111.77 & 9.6 & 20.5 & 25.5 & 42.1 \\
\hline RD-T-4 & Rapid River & 16.70 & 35.58 & 115.58 & 9.9 & NA & 29.5 & 32.1 \\
\hline LD-T-4 & Rapid River & 18.18 & 31.96 & 114.46 & 8.3 & 25.5 & 29.1 & 28.8 \\
\hline \multicolumn{9}{|c|}{1989 Releases } \\
\hline R\#-7H-\# & Dworshak & 11.34 & 28.75 & 117.75 & 8.5 & 21.4 & 34.0 & 25.3 \\
\hline RA-R-\# & McCall & 10.57 & 52.05 & 132.05 & 9.0 & 21.3 & 23.9 & 23.6 \\
\hline L\#-7H-\# & Rapid River & 13.82 & 31.83 & 113.33 & 7.9 & 23.5 & 29.3 & NA \\
\hline LA-R-\# & Sawtooth & 10.90 & 39.07 & 113.07 & 7.5 & 20.2 & NA & 23.6 \\
\hline \multicolumn{9}{|c|}{1990 Releases } \\
\hline \#\#-7U-\# & Dworshak & 16.66 & 24.91 & 119.91 & 9.3 & 22.56 & 34.14 & 39.28 \\
\hline LD-T-\# & McCall & 10.39 & 62.09 & 142.43 & 10.2 & NA & 46.60 & 38.31 \\
\hline RA-T-\# & Rapid River & 12.25 & 30.22 & 113.22 & 9.0 & 20.42 & 25.90 & 33.02 \\
\hline LA-T-\# & Sawtooth & 11.08 & 37.20 & 113.20 & 7.1 & 27.11 & NA & 28.68 \\
\hline
\end{tabular}

1. Estimated travel time (days) through Lower Granite to McNary reach.

2. Estimated travel time (days) from release to Lower Granite Dam.

3. Estimated date (Julian) of median entry into Lower Granite to McNary reach.

4. Gill ATPase activity $\left(\mu\right.$ moles $\mathrm{P}_{\mathrm{i}} \cdot \mathrm{mg} \operatorname{prot}^{-1} \cdot \mathrm{hr}^{-1}$ ) 
74

Table 23. Pairwise correlations between estimated travel time from Lower Granite to McNarv Dam (TTIME) and estimated travel time between release and Lower Granite Dam (TTLGR) with direct measurements of gill ATPase at Lower Granite Dam. Based on brand groups in Table 28 .

\begin{tabular}{|cc|cc|cc|}
\hline Variable & Sample & $\begin{array}{c}\text { Correlation } \\
\text { with TTME }\end{array}$ & p-value' & $\begin{array}{c}\text { Correlation } \\
\text { with TTLGR }\end{array}$ & $p$-value \\
\hline ATPase & Early & $0.135(\mathrm{n}=9)$ & 0.63 & $0.061(\mathrm{n}=9)$ & 0.44 \\
& Middle & $-0.322(\mathrm{n}=9)$ & 0.20 & $0.497(\mathrm{n}=9)$ & 0.09 \\
& Late & $0.520(\mathrm{n}=10)$ & 0.94 & $-0.225(\mathrm{n}=10)$ & 0.73 \\
\hline
\end{tabular}

1. One sided p-value for testing null hypothesis that correlation coefficient is zero vs. alternative that correlation is less than 0 .

2. One sided p-value for testing null hypothesis that correlation coefficient is zero vs. alternative that correlation is greater than 0 . 
ATPase activity level at from each of the early, middle and late samples. The ATPase measurements were not significant in any of these regression equations.

Our analyses of this limited data set did not detect a relationship between travel time from Lower Granite to McNary and the gill ATPase activity at the time of passage at Lower Granite Dam. However, this result cannot be construed as conclusive evidence that such a relationship does not exist. Beeman et al $(1990,1991)$ have reported analyses indicating that travel time of spring chinook from the Snake River trap to Lower Granite Dam is related to the level of ATPase activity at the time of release. There are important differences between the studies of Beeman et al $(1990,1991)$ and our analyses that could explain the inconsistent results. First, there is the difference in the reach that is studied; from release point to Lower Granite in the Beeman investigations and Lower Granite to McNary in ours. It has been suggested that the effect of smoltification is to influence the amount of time smolt spend in the Lower Granite reservoir, that all smolts have attained a certain level of development by the time they actually pass Lower Granite Dam, and that the differences in ATPase activity are not significant after they have active migrant status.

Second, and more importantly, there is a difference between the way the smolt were collected and measurements taken. In the Beeman studies, a group of in-river smolt is intercepted at the Snake River trap. A sample of smolt is taken to estimate the average ATPase activity for the group. The smolt that are not destroyed to sample ATPase activity are then marked and returned to the river. Thus, the measure of ATPase activity for the group is very direct. In contrast, the timing of the measure of enzyme activity for the brand groups is only approximate, and it is not certain that the measure we used for the average enzyme activity is appropriate. At the very least, the uncertainty in the timing increases the noise in the data and decreases the power to detect travel time relationships.

The correlation between TTLGR and the mean ATPase activity in the middle sample at Lower Granite Dam is significant at the 0.09 level, suggesting that TTLGR might serve as a surrogate for ATPase activity in this data set. However, while the correlation between TTLGR and TTIME is significant ( $\mathrm{r}=-0.638, \mathrm{n}=1$, one-sided $p=0.01$ ), there is no significant correlation between TTIME and the ATPase measure.

For description of the travel time from Lower Granite to McNary Dam, both TTLGR and the ATPase activity available here are flawed measures of the relevant smoltification level. The TTLGR variable is contaminated by such influences as the distance from release to Lower 
Granite Dam, while the enzyme activity measure is necessarily approximate, as it is taken on one day in the middle of the passage distribution. It is not surprising that the results are inconclusive. Further investigation of direct measurement of smoltification is required to eliminate the uncertainty. Non-destructive methods for directly measuring smoltification are being developed by the U.S. Fish and Wildlife Service (Beeman, et al, 1990, 1991). As these methods are perfected, they should be used in conjunction with individual PIT-tagged fish to investigate the relationships between smolt development, travel time, and survival.

\section{Section 8. Repression Analvses for Transportation Control Releases.}

In 1986 and 1989, the smolt transportation program released a series of freeze branded groups of yearling chinook just below Little Goose Dam to serve as controls for the experimental groups that were transported below Bonneville Dam. Brand recoveries at McNary Dam enable the transportation control releases to be used to estimate smolt travel time between Little Goose to McNary Dams.

\subsection{Data Base}

Smolt used in control release groups were active migrants collected at Lower Granite Dam and transported below Little Goose by truck every few days. A unique brand code was used over several days until a specified number of smolts had been collected and released. Table 24 shows the brand codes that were used in 1986 and 1989 for control groups, the dates that each code was first and last released, the total number of smolts released with each code, the date of median release (Julian), the estimated date of median recovery at McNary Dam, and the estimated median travel time from Little Goose to McNary for each group. Median travel time was estimated by subtracting the median release date below Little Goose from the estimated median date of arrival at McNary Dam (see Section 2). Appendix 2 gives minimum, average and maximum values for flow volume, spill volume, water temperature, and turbidity at each of Little Goose, Lower Monumental, Ice Harbor, and McNary Dams during the intermedian period (the period between median release at Little Goose and median arrival at McNary) for each control release group. The variable names are the same as in the analysis of hatchery brand releases in the previous sections. For the transportation controls, the estimated travel time variable is for the Little Goose to McNary Dam reach, in contrast with the Lower Granite to McNary reach for the hatchery releases. To emphasize the difference in reaches, we will denote the travel time for the transportation control groups as TTIMEC. For the control groups, the variable TTLGR (travel time from release point to Lower Granite Dam) is not defined. The 
77

Table 24. Transportation_program control releases used in travel time analvses,

\begin{tabular}{|c|c|c|c|c|c|c|c|}
\hline \multirow[b]{2}{*}{ Year } & \multirow{2}{*}{$\begin{array}{l}\text { Brand } \\
\text { Code }\end{array}$} & \multicolumn{2}{|c|}{ Release Date } & \multirow{2}{*}{$\begin{array}{c}\text { Total } \\
\text { Number }\end{array}$} & \multirow{2}{*}{$\begin{array}{c}\text { Date of } \\
\text { Median } \\
\text { Release } \\
\text { (Julian) }\end{array}$} & \multirow{2}{*}{$\begin{array}{c}\text { Median } \\
\text { Recovery } \\
\text { Date } \\
\text { (Julian) }\end{array}$} & \multirow{2}{*}{$\begin{array}{c}\text { Estimated } \\
\text { Travel } \\
\text { Time } \\
\text { (Days) }\end{array}$} \\
\hline & & start & Finish & & & & \\
\hline 1986 & LA-P- 1 & 09 Apr & 11 Apr & 5000 & 101 & 113.2 & 12.2 \\
\hline 1986 & LA-P-2 & $11 \mathrm{Apr}$ & $15 \mathrm{Apr}$ & 5000 & 103 & 117.6 & 14.6 \\
\hline 1986 & LA-P-3 & $15 \mathrm{Apr}$ & $17 \mathrm{Apr}$ & 5104 & 105 & 119.0 & 14.0 \\
\hline 1986 & LA-W- 1 & $21 \mathrm{Apr}$ & $23 \mathrm{Apr}$ & 5000 & 109 & 123.6 & 14.6 \\
\hline 1986 & LA- W-2 & $23 \mathrm{Apr}$ & $27 \mathrm{Apr}$ & 5000 & 115 & 127.0 & 12.0 \\
\hline 1986 & LA-W-3 & $29 \mathrm{Apr}$ & 03 May & 5000 & 121 & 131.4 & 10.4 \\
\hline 1986 & LA- W-4 & 03 May & 15 May & 4998 & 130 & 141.0 & 11.0 \\
\hline 1989 & LA-2-1 & $07 \mathrm{Apr}$ & 13 Apr & 10,016 & 100 & 116.5 & 16.5 \\
\hline 1989 & LA-2-2 & $14 \mathrm{Apr}$ & 16 Apr & 10,085 & 106 & 117.8 & 11.8 \\
\hline 1989 & LA-2-3 & 17 Apr & 18 Apr & 9831 & 107 & 118.6 & 11.6 \\
\hline 1989 & LA-2-4 & $20 \mathrm{Apr}$ & $21 \mathrm{Apr}$ & 10,043 & 110 & 119.9 & 9.9 \\
\hline 1989 & LA-RT- 1 & $21 \mathrm{Apr}$ & $22 \mathrm{Apr}$ & 10,184 & 111 & 120.9 & 9.9 \\
\hline 1989 & LA-RT-2 & $22 \mathrm{Apr}$ & $24 \mathrm{Apr}$ & 10,000 & 113 & 122.8 & 9.8 \\
\hline 1989 & LA-RT-3 & $24 \mathrm{Apr}$ & $24 \mathrm{Apr}$ & 10,123 & 114 & 123.5 & 9.5 \\
\hline 1989 & LA-RT-4 & $25 \mathrm{Apr}$ & 26 Apr & 10,005 & 116 & 124.7 & 8.7 \\
\hline 1989 & LA-3-1 & $26 \mathrm{Apr}$ & $28 \mathrm{Apr}$ & 10,058 & 117 & 126.5 & 9.5 \\
\hline 1989 & LA-3-2 & $28 \mathrm{Apr}$ & 11 May & 1213 & 124 & 131.5 & 7.5 \\
\hline 1989 & LA-3-4 & 27 May & 27 May & 1129 & 147 & 156.2 & 9.2 \\
\hline
\end{tabular}


release date (RELDATE) has been suggested as a surrogate measurement of smoltification for the control releases. Because the control releases are composed of active migrants, the use of RELDATE as a smoltification surrogate amounts to an assumption that later-migrating smolts are more developed.

\subsection{Correlation and Regression Analyses}

The pair-wise linear correlations between the independent variables and TTIMEC are listed in Table 25. Among the flow measurements, 'ITIMEC is significantly correlated on a pairwise basis only with the inverse of the maximum flow at Ice Harbor Dam $\mathbf{P}(|r| \geq 0.4871 n=18) \approx 0.049$ In addition, 'ITIMEC is significantly negatively correlated with the median release date (RELDATE), all the temperature measures except maximum at Lower Monumental, several measures of turbidity, and with spill measurements at Little Goose and Lower Monumental dams. The single variable most strongly correlated (pairwise) with TTIMEC is the minimum temperature at McNary Dam.

The pairwise linear correlations among the estimated travel time and selected independent variables are summarized graphically in Figures 13 and 14. There is substantial multicollinearity among these variables, making interpretation of the pairwise correlations difficult. In particular, both water temperature and turbidity are significantly positively correlated with the release date; the water becomes warmer and clearer as the season progresses and estimated travel times become shorter.

To compare travel time relationships in the transportation control data with those in the hatchery release data, regression analyses analogous to those of Sections 2.3 and 6.3 were performed on the transportation data. First, as in Section 2.3, stepwise regression was performed using Ice Harbor Dam as the index for measurements at all dams. Initially, temperature and turbidity were not considered as predictors, as Ice Harbor is not a reliable index for these measures. In this analysis, comparable to those reported in Table 6 for the hatchery releases, the stepwise regression procedure selected a model that included only the release date as a predictor of travel time $\left(\left(R^{2}=36.7\right)\right)$. However, the best-subsets regression procedure identified the model containing RELDATE, AVGFLOW ${ }^{-1}$, and MAXFLOW ${ }^{-1}$ as the best 3-variable model under these conditions $\left(R^{2}=74.3\right)$ with all three predictors significant at the $P=0.05$ level. (The best 4-variable model adds MINFLOW- 1 to the above three predictors, but the coefficient for MINFLOW ${ }^{-1}$ is not significant). 
Table 25. Pairwise correlations between travel time (TTIMEC) through index reach and \$3 continuous predictor variables. Based on 18 transportation program control releases listed in Table 24.

\begin{tabular}{|c|}
\hline $\begin{array}{c}\text { Median } \\
\text { Release Date } \\
\text { (Julian) }\end{array}$ \\
\hline$-0.606^{*}$ \\
\hline
\end{tabular}

\begin{tabular}{|c|c|c|c|c|c|c|c|c|c|c|c|c|c|}
\hline & \multicolumn{3}{|c|}{ FLOW $^{-1}$} & \multirow[b]{2}{*}{ DFLOW' } & \multicolumn{3}{|c|}{ SPILL (kcfs) } & \multicolumn{3}{|c|}{ Temperature } & \multicolumn{3}{|c|}{ Turbidity } \\
\hline & Min. & Avg. & Max. & & Min. & Avg. & Max. & Min. & Avg. & Max. & Min. & Avg. & Max. \\
\hline Little Goose & -0.028 & -0.128 & -0.387 & 0.123 & NA & $0.624^{*}$ & $0.619^{*}$ & NA & NA & NA & NA & NA & NA \\
\hline Lower Monumental & -0.269 & -0.185 & -0.392 & -0.176 & $-0.482 *$ & -0.319 & -0.376 & $-0.709 *$ & $-0.744^{*}$ & -0.428 & $-0.630^{*}$ & -0.478 & $-0.502^{*}$ \\
\hline Ice Harbor & -0.365 & -0.188 & $-0.487^{*}$ & -0.282 & -0.348 & -0.183 & -0.248 & $-0.529 *$ & $-0.616^{*}$ & $-0.522 *$ & -0.415 & -0.434 & -0.251 \\
\hline McNary & 0.174 & 0.195 & 0.041 & 0.186 & NA & 0.190 & 0.146 & $-0.858^{*}$ & $-0.746^{*}$ & $-0.561 *$ & $-0.637 *$ & $-0.616^{*}$ & -0.380 \\
\hline
\end{tabular}

* Pairwise correlation is significant at the two-sided 0.05 level $\left(P_{H_{0}}(|r| \geq 0.4681 n=18)=0.05\right)$ 
Figure 13. Scatterplots of estimated travel time versus selected predictor variables for transportation control releases.

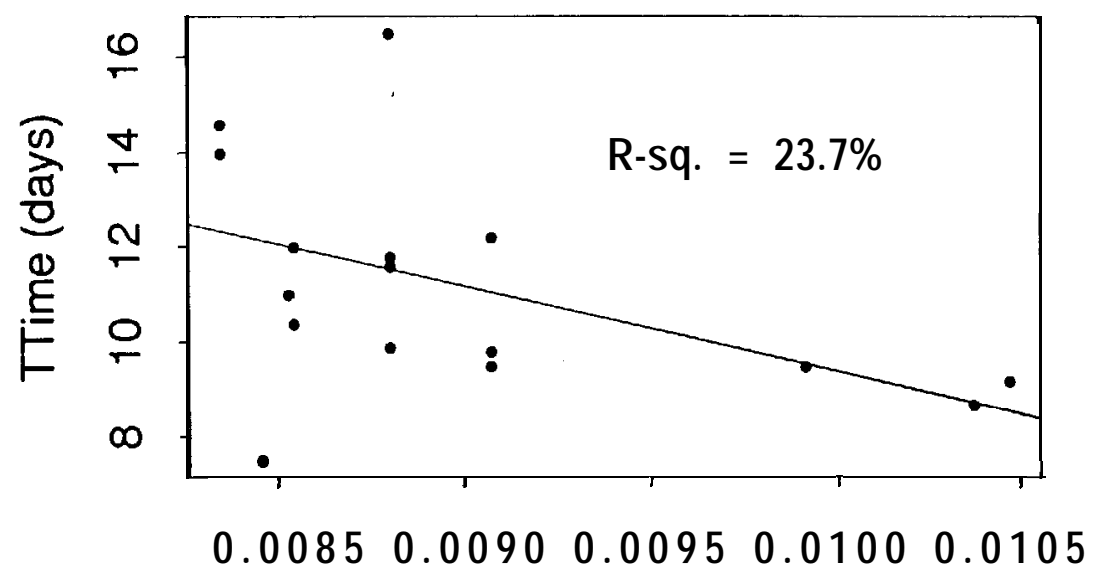

inv. IHR max. flow

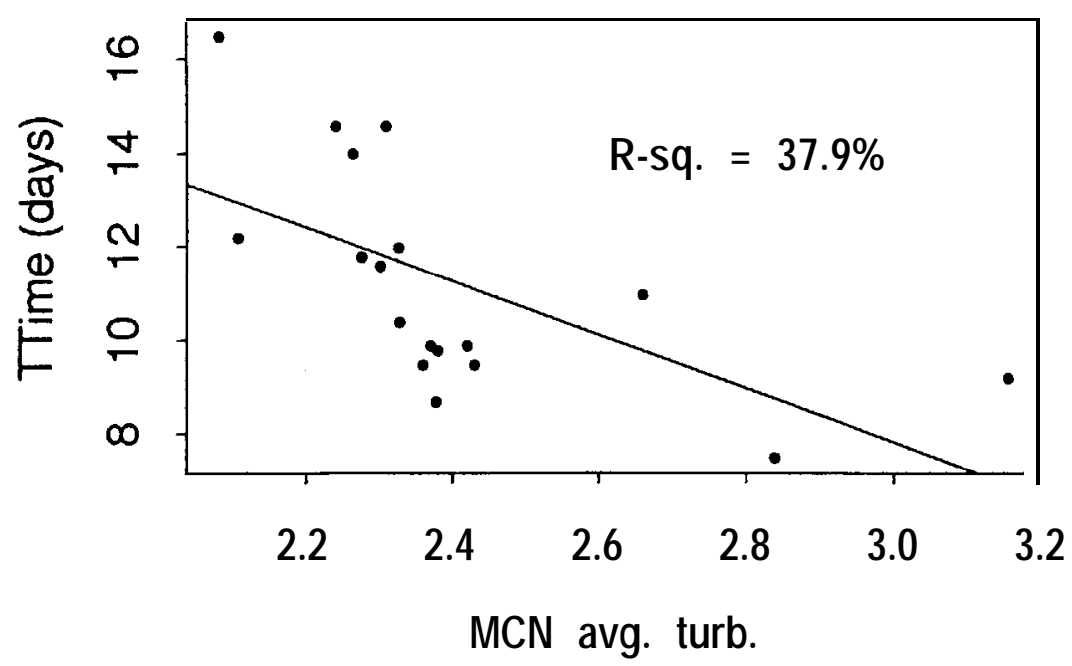

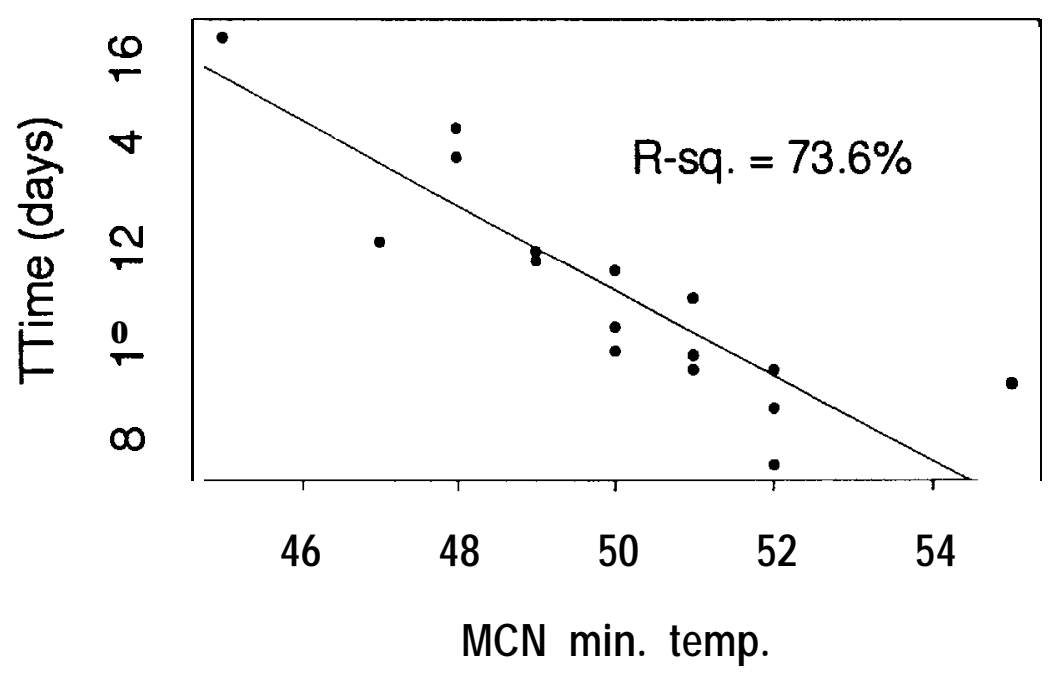

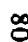

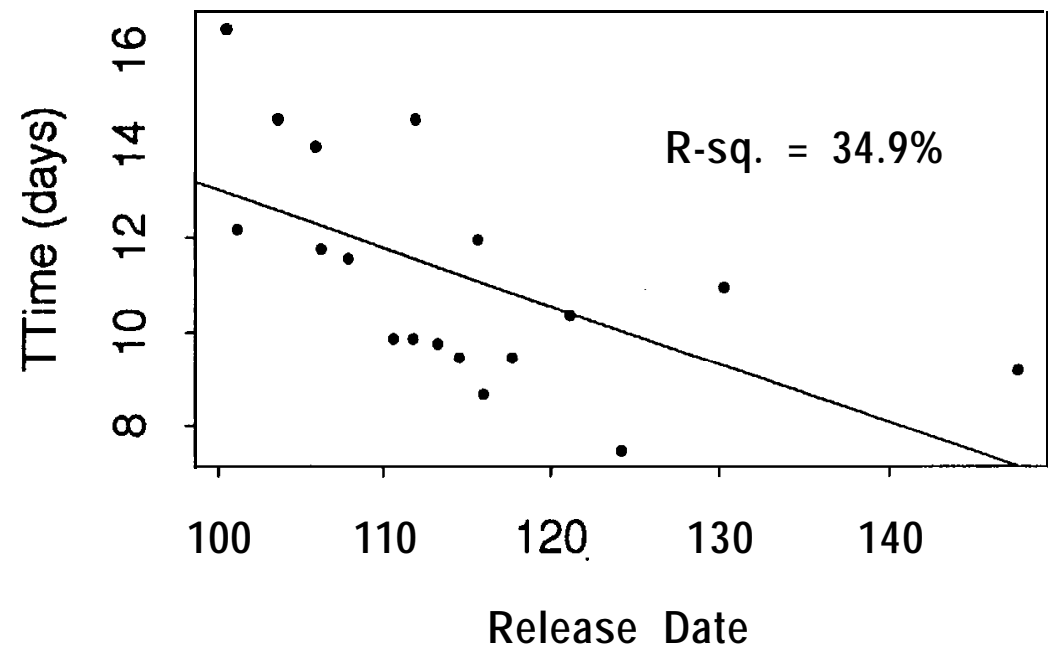


Figure 14. Scatterplots among selected predictor variables for transportation control releases,
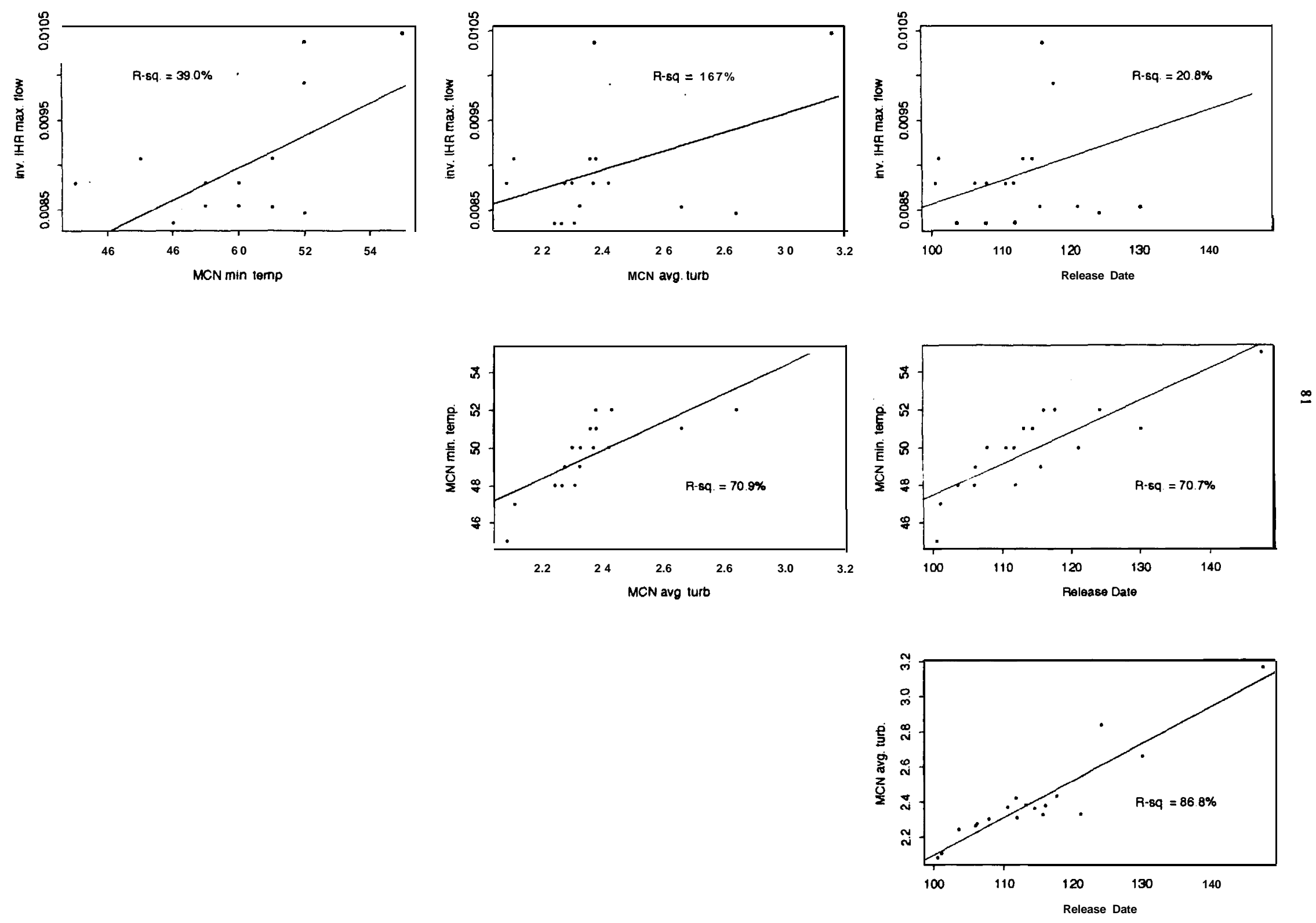
Finally, stepwise and best-subsets regression analyses were performed on the transportation control data using all the measurements from Ice Harbor Dam, including temperature and turbidity, as potential predictors. These analyses are comparable to the "Individual-Dam" analysis for Ice Harbor reported in Table 21 (d). The stepwise procedure selected a model that contained only AVGTEMP $\left(R^{2}=38.0\right)$. The best 4 -variable model in this analysis included the variables RELDATE, MINSP, MINTEMP, and MAXTURB $\left(R^{2}=88.8\right)$.

The strongest signal apparent in the transportation control data is that travel times became shorter as the season progressed; the fish released later in the spring traveled fastest. As with the hatchery data, there is no direct data on the degree of smoltification for the transportation controls. However, travel time was most strongly correlated with the water temperature, which has been shown to be a factor influencing smoltification (Wedemeyer et al, 1980). Of course, there are other factors that influence the degree of smoltification as well. The information in the control release data regarding the influence of smoltification on travel time is similar to that in the hatchery data. There is a suggestion, through a surrogate measure, that smoltification is a significant factor in determining travel times, but the relationship is clouded by the lack of any direct measurements of smoltification.

The transportation control data is limited in that control releases are made only in relatively high flow years, restricting the range of conditions that can be studied. The limited range makes it more difficult to find significant relationships, as also shown by the analysis of the nine hatchery releases from 1986 and 1989. Because transportation control groups are released below Little Goose Dam, there is no need to undertake the convoluted adjustment procedures required for the hatchery data. Consequently, the transportation program is a potential source of valuable information on the relationships of travel time with explanatory variables, but only if control releases are made under a wider range of conditions, especially in low flow years.

\subsection{Comparison with Results for Hatchery Brand Releases}

For comparison, the analyses performed both on transportation control releases and on hatchery releases are summarized in Table 26. The table lists differences in the data set and in the regression models that were chosen to describe travel times through the respective reaches. There are important differences between the analyses in the reach for which travel time can be estimated using the two groups and in the way in which smolts are collected for the brand releases. The difference in the smolt collection suggests that the fish marked in the 
Table 26. Comparison of regression analvses of transportation control release data and hatchery release data. Independent variables measured at Ice Harbor.

\begin{tabular}{|c|c|c|}
\hline & Hatchery Releases & $\begin{array}{c}\text { Transportation } \\
\text { Controls }\end{array}$ \\
\hline $\begin{array}{l}\text { Number of } \\
\text { Releases }\end{array}$ & 42 & 18 \\
\hline Reach & $\begin{array}{l}\text { Lower Granite } \\
\text { to McNary }\end{array}$ & $\begin{array}{l}\text { Little Goose } \\
\text { to McNary }\end{array}$ \\
\hline $\begin{array}{c}\text { Source of } \\
\text { marked smolts }\end{array}$ & $\begin{array}{l}\text { Marked prior to } \\
\text { release at hatchery }\end{array}$ & $\begin{array}{c}\text { Active migrants } \\
\text { collected at } \\
\text { Lower Granite }\end{array}$ \\
\hline $\begin{array}{l}\text { Dates off } \\
\text { median entry } \\
\text { into reach }\end{array}$ & $\begin{array}{l}\text { April } 13 \text { to } \\
\text { May } 22 \\
\text { (estimated) }\end{array}$ & $\begin{array}{l}\text { April } 11 \text { to } \\
\text { May } 27\end{array}$ \\
\hline $\begin{array}{l}\text { Mean } \\
\text { estimated } \\
\text { travel time }\end{array}$ & 12.4 days & 11.3 days \\
\hline $\begin{array}{l}\text { Best } 3 \text {-variable } \\
\text { model omitting } \\
\text { temperature } \\
\text { and turbidity }\end{array}$ & $\begin{array}{c}\text { TTLGR } \\
\text { AVGFLOW-1 } \\
\text { MAXFLOW-' } \\
R^{2}=65.8\end{array}$ & $\begin{array}{l}\text { RELDATE } \\
\text { AVGFLOW'-1 } \\
\text { MAXFLOW-1 }^{-1} \\
R^{2}=74.3\end{array}$ \\
\hline $\begin{array}{c}\text { Best } 4 \text {-variable } \\
\text { model including } \\
\text { temperature } \\
\text { and turbidity }\end{array}$ & $\begin{array}{c}\text { TTLGR } \\
\text { MINSP } \\
\text { AVGTURB } \\
\text { MAXTURB } \\
R^{2}=72.5\end{array}$ & $\begin{array}{c}\text { RELDATE } \\
\text { MINSP } \\
\text { MINTEMP } \\
\text { MAXTURB } \\
R^{2}=88.8\end{array}$ \\
\hline
\end{tabular}


transportation studies (active migrants) might be physiologically different from their counterparts marked in the hatcheries before initiation of migration.

Despite the important differences in the nature of the data sets, the selected regression models are similar. Using Ice Harbor as the index, and omitting the temperature and turbidity measures from the set of potential predictors, essentially the same model was selected for both data sets. The models included the inverses of the average and maximum flow volumes and a variable proposed as a surrogate for smoltification, TTLGR for the hatchery releases and RELDATE for the transportation controls. When the Ice Harbor measurements of temperature and turbidity are also considered, the best regression models were again similar. Both models included the minimum spill volume, the maximum turbidity, and the smoltification-surrogate. The difference between the models is in the fourth variable, average turbidity for the hatchery releases and minimum temperature for the transportation controls.

\section{Section 9: Summarv and Recommendations,}

\subsection{Summarv of Findings}

The purpose of this analysis was to assess the strengths and limitations of freeze-brand recapture data for describing the migratory characteristics of yearling chinook salmon through the impounded sections of the mainstem Snake River. We were particularly interested in statistical properties of smolt travel time estimates, and relationships between that response and environmental and biological variables. We also examined the prospects for using existing brandrecapture data to estimate smolt survival. Specific objectives were:

1. Assess the sensitivity of smolt travel time estimates to assumed input parameter values and functions .

2. Investigate alternative regression models.

3. Assess the sensitivity of regression results to critical assumed input parameter values and functions .

4. Assess the effects of sampling precision of travel time estimates on the regression relationships.

4. Investigate strengths and limitations of surrogate measurements of smolt development. 
5. Compare results of regression analyses based on brand recapture data from different sources, specifically hatchery production releases and control releases from the smolt transportation program.

Two sets of brand recapture data were used in this investigation; index groups from spring and summer chinook hatchery populations in the Snake River Basin upstream from Lower Granite Dam (1982-1990), and transportation evaluation groups released as controls in the tailrace of Little Goose Dam (1986, 1989).

The first task was to investigate the use of the brand recovery data to estimate travel times between Lower Granite Dam and McNary Dam for the hatchery releases (Section 2.2). Because groups are batch-marked, travel times of individual smolts cannot be obtained. Instead, the median travel time for all smolts in a group is estimated to serve as an index of the behavior of the group. The estimated median is derived from approximate passage distributions at each sampling site. Daily recovery counts are available from Lower Granite Dam and McNary Dam, but not from the three Snake River dams in the Lower Granite to McNary reach. Thus, the index reach for which travel time could be estimated was Lower Granite to McNary. We selected a set of 42 release groups that had sufficient numbers of recoveries at Lower Granite and McNary.

To estimate the median travel time, we estimated the daily distributions of smolts entering the index reach and arriving at the end of the reach (McNary Dam). The median travel time is estimated as the difference between the median dates of entrance and exit. Smolts may enter the index reach by passing one of several routes at Lower Granite Dam: the spillway, the turbines or the bypass. The same passage routes exist at McNary Dam. At both dams, the brand recovery data are enumerated in a subsample from the bypass population. Thus, the total numbers entering and exiting the index reach must be estimated indirectly. The total numbers are estimated by adjusting the brand recoveries for factors including fish guidance efficiency (FGE), spill effectiveness (SE), turbine mortality, bypass mortality, and spillway mortality. Additional adjustments are required for brand removals with the smolt transportation program at both Lower Granite and Little Goose dams.

The algorithm for adjusting the brand recoveries to estimate the entrance and exit distributions is a complicated, non-linear equation involving numerous parameter values. (Section 2.2). In all cases parameter values are generalized estimates, in some cases never verified. For the purposes of later analysis, we selected a set of values for the parameters that we 
refer to as the "standard values" (Table 3). These are the same values assumed by the Fish Passage Center (FPC) in their analyses of hatchery brand data (Berggren and Filardo, 1993).

The second task was to investigate the sensitivity of the median travel time estimates to changes in the assumed values for the parameters in the adjustment algorithm (Section 3). We found that the estimated travel times were not greatly affected by changing the assumed values for any of the parameters spillway survival, bypass survival, turbine survival, travel time from Lower Granite to Little Goose Dam (which determined the transportation adjustment applied for Little Goose), or the survival in the Lower Granite to Little Goose reach. However, the estimated travel times were sensitive to changing values of FGE and SE, particularly for brand groups that migrated during periods of spill at Lower Granite and/or McNary Dams.

In typical statistical analyses, point estimates of a particular response are accompanied with estimates of the associated variability of the estimates. This provides an indication of the precision or certainty of the estimation. However, the paucity of variance estimates for the parameter values used in the adjustment algorithm precludes estimation of standard errors and construction of confidence intervals around the median travel time estimates. Thus, in subsequent analyses, we are forced to present estimated travel times as if they were measured without error. Undoubtedly, confidence intervals around the estimates obtained from the complicated non-linear algorithm would be very wide.

The third task was to describe the relationship between smolt travel time and environmental and physiological variables (Section 2.3). The main statistical tool was multiple linear regression. The estimated travel time for the 42 hatchery production releases was the dependent variable in the regressions. Two classes of predictor variables were considered: measures of ambient river conditions and surrogate measures of the degree of smoltification. The river variables included flow and spill volumes, water temperature, and turbidity. For each of these variables we used the minimum, average, and maximum values during the period between the median dates of entry into and exit from the index reach. The river variables were all measured at each of the five dams in the index reach (Lower Granite, Little Goose, Lower Monumental, Ice Harbor, and McNary). Considerations regarding the appropriate response model led us to use the inverse of the flow volume measurements as the potential predictor. Inverse flow volume is correlated with the velocity of water flow in the river and was used as an index of water velocity in this analysis. Direct measurements of smoltification were not available, so surrogate measurements were devised. The date of release and the travel time from release to Lower Granite (TTLGR) were used as predictor variables. These variables are 
presumed to be correlated with the degree of smoltification and, hence, to the readiness of the smolts to move downstream.

Our initial regression analyses (Section 2.3) used river condition data measured at Ice Harbor Dam as an index of conditions at all the dams in the reach, consistent with the analyses by FPC (Berggren and Filardo, 1993). Correlations with the data from all dams showed that Ice Harbor can serve as a reliable index for flow and spill volumes, but not for water temperature or turbidity. Stepwise regression and best-subsets regression were applied, using the release date, TTLGR, and the flow and spill variables as potential predictors. The resulting models were similar to those reported in the FPC analyses (Berggren and Filardo, 1993), suggesting that travel time from Lower Granite to McNary is related to the amount of time spent in-river before entering the index reach (TTLGR), to the absolute volume of flow, and to the degree of fluctuation in flow. The importance of the fluctuation suggests that fish may respond to changes in water velocity. In addition, our investigations also identify minimum spill volumes as an important predictor. Experiments to manipulate dam operations may be needed to resolve the relative importance of the effects of spill and flow.

We also performed regression analyses using the data available from additional dams other than Ice Harbor alone (Section 6). The purpose of this analysis was to identify effects associated with turbidity and water temperature measurements, which are not reliably indexed at Ice Harbor alone. In the "All-Dam Analysis," all predictors measured at all the dams were used in one large stepwise regression analysis (Section 6.2). The stepwise procedure selected the predictors TTLGR, average temperature at Lower Granite, maximum temperature at McNary, minimum spill at Ice Harbor, and the inverses of the minimum, average, and maximum flow volumes at McNary. This is an especially difficult model to interpret. The high degree of collinearity among the predictor variables, both included and excluded from the model, ensures that there are many competing models with nearly the same explanatory power. It is impossible to ascribe particular importance to any one predictor variable, when another model that excludes that variable is virtually as good.

A second set of expanded regression analyses considered the expanded set of predictor variables on a dam-by-dam basis ("Individual-Dam Analysis", Section 6.3). That is, a series of stepwise and best- subsets regressions were performed using TTLGR, the release date, and all the river variables measured at a single dam. These "Individual-Dam Analyses" are not plagued with the problems of multicollinearity to the degree of the All-Dam Analysis. The IndividualDam analyses corroborate the original analysis, identifying TTLGR, spill volumes, and the 
inverses of average and maximum flow volumes as the most important predictors. Moreover, more resolution is gained in describing the influence of spill volumes. Specifically, minimum spill volume is not significantly correlated with the travel time at the dams of the upper reach (Lower Granite and Little Goose), but is an important predictor at the lower reach dams (Lower Monumental, Ice Harbor, and McNary), where water is routinely spilled for fish passage. In addition, the Individual-Dam analysis indicated that turbidity measures are also significant predictors of travel time. Longer travel times are associated with increased variability of turbidity during the period of migration in the index reach.

The fourth task was to investigate the sensitivity of the regression results to changes to the assumed parameter values used in the travel time estimation algorithm (Section 4). We investigated both the sensitivity of the stepwise and best-subsets model selection procedures and the magnitude of the regression coefficients obtained using a particular set of predictors.

We used Ice Harbor as the index dam for the investigations of the model selection procedures. The potential predictors were TTLGR, release date, the inverse of the minimum, average and maximum flow volumes and the minimum, average, and maximum spill volumes, as in our original analysis. Regardless of the set of assumed parameter values in the adjustment procedure, the stepwise procedure included TTLGR in the selected model, and selected the minimum spill volume for most parameter sets. The other variables included were less consistent, however. The inverse average and maximum flows were included under several sets, including the standard assumptions, but the inverse minimum spill and the difference between maximum and minimum inverse flows ("DFLOW-1") were included for several others. The bestsubsets procedure was less sensitive than the stepwise procedure. The best 3-variable model was the same for all values of FGE and for the lower values of SE. Only for the largest values of SE did the selected model deviate, typically selecting DFLOW ${ }^{-1}$ rather than the inverse average and maximum flows. The best 4-variable models showed a similar pattern. In summary, using the Ice Harbor index, there was inconsistency in the model selected by the stepwise procedure, but the best-subsets procedure was consistent. Because the best-subsets procedure, by definition, chooses models with more explanatory power, we conclude that the sensitivity of the model selection procedure is not a large problem in this data set.

The best 2-variable model under the standard assumptions and using the Ice Harbor index includes TTLGR and the inverse average flow. We used this model in our investigation of the sensitivity of regression equations to underlying parameters. The values of the regression slopes, 
significance levels and coefficients of determination were only sensitive to extreme values of FGE (greater than 0.8) and SE (greater than 1.50).

The fifth task was to consider the strengths and limitations of the surrogate measures of smoltification (Section 7). Surrogate measures, such as TTLGR, reflect mechanisms in addition to physiological effects. Distance from the release site to the dam (LGR) as well as individual tributary discharge also influence the TTLGR measure. Thus, the surrogate cannot completely represent physiological effects.

The sixth task was to analyze the data from the transportation control releases and to compare the results with those obtained with the hatchery releases (Section 8). We identified a total of 19 control groups from 1986 and 1989. The transportation control groups are released below Little Goose Dam and recaptured downstream at McNary Dam, providing estimates through that reach. Pairwise correlations showed that the estimated travel times of the transportation control groups were significantly correlated with the release date, all the temperature variables, several measures of turbidity, and with the minimum spill at Lower Monumental Dam. The estimated travel times were not significantly correlated with any of the flow variables. Among the variables that were correlated with travel time, there is high collinearity. All are correlated with the release date. In short, the travel times became shorter as the season progressed; the fish released later in the spring traveled fastest, and the relative importance of the individual predictor variables is uncertain. Also, the range of flows was small, perhaps limiting the opportunity to detect correlations. Nevertheless, travel times changed dramatically, despite the relatively stable flows.

\subsection{Conclusions}

Our investigations indicate that freeze brand data can be used to provide broad, general estimates of median travel times for groups of migrating smolts over extensive reaches and relatively long periods of time. In addition, the brand data offer a limited opportunity to study the relationships between travel time and environmental and (surrogates of) physiological variables. However, there are fundamental limitations of the brand data, mostly arising from the complicated algorithm required to estimate critical passage distributions.

The greatest statistical liability of the travel time estimation procedure is the inability to compute meaningful measures of the uncertainty of the estimates. In a proper statistical analysis, confidence intervals are generally provided along with point estimates. Confidence intervals for 
the estimated travel times are not possible using the brand recovery data. Given the large number of uncertain parameters used in the adjustment algorithm, and the complicated, nonlinear way in which they are combined to produce the distribution estimates, it is certain that if confidence intervals could be constructed, they would be very wide.

We uncovered another limitation of the passage-distribution adjustment algorithm. The set of parameter values used in both the Fish Passage Center analyses (Berggren and Filardo, 1993) and as the "standard" set in our analyses led to estimates of the total number of branded fish arriving at McNary Dam in excess of the estimated total number entering the index reach below Lower Granite Dam. This paradoxical result clearly makes survival estimation impossible, and also casts doubt on the appropriateness of estimating travel times based on the adjustment algorithm.

Our sensitivity analyses showed that the travel time estimates, selected regression models, and regression equations can all be sensitive to the assumed values for the unknown parameters in the adjustment algorithm, particularly when values near the extremes of the plausible ranges are assumed for fish guidance efficiency and spill effectiveness. The sensitivity is particularly important for brand release groups that pass the dams during periods of high spill or at a time when the transportation program is starting up or closing down. Sensitivity to underlying parameters is important because for many of the parameters there is very little experimental information on the correct values and we are left with "guesstimates".

With monitoring only at Lower Granite and McNary Dams, we are forced to estimate travel times through an extensive reach of the river, including three other hydroelectric projects where data on smolt passage are unavailable. The average estimated travel time for the 42 hatchery releases was 12.37 days. Thus, the river condition variables that we attempted to relate to travel time are summarized over a nearly two-week period. There is no biological basis to suppose that this is the appropriate time-scale on which to summarize river conditions. It has been suggested that migrating smolts react to trends and changes in flows on a much smaller time-scale. Methods of relating migratory dynamics to river conditions that do not require such broad summarization would be much more useful in devising plans to accelerate migration. Moreover, we have found that the selection of a single dam to serve as an index for all the others is problematic. Ice Harbor Dam provides a reasonable index for flow volumes and possibly spill volumes, but cannot be used to index water conditions such as temperature and turbidity. Correlations of travel time with these variables can be investigated on a dam-by-dam basis, but 
the presence of several dams in the index reach complicates the interpretation of regression results.

As a final important limitation, we find that proposed as surrogate measurements of smolt development are not entirely satisfactory. We found that the smoltification-surrogate that is most important in explaining and predicting travel time from Lower Granite to McNary Dam was the travel time from the point of release to arrival at Lower Granite. However, the connection between the degree of smoltification and the previous time spent in-river is clearly not one-toone. Both the travel time to Lower Granite and the smolt development are influenced by other important factors. Any conclusions regarding the relationship between smolt development and migration speed that are based on the travel time to Lower Granite must be very carefully stated and interpreted and ultimately cannot be definitive.

In summation, our major conclusions are as follows:

1. Existing brand recovery data provide broad, general estimates of travel time through the impounded section of the mainstem Snake River for the expansive reach from Lower Granite to McNary Dam.

2. It is not possible to estimate standard errors of the point estimates of travel time. The complicated adjustment procedure used to derive estimates requires numerous parameter values that are presumed general estimates, unverified and without measures of variance themselves.

3. The relationships between the travel time estimates and predictor variables are also necessarily general and have poor resolution, but can serve as general descriptions. The expansive distances for which travel time can be estimated necessitate the development of environmental indices that span protracted periods of time. Consequently, the resolution of the travel time estimates is not fine enough to detect changes in travel time resulting from changing conditions in the individual reaches. Furthermore, direct measures of physiological indices are not available for branded groups. Thus, we must use surrogate measures that may not capture true effects.

4. Both the estimated travel time and derived relationships are sensitive to assumed values for the input parameters Fish Guidance Efficiency and Spill Effectiveness. This pertains to brand groups that encounter spill conditions at Lower Granite, Little Goose, or McNary Dam. 
5. Estimated population totals at McNary Dam are typically larger than totals estimated at Lower Granite Dam, in many cases by several fold. This indicates that certain unidentified input parameter values are in error. This condition precludes the'opportunity to use the brand recovery data to estimate reach survival. Perhaps more importantly, this condition suggests that some commonly-held values for key parameters, e.g. FGE, spill effectiveness, or dam and reservoir mortality are substantially in error. This in turn, may have a detrimental effect on the usefulness of the data for travel time estimation.

6. There are numerous models that can equally explain the travel time response in the hatchery releases. Typically, these models include as key predictor variables some measure of flow, a surrogate for smolt development, and an index of spill at the projects of the lower reach.-

\subsection{Recommendations}

In light of the limitations of the freeze-brand data base, we have several recommendations. First, future investigations of relationships of travel time to river conditions should focus on shorter reaches and shorter periods of time than have been historically possible using brand data. This will allow more resolution in describing migratory dynamics. Migrating smolts respond to their immediate environment; the information we use to describe the migratory dynamics should be on the appropriate scale. This recommendation will require monitoring smolt passage at additional dams on the Snake River.

When batches of identically-marked smolts are used to study migratory dynamics, our only tools for estimating travel times are passage distributions at the monitoring sites. Total passage must be estimated from counts tallied in only one of three possible passage routes. The transportation program ensures that the one route for which we have direct counts is a route from which most of the fish are removed. These factors lead to the use of complicated algorithms to adjust the actual counts up to estimates of total passage, with all the attendant problems we have identified above. However, the adjustment algorithm would be unnecessary if we could obtain information on the travel times of individual fish. We would no longer have to deal with the releases on the level of the batch. Information on individual travel times can be collected using individual-specific PIT tags rather than freeze brands. Average travel time estimates for batches of fish can then be based on the distribution of individual travel times, rather than comparing distributions of passage. The estimation procedure under these conditions

can be more rigorous statistically, including proper characterization (confidence intervals) of the uncertainty of point estimates. 
Direct measures of smoltification are needed to study more fully the relationships among travel time, flow variables, and physiological variables. Non-destructive methods of measuring smoltification are being developed, and should prove quite useful (Beeman et al., 1990, 1991).

Finally, we recommend the use of multiple detection sites for PIT-tags, equipped with mechanisms to divert PIT-tagged smolts away from transportation barges and trucks and back into the river. If individual fish can be detected multiple times, the detection data can be analyzed using tag-recapture models to describe both the survival and the capture processes. The state-of-the-art in tag-recapture methodology is regression-like models that allow survival probabilities to be related to concomitant variables, both on the batch level (e.g. river conditions) and on the individual level (smoltification measures). Travel time investigations have been the focus of freeze-branding studies, with the implicit assumption that travel time equates to smolt survival. Current technology can be used to provide data on survival rates directly, eliminating the need to assume the travel time/survival relationship. The future direction of studies of migratory dynamics of juvenile salmon should be toward shedding light on the requirements for smolt survival.

In summation, our major recommendations are as follows:

1. Develop travel time estimates through shorter reaches of river, over briefer periods. This will improve our ability to detect changes in fish response to changes in environmental conditions.

2. Abandon the travel time estimation protocol that requires the adjustment algorithm as applied to hatchery freeze-branded groups. Provide more direct measures of smolt travel time. This would require either (1) intercepting, marking, and releasing active migrants at the head of the reach of interest, or (2) rereleasing marked fish at serial sampling sites. These two preferred protocols could be readily implemented (and currently are implemented to a limited extent) by employing PIT-tag technology available in the basin.

3. Obtain direct measures of important predictor variables for every group used in any analysis. This includes indices of smoltification, preferably using nondestructive techniques being developed by the U.S. Fish and Wildlife Service.

4. When and where possible, characterize individual traits and use these data in conjunction with travel time data from rereleasing uniquely-coded individuals.

5. Pursue new methodologies for estimating smolt survival through the mainstem Snake and Columbia Rivers. Existing brand recapture data are not suitable for deriving survival estimates from Little Goose to McNary Dam (or any other reach). 


\section{LITERATURE CITED}

Beeman, J.W., D.W. Rondorf, J.C. Faler, M.E. Free, and P. V. Haner. 1990. Assessment of smolt condition for travel time analysis. Annual Report (Contract DE-AI79-87BP35245) to Bonneville Power Administration, Portland, Oregon.

Beeman, J.W., D.W. Rondorf, J.C. Faler, P. V. Haner, S.T. Sauter, and D.A. Venditti. 1991. Assessment of smolt condition for travel time analysis. Annual Report (Contract DE-AI7987BP35245) to Bonneville Power Administration, Portland, Oregon.

Berggren, T.J., and M.J. Filardo, 1993 (in press). An analysis of variables influencing the migration of juvenile salmonids in the Columbia River Basin. North American Journal of Fisheries Management.

Cook, R.D., and S. Weisberg. 1982. Residuals and Influence in Regression. New York: Chapman and Hall, 230 pp.

Folmar, L.C., and W.W. Dickhoff. 1980. The par-r-smolt transformation (smoltification) and seawater adaptation in salmonids. A review of selected literature. Aquaculture 21: 1-37.

Giorgi, A.E. 1990. Biological manipulation of migratory behavior: the use of advanced photoperiod to accelerate smoltification in yearling chinook salmon. Pages 108- 114 in: D.L.Park, editor, Status and future of spring chinook salmon in the Columbia River Basin-conservation and enhancement. NOAA Tech. Memo., NMFS F/NWC-187.

Giorgi, A., W. Muir, W. Zaugg, and S. McCutcheon. 1991. Biological manipulation of migration rate: the use of advanced photoperiod to accelerate smoltification in yearling chinook salmon. 1989 Annual Report to BPA, Project 88-141. NMFS Seattle, WA 35 pp.

Hoar, W.S. 1988. The physiology of smolting salmonids. Pages 257-343 in W.S. Hoar and D.J. Randall, editors. Fish Physiology, Volume XI, The physiology of developing fish, Part B viviparity and posthatching juveniles. New York: Academic Press

Lehmann, E.L. 1983. Theory of Point Estimation. New York: John Wiley \& Sons, 506 pp.

Neter, J., W. Wasserman, and M.H. Kutner. 1985. Applied Linear Statistical Models. 2nd edition. Homewood, Illinois: Richard D. Irwin, Inc., 1127 pp.

Rondorf, D.W., M.S. Dutchuk, A.S. Kolok, and M.L. Gross. 1985. Bioenergetics of juvenile salmon during the spring outmigration. Annual Report to BPA, Portland, OR 78 pp. 
Rondorf, D.W., J.W. Beeman, J.C. Fạler, M.E. Free, and E.J. Wagner. 1989. Assessment of smolt condition for travel time analysis. Annual Report (Contract DE-AI79-87BP35245) to Bonneville Power Administration, Portland, Oregon.

Scully, R.J., and E. Buettner. 1986. Smolt condition and timing of arrival at Lower Granite Reservoir. Annual Report (Contract DE-AI79-83BP11631) to Bonneville Power Administration, Portland, Oregon.

Smith, L.S. 1982. Decreased swimming performance as a necessary component of the smolt migration in salmon in the Columbia River. Aquaculture 28: 153- 161.

Snedecor, G.W. and W.G. Cochran. 1980. Statistical Methods. Seventh Edition. Ames, Iowa. Iowa State University Press, 507 pp.

Sokal, R.R. and F.J. Rohlf. 1981. Biometry. Second Edition. New York: W.H. Freeman, 859 pp.

Swan, G.A., R.F.Krcma, and F.J. Ossiander. 1986. Continuing studies to improve and evaluate juvenile salmonid collection at Lower Granite Dam - 1985. Annual Report (Contract DACW68-84-H-0034) to Coastal Zone and Estuarine Studies Division, National Marine Fisheries Service, Seattle, Washington.

Swan, G.A., B.H.Monk, J.G.Williams, and B.P.Sanford. 1990. Fish guidance efficiency of submersible traveling screens at Lower Granite Dam - 1989. Annual Report (Contract DACW68-84-H-0034) to Coastal Zone and Estuarine Studies Division, National Marine Fisheries Service, Seattle, Washington.

Wedemeyer, G.A., R.L. Saunders, and W.C. Clarke. 1980. Environmental factors affecting smoltification and early marine survival of anadromous salmonids. Marine Fisheries Review 42:1-14.

Wilson, J.W., A.E. Giorgi, and L.C. Stuehrenberg. 1991. A method for estimating spill effectiveness for passing juvenile salmon and its applications at Lower Granite Dam on the Snake River. Canadian Journal of Fisheries and Aquatic Sciences 10: 1872-1876. 


\section{Appendix A}

Complete Repression Data for Snake River Releases of Freeze-Branded Iuvenile Spring and Summer Chinook Salmon, 
97

Table A.l. Complete regression data for Snake River releases of freeze-branded iuvenile spring and summer chinook salmon,

\begin{tabular}{|c|c|c|c|c|c|c|}
\hline Year & $\begin{array}{l}\text { Brand } \\
\text { Code }\end{array}$ & $\begin{array}{c}\text { Median } \\
\text { Release Date } \\
\text { (Julian) }\end{array}$ & $\begin{array}{l}\text { Median } \\
\text { Entry Date } \\
\text { (Julian) }\end{array}$ & $\begin{array}{l}\text { Travel } \\
\text { lime } \\
\text { (Days }\end{array}$ & $\begin{array}{l}\text { Days } \\
\text { to } \\
\text { LGR }\end{array}$ & Race* \\
\hline 83 & RD _ SU _ 3 & 91.0 & 112.9 & 13.7 & 21.9 & 1 \\
\hline 85 & RD-R-2 & 93.5 & 117.8 & 12.1 & 24.3 & 1 \\
\hline 86 & RA-Y-2 & 92.5 & 111.8 & 20.6 & 19.3 & 1 \\
\hline 87 & RA-R-I & 92.0 & 114.2 & 12.4 & 22.2 & 1 \\
\hline 88 & LA-T-2 & 90.0 & 111.8 & 18.2 & 21.8 & 1 \\
\hline 89 & R\#-7H-\# & 89.0 & 117.8 & 11.3 & 28.8 & 1 \\
\hline 90 & \#-7U-\# & 95.0 & 119.9 & 16.7 & 24.9 & 1 \\
\hline 83 & RD-T-1 & 95.5 & 125.2 & 8.0 & 29.7 & 0 \\
\hline 84 & LD-J-l & 101.0 & 137.3 & 8.3 & 36.3 & 0 \\
\hline 85 & RD-R-3 & 92.5 & 133.6 & 13.1 & 41.1 & 0 \\
\hline 86 & RD-Y-3 & 86.5 & 124.9 & 10.8 & 38.4 & 0 \\
\hline 87 & LD-R-3 & 90.5 & 122.0 & 10.7 & 31.5 & 0 \\
\hline 89 & RA-R-\# & 80.0 & 132.0 & 10.6 & 52.0 & 0 \\
\hline 90 & LD-T-\# & 80.0 & 142.4 & 10.4 & 62.4 & 0 \\
\hline 82 & RD-4-1 & 86.0 & 113.8 & 9.6 & 27.8 & 1 \\
\hline 83 & RD-12-I & 81.0 & 112.6 & 11.4 & 31.6 & 1 \\
\hline 84 & RD-J-3 & 86.5 & 118.5 & 10.3 & 32.0 & 1 \\
\hline 85 & LD-R-1 & 95.0 & 115.4 & 13.9 & 20.4 & 1 \\
\hline 86 & LD-Y-1 & 95.5 & 110.1 & 14.6 & 14.6 & 1 \\
\hline 87 & LD-R-2 & 86.0 & 116.7 & 10.8 & 30.7 & 1 \\
\hline 88 & RD-T-4 & 80.0 & 115.6 & 16.7 & 35.6 & 1 \\
\hline 89 & L\#-7H-\# & 81.5 & 113.3 & 13.8 & 31.8 & 1 \\
\hline 90 & RA-T-\# & 83.0 & 113.2 & 12.2 & 30.2 & 1 \\
\hline 83 & RD-T-2 & 88.0 & 123.5 & 7.3 & 35.5 & 1 \\
\hline 84 & LD-J-3 & 88.0 & 127.5 & 12.5 & 39.5 & 1 \\
\hline 85 & RD-R-1 & 86.0 & 124.3 & 12.9 & 38.3 & 1 \\
\hline 86 & RD-Y-1 & 76.0 & 114.0 & 9.1 & 38.0 & 1 \\
\hline 87 & RD-R-1 & 71.0 & 117.5 & 9.0 & 46.5 & 1 \\
\hline 88 & RD-T-1 & 75.0 & 117.8 & 14.6 & 42.8 & 1 \\
\hline 89 & LA-R-\# & 74.0 & 113.1 & 10.9 & 39.1 & 1 \\
\hline 90 & LA-T-\# & 76.0 & 113.2 & 11.1 & 37.2 & 1 \\
\hline 82 & RD-SU\# & 99.0 & 137.0 & 4.1 & 38.0 & 1 \\
\hline 83 & RD-T-3 & 77.0 & 103.9 & 13.5 & 26.9 & 1 \\
\hline 87 & LA-J-\# & 91.0 & 114.3 & 12.2 & 23.3 & 1 \\
\hline 88 & \#A-I\#-\# & 92.0 & 112.3 & 19.9 & 20.3 & 1 \\
\hline 89 & \#D-J-\# & 93.0 & 112.3 & 12.1 & 19.3 & 1 \\
\hline 30 & \#A-A-\# & 92.0 & 109.4 & 15.9 & 17.4 & 1 \\
\hline 34 & RD-J-1 & 80.5 & 110.6 & 7.9 & 30.1 & 1 \\
\hline 85 & LD-R-3 & 78.0 & 103.5 & 15.4 & 25.5 & 1 \\
\hline 36 & LD-Y-3 & 85.5 & 106.7 & 12.6 & 21.2 & 1 \\
\hline 57 & LD-R-4 & 82.0 & 116.0 & 10.7 & 34.0 & 1 \\
\hline 38 & LD-T-4 & 82.5 & 114.5 & 18.2 & 32.0 & 1 \\
\hline
\end{tabular}

* $1=$ yearling; $0=$ sub-yearling. 
98

Table A. 1 (cont.1 Complete repression data for Snake River releases of freeze-branded juvenile spring and summer chinook salmon.

\begin{tabular}{|c|c|c|c|c|c|c|c|c|c|c|c|c|c|c|}
\hline & & & & & & Ieasur & ents at & ower G & ranite & & & & & \\
\hline & & & LOW (kc & & & & ILL (kc & & & mperatu & & & urbidit & \\
\hline Year & Code & Min. & Avg. & Max. & DFLOW $^{-1}$ & Min. & Avg. & Max. & Min. & Avg. & Max. & Min. & Avg. & Max. \\
\hline 83 & RD-SE-3 & 59.0 & 102.0 & 121.3 & 0.0087 & 2.7 & 27.1 & 42.8 & 50 & 51.8 & 54 & 1.6 & 1.7 & 1.8 \\
\hline 85 & RD-R-2 & 53.0 & 80.3 & 94.0 & 0.0082 & 0.0 & 4.8 & 35.6 & 49 & 51.5 & 53 & 2.5 & 2.8 & 3.5 \\
\hline 86 & RA-Y-2 & 81.3 & 97.3 & 115.9 & 0.0037 & 0.0 & 0.1 & 1.3 & 50 & 51.2 & 53 & 0.7 & 2.0 & 2.5 \\
\hline 87 & RA-R-I & 47.4 & 72.0 & 100.1 & 0.0111 & 0.0 & 0.0 & 0.1 & 50 & 52.2 & 54 & 0.2 & 2.7 & 3.9 \\
\hline 88 & LA-T-2 & 37.1 & 58.6 & 89.5 & 0.0158 & 0.0 & 0.0 & 0.0 & 49 & 51.1 & 53 & 2.5 & 3.5 & 4.5 \\
\hline 89 & 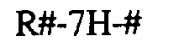 & 78.4 & 95.2 & 121.1 & 0.0045 & 0.0 & 0.0 & 0.0 & 50 & 51.9 & 54 & 2.4 & 3.1 & 3.4 \\
\hline 90 & \#-7U\#\# & 47.1 & 71.3 & 88.6 & 0.0100 & 0.0 & 0.0 & 0.0 & 46 & 51.3 & 54 & 2.1 & 3.6 & 4.2 \\
\hline 83 & RD-T-1 & 99.8 & 113.3 & 121.8 & 0.0018 & 0.0 & 19.9 & 44.2 & 53 & 53.7 & 54 & 1.6 & 1.7 & 1.8 \\
\hline 84 & LD-J-1 & 158.4 & 182.4 & 200.4 & 0.0013 & 32.0 & 58.6 & 79.3 & 50 & 51.4 & 53 & 0.8 & 1.3 & 1.8 \\
\hline 85 & RD-R-3 & 68.2 & 92.0 & 122.3 & 0.0065 & 0.0 & 0.0 & 0.0 & 51 & 54.2 & 56 & 2.8 & 3.1 & 3.5 \\
\hline 86 & RD-Y-3 & 89.7 & 99.9 & 109.3 & 0.0020 & 0.0 & 0.0 & 0.0 & 50 & 51.1 & 53 & 2.0 & 2.2 & 2.5 \\
\hline 87 & LD-R-3 & 65.1 & 79.9 & 98.8 & 0.0052 & 0.0 & 0.0 & 0.0 & 50 & 52.3 & 56 & 0.2 & 2.5 & 3.8 \\
\hline 89 & RA-R-\# & 62.3 & 80.2 & 104.6 & 0.0065 & 0.0 & 0.0 & 0.0 & 49 & 51.9 & 53 & 2.7 & 2.9 & 3.1 \\
\hline 90 & LD-T-\# & 40.9 & 77.1 & 121.2 & 0.0162 & 0.0 & 0.0 & 0.0 & 56 & 56.9 & 58 & 0.6 & 2.7 & 5.0 \\
\hline 82 & $\mathrm{RD}-4-1$ & 110.4 & 120.8 & 131.6 & 0.0015 & 17.2 & 28.3 & 49.8 & 47 & 49.6 & 50 & 1.6 & 1.8 & 1.9 \\
\hline 83 & RD-12-1 & 59.0 & 98.7 & 110.8 & 0.0079 & 2.7 & 26.8 & 42.8 & 50 & 51.3 & 54 & 1.6 & 1.7 & 1.8 \\
\hline 84 & RD-J-3 & 90.2 & 109.6 & 126.4 & 0.0032 & 10.0 & 24.1 & 44.0 & 39 & 48.3 & 50 & 1.5 & 1.8 & 2.0 \\
\hline 85 & LD-R-l & 53.0 & 79.9 & 94.0 & 0.0082 & 0.0 & 4.1 & 35.6 & 49 & 51.2 & 53 & 1.8 & 2.7 & 3.5 \\
\hline 86 & LD-Y-I & 81.3 & 93.9 & 115.9 & 0.0037 & 0.0 & 0.1 & 1.3 & 49 & 51.1 & 53 & 0.7 & 1.9 & 2.2 \\
\hline 87 & LD-R-2 & 49.7 & 77.1 & 100.1 & 0.0101 & 0.0 & 0.0 & 0.1 & 50 & 52.3 & 54 & 0.2 & 2.5 & 3.8 \\
\hline 88 & RD-T-4 & 37.1 & 57.9 & 89.5 & 0.0158 & 0.0 & 0.0 & 0.0 & 49 & 50.9 & 53 & 3.0 & 3.8 & 4.5 \\
\hline 89 & L\#-7H-\# & 77.6 & 94.0 & 114.5 & 0.0042 & 0.0 & 0.0 & 0.0 & 50 & 51.2 & 53 & 2.2 & 2.8 & 3.4 \\
\hline 90 & RA-T-\# & 56.5 & 64.1 & 77.8 & 0.0049 & 0.0 & 0.0 & 0.0 & 46 & 50.7 & 53 & 2.1 & 3.3 & 4.0 \\
\hline 83 & RD-T-2 & 106.9 & 114.9 & 121.8 & 0.0011 & 7.6 & 27.4 & 44.2 & 53 & 53.8 & 54 & 1.6 & 1.7 & 1.8 \\
\hline 84 & LD-J-3 & 111.4 & 144.8 & 200.4 & 0.0040 & 0.0 & 35.8 & 80.9 & 49 & 50.4 & 52 & 0.8 & 1.4 & 1.9 \\
\hline 85 & RD-R-1 & 68.2 & 80.5 & 91.8 & 0.0038 & 0.0 & 4.4 & 35.6 & 50 & 51.6 & 53 & 2.5 & 3.0 & 3.5 \\
\hline 86 & RD-Y-1 & 81.3 & 96.2 & 115.9 & 0.0037 & 0.0 & 0.1 & 1.3 & 50 & 51.2 & 53 & 0.7 & 1.8 & 2.2 \\
\hline 87 & RD-R-l & 53.8 & 78.2 & 100.1 & 0.0086 & 0.0 & 0.0 & 0.1 & 50 & 52.4 & 54 & 0.2 & 2.4 & 3.5 \\
\hline 88 & RD-T-l & 37.1 & 58.6 & 89.5 & 0.0158 & 0.0 & 0.0 & 0.0 & 49 & 51.1 & 53 & 3.1 & 3.9 & 4.5 \\
\hline 89 & LA-R-\# & 77.6 & 91.6 & 114.5 & 0.0042 & 0.0 & 0.0 & 0.0 & 50 & 50.6 & 51 & 2.2 & 2.7 & 3.2 \\
\hline 90 & LA-T-\# & 56.5 & 64.1 & 77.8 & 0.0049 & 0.0 & 0.0 & 0.0 & 46 & 50.7 & 53 & 2.1 & 3.3 & 4.0 \\
\hline 82 & RD-SU-\# & 138.1 & 151.8 & 165.0 & 0.0012 & 16.6 & 32.2 & 42.0 & 52 & 53.6 & 55 & 1.7 & 2.1 & 2.6 \\
\hline 83 & RD-T-3 & 49.5 & 74.1 & 110.8 & 0112 & 2.6 & 18.5 & 42.8 & 48 & 49.7 & 51 & 1.5 & 1.6 & 1.7 \\
\hline 87 & LA-J-\# & 47.4 & 72.0 & 100.1 & 0.0111 & 0.0 & 0.0 & 0.1 & 50 & 52.2 & 54 & 0.2 & 2.7 & 3.9 \\
\hline 88 & \#A-I\#-\# & 37.1 & 58.4 & 89.5 & 0.0158 & 0.0 & 0.0 & 0.0 & 49 & 50.9 & 53 & 2.5 & 3.7 & 4.5 \\
\hline 89 & \#D-J-\# & 77.6 & 94.0 & 117.8 & 0.0044 & 0.0 & 0.0 & 0.0 & 50 & 50.8 & 52 & 2.2 & 2.7 & 3.2 \\
\hline 90 & \#A-A\# & ‘56.5 & 64.4 & 77.8 & 0.0049 & 0.0 & 0.0 & 0.0 & 46 & 51.1 & 53 & 2.1 & 3.6 & 4.5 \\
\hline 84 & RD-J-1 & 126.4 & 135.9 & 143.7 & 0.0010 & 38.4 & 49.4 & 70.8 & 47 & 48.6 & 50 & 1.4 & 1.6 & 1.9 \\
\hline 85 & LD-R-3 & 53.0 & 89.7 & 112.5 & 0.0100 & 0.0 & 0.4 & 4.4 & 49 & 50.1 & 52 & 1.4 & 1.8 & 2.6 \\
\hline 86 & LD-Y-3 & 82.9 & 94.6 & 115.9 & 0.0034 & 0.0 & 0.1 & 1.3 & 49 & 50.6 & 53 & 0.7 & 1.9 & 2.2 \\
\hline 87 & LD-R-4 & 49.7 & 74.0 & 100.1 & 0.0101 & 0.0 & 0.0 & 0.1 & 50 & 52.3 & 54 & 0.2 & 2.7 & 3.9 \\
\hline 88 & LD-T-4 & 37.1 & 58.0 & 89.5 & 0.158 & 0.0 & 0.0 & 0.0 & 49 & 50.8 & 53 & 3.0 & 3.8 & 4.5 \\
\hline
\end{tabular}


99

Table A.2 (cont. 1 Complete regression data for Snake River releases of freeze-branded juvenile spring and summer chinook salmon.

\begin{tabular}{|c|c|c|c|c|c|c|c|c|c|c|c|c|c|}
\hline \multirow[b]{3}{*}{ Year Code } & \multicolumn{13}{|c|}{ Measurements at Little Goose } \\
\hline & \multicolumn{3}{|c|}{ FLOW (kcfs) } & \multicolumn{4}{|c|}{ SPILL (kcfs) } & \multicolumn{3}{|c|}{ Temperature } & \multicolumn{3}{|c|}{ Turbidity } \\
\hline & Min. & Avg. & Max. & DFLOW $^{-1}$ & Min. & Avg. & Max. & Min. & Avg. & Max. & Min. & Avg. & $\operatorname{Max}$ \\
\hline 83 RD-su-3 & 488 & 101.9 & 1168 & 001.19 & GO & 46.9 & 56.2 & NA & $\mathrm{NA}$ & NA & $\mathrm{NA}$ & NA & $\mathrm{NA}$ \\
\hline 85 RD-R-2 & 53.9 & 80.8 & 102.6 & 0.008 & 0.0 & 0.0 & 0.0 & NA & NA & NA & NA & NA & NA \\
\hline 86 RA-Y-2 & 82.1 & 97.4 & 117.4 & 0.00 & 0.0 & 0.7 & 8.7 & NA & NA & NA & NA & NA & NA \\
\hline 87 RA-R-l & 47.4 & 73.5 & 100.7 & 0.0 & 0.0 & 0.0 & 0.0 & NA & NA & NA & NA & NA & NA \\
\hline 88 LA-T-2 & 37.9 & 58.8 & 88.3 & 0.0 & 0.0 & 0.0 & 0.0 & NA & NA & NA & NA & NA & NA \\
\hline 89 R\#-7H-\# & 67.7 & 94.9 & 122.4 & 0.0066 & 0.0 & 0.0 & 0.0 & NA & NA & NA & NA & NA & NA \\
\hline 90 \#-7U-\# & 50.3 & 72.3 & 89.7 & 0.0 & 0.0 & 0.0 & 0.0 & NA & NA & NA & NA & NA & NA \\
\hline 83 RD-T-1 & 101.3 & 113.1 & 122.4 & 0.00 & 0.0 & 26.0 & 55.0 & NA & NA & NA & NA & NA & NA \\
\hline 84 LD-J-1 & 157.5 & 181.3 & 200.7 & & 46.5 & 64.4 & 88.5 & NA & NA & NA & NA & NA & NA \\
\hline 85 RD-R-3 & 63.5 & 92.9 & 123.9 & & 0.0 & & 0.0 & NA & NA & NA & NA & NA & NA \\
\hline 86 RD-Y- & 87.3 & 99.6 & 113.1 & & 0.0 & & 0.0 & NA & NA & NA & NA & NA & NA \\
\hline 87 LD-R-3 & 62.9 & 81.0 & 91.7 & & 0.0 & 0 . & 0.0 & NA & NA & NA & NA & NA & NA \\
\hline 89 RA-R-\# & 61.0 & 82.4 & 114.4 & & 0.0 & 0 . & 0.0 & NA & NA & NA & NA & NA & NA \\
\hline 90 LD-T $\#$ & 41.6 & 78.1 & 122.5 & & 0.0 & 0 . & 0.0 & A & NA & $A$ & $\mathrm{TA}$ & JA & NA \\
\hline 82 RD-4-1 & 104.2 & 120.1 & 125.7 & & 4.1 & 30.9 & 49.6 & NA & NA & $A$ & NA & NA & JA \\
\hline 83 RD-12-1 & 48.8 & 98.4 & 116.2 & & 6.0 & 45. & 56.2 & NA & NA & $A$ & NA & NA & NA \\
\hline 84 RD-J-3 & 94.8 & 109.2 & 125.3 & & 9.8 & 18. & 38.7 & A & A & $A$ & TA & A & JA \\
\hline 85 LD-R-1 & 53.9 & 80.5 & 102.6 & & 0.0 & & 0.0 & & & & A & A & JA \\
\hline 86 LD-Y-1 & 82.1 & 94.2 & 117 & & & & 8.7 & $A$ & & JA & IA & A & JA \\
\hline 87 LD-R- & 54.3 & 78.7 & 100.7 & & & & 0.0 & & & JA & TA & A & NA \\
\hline 88 RD-T-4 & 37.9 & 58.2 & & & $0 .($ & 0 . & 0.0 & JA & JA & NA & NA & NA & NA \\
\hline 89 L\#-7H-\# & 67.7 & 94.6 & 111.7 & & 0.0 & 0. & 0.0 & NA & NA & NA & NA & NA & NA \\
\hline 90 RA-T-\# & 56.4 & 64.5 & $7 \varepsilon$ & & & 0 . & 0.0 & NA & NA & NA & NA & NA & NA \\
\hline 83 RD-T-2 & 106.7 & 115.2 & 122.4 & 0012 & $7.3^{3}$ & 41.5 & 56.2 & NA & NA & NA & NA & A & NA \\
\hline 84 LD-J-3 & 101.1 & 143.3 & 200.7 & & $11 . \mathrm{c}$ & 39. & 88.5 & NA & NA & NA & NA & NA & NA \\
\hline 85 RD-R-1 & & .5 & 102.6 & & & 0. & 0.0 & NA & NA & NA & NA & NA & NA \\
\hline 86 RD-Y-1 & 8 & 96.4 & 117.4 & & & & 8.7 & NA & $\mathrm{N}$ & $\mathrm{N}$ & NA & $A$ & NA \\
\hline 87 RD-R-1 & 55.3 & 79.8 & 100.7 & & & 0 . & 0.0 & NA & NA & NA & NA & NA & NA \\
\hline 88 RD-T-1 & 37.9 & 59.1 & 88.3 & & & 0 . & 0.0 & NA & NA & $\mathrm{N}$ & NA & NA & NA \\
\hline 89 LA-R-\# & 67.7 & 92.6 & 111.7 & & & 0 . & 0.0 & NA & NA & NA & NA & NA & NA \\
\hline 90 LA-T-\# & 56.4 & 64.7 & 78 & & & & 0. & NA & $\mathrm{N}$ & $\mathrm{N}$ & NA & A & NA \\
\hline 82 RD-SU-\# & $34.9 \quad 1$ & 152.1 & 166 & & & 24 . & 31. & NA & $\mathrm{N}$ & $\mathrm{N}$ & NA & NA & NA \\
\hline 83 RD-T-3 & 48.8 & 74.5 & 112.6 & & 6. & 27. & 56.1 & NA & NA & NA & NA & NA & NA \\
\hline 87 LA-J-\# & 47.4 & 73.5 & 100.7 & & 0.0 & 0. & 0.0 & NA & NA & NA & NA & NA & NA \\
\hline 88 \#A-I\#-\# & 37.9 & 58.8 & & & 0.0 & $0 .($ & 0.0 & NA & NA & NA & NA & NA & NA \\
\hline 89 \#D-J-\# & 67.7 & 94.4 & 112.1 & & 0.0 & 0.0 & 0.0 & NA & NA & NA & NA & NA & NA \\
\hline 90 \#A-A-\# & 56.4 & 64.9 & & & & 0.0 & 0.0 & NA & NA & NA & NA & NA & NA \\
\hline 84 RD-J-1 & 125.3 & 134.3 & 140.9 & 0009 & 28.5 & 42.2 & 51.0 & NA & NA & NA & NA & NA & NA \\
\hline 85 LD-R-3 & 53.9 & 92.4 & 116.7 & & & 0. & 0.0 & NA & NA & NA & NA & NA & NA \\
\hline 86 LD-Y-3 & 1 & 95.2 & 117.4 & & 0 & 1.2 & 8.7 & NA & NA & NA & NA & NA & NA \\
\hline 87 LD-R-4 & & 75.7 & 100.7 & & & 0.0 & 0.0 & & NA & & NA & NA & NA \\
\hline 88 LD-T-4 & 37.9 & 58.3 & 88.3 & 0.0151 & 0.0 & 0.0 & 0.0 & NA & NA & NA & NA & NA & NA \\
\hline
\end{tabular}


100

Table A.1 (cont.1 Comolete repression data for Snake River releases of freeze-branded juvenile spring and summer chinook salmon.

\begin{tabular}{|c|c|c|c|c|c|c|c|c|c|c|c|c|c|c|}
\hline \multirow[b]{3}{*}{ Year } & & \multicolumn{13}{|c|}{ Measurements at Lower Monumental } \\
\hline & & \multicolumn{3}{|c|}{ PLOW (kcfs) } & \multicolumn{4}{|c|}{ SPILL (kcfs) } & \multicolumn{3}{|c|}{ Temperature } & \multicolumn{3}{|c|}{ Turbidity } \\
\hline & - Code & Min. & Avg. & Max. & DFLOW $^{-1}$ & Min. & Avg. & Max. & Min. & Avg. & Max. & Min. & Avg. & $\operatorname{Max}$ \\
\hline 83 & RDSU3 .. & 46.3 & 98.7 & 116.4 & 0.0130 & 11.1 & 55.6 & 89.6 & 50 & 51.1 & 53 & 1.5 & 1.8 & 2.0 \\
\hline 85 & RD-R-2 & 52.0 & 80.9 & 107.8 & 0.0099 & 9.4 & 16.1 & 23.3 & 51 & 51.5 & 54 & 1.5 & 1.9 & 2.0 \\
\hline 86 & RA-Y-2 & 79.4 & 98.0 & 116.4 & 0.0040 & 17.2 & 31.7 & 62.6 & 51 & 51.8 & 53 & 1.4 & 1.5 & 1.6 \\
\hline 87 & RA-R-1 & 44.2 & 72.6 & 94.8 & 0.0121 & 1.5 & 11.5 & 24.1 & 51 & 52.8 & 54 & 1.5 & 1.6 & 2.0 \\
\hline 88 & LA-T-2 & 37.8 & 59.4 & 91.5 & 0.0155 & 0.0 & 6.5 & 16.9 & 50 & 51.5 & 53 & 2.0 & 2.6 & 2.8 \\
\hline 89 & R\#-7H\# & 61.6 & 94.1 & 118.9 & 0.0078 & 23.3 & 37.1 & 78.5 & 51 & 52.5 & 55 & 1.3 & 1.8 & 2.2 \\
\hline 90 & \#-7U一\# & 51.7 & 73.5 & 91.0 & 0.0084 & 15.1 & 24.2 & 31.2 & 51 & 52.6 & 55 & 2.0 & 3.0 & 4.0 \\
\hline 83 & RD-T-1 & 100.7 & 111.1 & 125.2 & 0.0019 & 53.2 & 65.7 & 88.0 & 53 & 53.8 & 54 & 2.0 & 2.2 & 2.4 \\
\hline 84 & LD-J-l & 156.9 & 180.4 & 201.6 & 0.0014 & 43.5 & 66.4 & 86.5 & 52 & 53.0 & 54 & 1.2 & 1.3 & 1.5 \\
\hline 85 & RD-R-3 & 61.7 & 93.5 & 121.1 & 0.0079 & 11.7 & 20.1 & 27.7 & 52 & 54.2 & 58 & 2.0 & 2.0 & 2.0 \\
\hline 86 & RD-Y-3 & 88.2 & 99.7 & 116.4 & 0.0028 & 21.8 & 33.1 & 62.6 & 51 & 51.9 & 52 & 1.4 & 1.5 & 1.5 \\
\hline 87 & LD-R-3 & 69.3 & 81.1 & 92.0 & 0.0036 & 9.5 & 15.7 & 24.1 & 54 & 54.5 & 55 & 1.5 & 1.8 & 2.0 \\
\hline 89 & RA-R-\# & 58.9 & 81.7 & 117.6 & 0.0085 & 15.5 & 24.7 & 41.0 & 53 & 54.4 & 55 & 2.1 & 2.2 & 2.2 \\
\hline 90 & LD-T-\# & 41.2 & 79.0 & 129.4 & 0.0165 & 12.0 & 25.7 & 46.8 & 54 & 55.3 & 57 & 1.0 & 3.1 & 3.6 \\
\hline 82 & RD-4-1 & 101.0 & 118.0 & 125.3 & 0.0019 & 44.0 & 68.7 & 99.1 & 48 & 49.6 & 52 & 0.9 & 1.1 & 1.5 \\
\hline 83 & RD-12-l & 46.3 & 95.8 & 116.4 & 0.0130 & 11.1 & 56.5 & 89.6 & 50 & 50.8 & 52 & 1.5 & 1.8 & 2.0 \\
\hline 84 & RD-J-3 & 94.7 & 109.1 & 125.6 & 0.0026 & 14.0 & 30.9 & 63.0 & 50 & 50.0 & 50 & 1.0 & 1.2 & 1.2 \\
\hline 85 & LD-R-1 & 52.0 & 80.7 & 107.8 & 0.0099 & 9.4 & 15.9 & 23.3 & 51 & 51.4 & 54 & 1.5 & 1.9 & 2.0 \\
\hline 86 & LD-Y-1 & 79.4 & 95.2 & 116.4 & 0.0040 & 17.2 & 29.1 & 44.0 & 51 & 51.6 & 53 & 1.5 & 1.5 & 1.6 \\
\hline 87 & LD-R-2 & 53.9 & 77.7 & 94.8 & 0.0080 & 4.1 & 13.5 & 24.1 & 52 & 53.3 & 55 & 1.5 & 1.6 & 2.0 \\
\hline 88 & RD-T-4 & 37.8 & 58.3 & 91.5 & 0.0155 & 1.9 & 7.9 & 16.9 & 51 & 51.9 & 53 & 2.0 & 2.5 & 2.8 \\
\hline 89 & L\#-7H-\# & 61.6 & 94.0 & 108.8 & 0.0071 & 23.3 & 36.0 & 78.5 & 51 & 52.0 & 54 & 1.3 & 1.6 & 2.1 \\
\hline 90 & RA-T-\# & 53.8 & 65.4 & 76.7 & 0.0056 & 17.7 & 21.9 & 29.5 & 51 & 52.6 & 54 & 2.0 & 3.0 & 4.0 \\
\hline 83 & RD-T-2 & 97.5 & 111.0 & 125.2 & 0.0023 & 49.1 & 57.1 & 64.9 & 52 & 53.3 & 54 & 2.0 & 2.1 & 2.4 \\
\hline 84 & LD-J-3 & 103.0 & 142.7 & 201.6 & 0.0048 & 18.4 & 39.8 & 86.5 & 50 & 51.5 & 53 & 1.2 & 1.3 & 1.5 \\
\hline 85 & RD-R-1 & 61.7 & 80.7 & 107.8 & 0.0069 & 11.7 & 17.0 & 23.3 & 51 & 52.6 & 54 & 2.0 & 2.0 & 2.0 \\
\hline 86 & RD-Y-1 & 83.8 & 97.2 & 116.4 & 0.0033 & 17.2 & 30.8 & 44.0 & 51 & 51.7 & 53 & 1.5 & 1.5 & 1.6 \\
\hline 87 & RD-R-1 & 55.5 & 79.1 & 94.8 & 0.0075 & 4.2 & 14.2 & 24.1 & 52 & 53.3 & 54 & 1.5 & 1.6 & 2.0 \\
\hline 88 & RD-T-1 & 37.8 & 59.1 & 91.5 & 0.0155 & 1.9 & 8.5 & 16.9 & 51 & 52.1 & 53 & 2.0 & 2.5 & 2.8 \\
\hline 89 & LA-R-\# & 61.6 & 92.1 & 108.8 & 0.0071 & 23.3 & 37.3 & 78.5 & 51 & 51.6 & 52 & 1.3 & 1.5 & 2.1 \\
\hline 90 & LA-T-\# & 53.8 & 65.7 & 76.7 & 0.0056 & 17.7 & 21.9 & 29.5 & 51 & 52.7 & 54 & 2.0 & 3.0 & 4.0 \\
\hline 82 & RD-SU-\# & 137.6 & 152.8 & 167.7 & 0.0013 & 91.8 & 106.9 & 135.1 & 52 & 53.2 & 54 & 2.0 & 2.0 & 2.0 \\
\hline 83 & RD-T-3 & 46.3 & 73.1 & 108.7 & 0.0124 & 11.1 & 39.3 & 89.6 & 48 & 49.2 & 51 & 1.5 & 1.7 & 2.0 \\
\hline 87 & LA-J-\# & 44.2 & 72.6 & 94.8 & 0.0121 & 1.5 & 11.5 & 24.1 & 51 & 52.8 & 54 & 1.5 & 1.6 & 2.0 \\
\hline 88 & \#A-I\#-\# & 37.8 & 59.1 & 91.5 & 0.0155 & 0.0 & 7.2 & 16.9 & 50 & 51.7 & 53 & 2.0 & 2.5 & 2.8 \\
\hline 89 & \#D-J-\# & 61.6 & 93.9 & 116.0 & 0.0076 & 23.3 & 37.2 & 78.5 & 51 & 51.6 & 52 & 1.3 & 1.5 & 2.1 \\
\hline 90 & \#A-A\# & ‘53.8 & 65.8 & 76.7 & 0.0056 & 11.9 & 21.6 & 29.5 & 51 & 52.7 & 54 & 2.0 & 3.0 & 4.0 \\
\hline 84 & RD-J-1 & 125.3 & 133.4 & 141.0 & 0.0009 & 43.1 & 65.7 & 80.5 & 49 & 49.3 & 50 & 1.0 & 1.1 & 1.2 \\
\hline 85 & LD-R-3 & 52.0 & 93.4 & 118.8 & 0.0108 & 9.4 & 18.3 & 29.4 & 46 & 49.3 & 51 & 1.0 & 1.3 & 1.5 \\
\hline 86 & LD-Y-3 & 79.4 & 95.9 & 116.4 & 0.0040 & 18.3 & 31.4 & 44.0 & 50 & 51.1 & 52 & 1.0 & 1.5 & 1.6 \\
\hline 87 & LD-R-4 & 53.9 & 75.0 & 94.8 & 0.0080 & 2.1 & 12.4 & 24.1 & 51 & 53.0 & 54 & 1.5 & 1.6 & 2.0 \\
\hline $88 \mathrm{I}$ & LD-T-4 & 37.8 & 58.4 & 91.5 & 0.0155 & 1.9 & 7.7 & 16.9 & 51 & 51.9 & 53 & 2.0 & 2.5 & 2.8 \\
\hline
\end{tabular}


101

Table A.1 (cont.) Complete regression data for Snake River releases of freeze-branded juvenile spring and summer chinook salmon.

\begin{tabular}{|c|c|c|c|c|c|c|c|c|c|c|c|c|c|c|}
\hline \multirow[b]{3}{*}{ Year } & & \multicolumn{13}{|c|}{ Measurements at Ice Harbor } \\
\hline & & \multicolumn{3}{|c|}{ FLOW (kcfs) } & \multirow[b]{2}{*}{ DFLOW $^{-1}$} & \multicolumn{3}{|c|}{ SPILL (kcfs) } & \multicolumn{3}{|c|}{ Temperature } & \multicolumn{3}{|c|}{ Turbidity } \\
\hline & Code & Min. & Avg. & Max. & & Min. & Avg. & Max. & Min. & Avg. & Max. & Min. & Avg. & Max. \\
\hline 83 & RDSU .-3 & 40.8 & 100.5 & 119.7 & 0.0162 & 7.4 & 45.2 & 90.0 & 51 & 53.0 & 54 & 1.5 & 2.0 & 2.3 \\
\hline 85 & RD-R-2 & 53.0 & 78.8 & 107.9 & 0.0096 & 5.6 & 9.8 & 14.9 & 51 & 51.5 & 52 & 2.0 & 2.1 & 2.2 \\
\hline 86 & RA-Y-2 & 78.2 & 97.8 & 119.8 & 0.0044 & 0.0 & 23.2 & 57.3 & 52 & 52.1 & 53 & 1.9 & 2.5 & 3.0 \\
\hline 87 & RA-R-1 & 42.0 & 70.9 & 93.1 & 0.0131 & 0.0 & 2.5 & 12.3 & 52 & 54.6 & 57 & 2.9 & 3.6 & 4.0 \\
\hline 88 & LA-T-2 & 35.4 & 57.5 & 90.4 & 0.0172 & $\mathbf{0 . 0}$ & $\mathbf{0 . 0}$ & $\mathbf{0 . 0}$ & 48 & 52.2 & 54 & 2.0 & 2.5 & 3.3 \\
\hline 89 & $\mathrm{R \# -7H- \#}$ & 57.1 & 93.6 & 114.1 & 0.0088 & 8.5 & 20.4 & 71.9 & 52 & 52.8 & 54 & 2.0 & 2.5 & 2.7 \\
\hline 90 & \#-7U\# & 53.5 & 72.8 & 89.7 & 0.0075 & 6.1 & 9.3 & 13.8 & 52 & 54.2 & 55 & 4.0 & 4.2 & 4.5 \\
\hline 83 & RD-T-1 & 107.6 & 112.9 & 119.6 & 0.0009 & 42.3 & 46.1 & 51.3 & 54 & 54.7 & 55 & 1.9 & 2.1 & 2.5 \\
\hline 84 & LD-J-1 & 159.7 & 180.0 & 197.0 & 0.0012 & 54.7 & 75.8 & 93.4 & 52 & 52.9 & 54 & 1.3 & 1.5 & 1.7 \\
\hline 85 & RD-R-3 & 59.1 & 91.2 & 118.0 & 0.0084 & 7.9 & 10.9 & 15.0 & 53 & 54.6 & 57 & 2.5 & 2.8 & 3.1 \\
\hline 86 & RD-Y-3 & 90.2 & 99.9 & 117.1 & 0.0025 & 0.0 & 30.1 & 57.3 & 52 & 52.6 & 54 & 2.2 & 2.7 & 3.3 \\
\hline 87 & LD-R-3 & 60.6 & 79.9 & 92.6 & 0.0057 & 0.0 & 1.2 & 10.2 & 55 & 56.3 & 57 & 1.4 & 3.4 & 4.0 \\
\hline 89 & RA-R-\# & 56.4 & 82.2 & 120.5 & 0.0094 & 4.5 & 8.9 & 17.0 & 54 & 54.6 & 55 & 2.8 & 3.2 & 3.8 \\
\hline 90 & LD-T-\# & 41.3 & 77.5 & 124.7 & 0.0162 & 4.2 & 13.6 & 36.7 & 54 & 54.9 & 56 & 2.6 & 4.0 & 4.5 \\
\hline 82 & RD-4-1 & 100.8 & 118.0 & 125.9 & 0.0020 & 32.9 & 49.1 & 63.8 & 48 & 49.4 & 51 & 1.2 & 1.2 & 1.2 \\
\hline 83 & RD-12-l & 40.8 & 97.8 & 119.7 & 0.0162 & 7.4 & 45.4 & 90.0 & 51 & 52.8 & 54 & 1.5 & 2.0 & 2.3 \\
\hline 84 & RD-J-3 & 87.5 & 108.0 & 127.7 & 0.0036 & 15.3 & 24.0 & 42.4 & 49 & 49.3 & 50 & 1.7 & 1.8 & 2.0 \\
\hline 85 & LD-R-1 & 53.0 & 78.8 & 107.9 & 0.0096 & 5.6 & 9.6 & 14.9 & 51 & 51.4 & 52 & 1.8 & 2.1 & 2.2 \\
\hline 86 & LD-Y-l & 78.2 & 94.5 & 119.8 & 0.0044 & 0.0 & 16.2 & 40.2 & 52 & 52.0 & 52 & 1.9 & 2.4 & 2.6 \\
\hline 87 & LD-R-2 & 49.6 & 76.0 & 93.1 & 0.0094 & 0.0 & 2.7 & 12.3 & 53 & 55.3 & 57 & 2.9 & 3.8 & 4.0 \\
\hline 88 & RD-T-4 & 35.4 & 56.6 & 90.4 & 0.0172 & 0.0 & 0.0 & 0.0 & 51 & 52.9 & 54 & 2.0 & 2.3 & 3.3 \\
\hline 89 & L\#-7H-\# & 57.1 & 94.0 & 110.2 & 0.0084 & 8.5 & 19.4 & 71.9 & 51 & 52.4 & 54 & 2.0 & 2.5 & 2.7 \\
\hline 90 & RA-T-\# & 53.4 & 64.9 & 76.8 & 0.0057 & 6.1 & 8.7 & 12.0 & 54 & 54.5 & 55 & 4.2 & 4.3 & 4.5 \\
\hline 83 & RD-T-2 & 97.9 & 112.0 & 119.6 & 0.0019 & 41.9 & 44.8 & 47.9 & 54 & 54.4 & 55 & 1.9 & 2.1 & 2.2 \\
\hline 84 & LD-J-3 & 104.5 & 142.1 & 197.0 & 0.0045 & 18.3 & 44.1 & 93.1 & 50 & 51.8 & 53 & 1.5 & 1.7 & 2.0 \\
\hline 85 & RD-R-l & 59.1 & 79.2 & 107.9 & 0.0077 & 7.9 & 10.2 & 14.9 & 51 & 52.8 & 54 & 2.0 & 2.4 & 2.8 \\
\hline 86 & RD-Y-1 & 78.2 & 97.0 & 119.8 & 0.0044 & 3.1 & 20.0 & 40.2 & 52 & 52.0 & 52 & 1.9 & 2.4 & 2.6 \\
\hline 87 & RD-R-1 & 56.5 & 77.6 & 93.1 & 0.0070 & 0.0 & 3.3 & 12.3 & 53 & 54.9 & 56 & 3.0 & 3.8 & 4.0 \\
\hline 88 & RD-T-1 & 35.4 & 57.5 & 90.4 & 0.0172 & 0.0 & 0.0 & 0.0 & 51 & 53.2 & 54 & 2.0 & 2.3 & 3.3 \\
\hline 89 & LA-R-\# & 57.1 & 92.5 & 110.2 & 0.0084 & 8.5 & 22.0 & 71.9 & 51 & 52.1 & 53 & 2.0 & 2.5 & 2.6 \\
\hline 90 & LA-T-\# & 53.4 & 65.6 & 76.8 & 0.0057 & 6.1 & 8.8 & 12.0 & 54 & 54.4 & 55 & 4.2 & 4.3 & 4.5 \\
\hline 82 & RD-SU\#\# & 139.0 & 152.1 & 167.8 & 0.0012 & 51.8 & 63.0 & 81.5 & 53 & 54.0 & 55 & 1.8 & 2.1 & 2.3 \\
\hline 83 & RD-T-3 & 40.8 & 74.1 & 118.8 & 0.0161 & 7.4 & 30.8 & 90.0 & 48 & 49.9 & 52 & 1.8 & 2.0 & 2.2 \\
\hline 87 & LA-J-\# & 42.0 & 70.9 & 93.1 & 0.0131 & 0.0 & 2.5 & 12.3 & 52 & 54.6 & 57 & 2.9 & 3.6 & 4.0 \\
\hline 88 & \#A-I\#-\# & 35.4 & 57.4 & 90.4 & 0.0172 & 0.0 & 0.0 & 0.0 & 50 & 52.5 & 54 & 2.0 & 2.4 & 3.3 \\
\hline 89 & \#D-J-\# & 57.1 & 94.1 & 113.7 & 0.0087 & 8.5 & 20.7 & 71.9 & 51 & 52.1 & 53 & 2.0 & 2.5 & 2.6 \\
\hline 90 & \#A-A-\# & ‘53.4 & 65.1 & 76.8 & 0.0057 & 0.0 & 6.9 & 12.0 & 52 & 54.2 & 55 & 3.9 & 4.2 & 4.5 \\
\hline 84 & RD-J-1 & 127.7 & 135.3 & 142.7 & 0.0008 & 37.7 & 46.5 & 54.6 & 48 & 49.2 & 50 & 1.5 & 1.7 & 1.9 \\
\hline 85 & LD-R-3 & 53.0 & 91.7 & 117.7 & 0.0104 & 0.0 & 8.2 & 17.7 & 50 & 51.0 & 52 & 1.8 & 2.0 & 2.3 \\
\hline 86 & LD-Y-3 & 78.2 & 95.9 & 119.8 & 0.0044 & 6.6 & 17.7 & 40.2 & 52 & 52.0 & 52 & 2.1 & 2.4 & 2.6 \\
\hline 87 & LD-R-4 & 49.6 & 73.3 & 93.1 & 0.0094 & 0.0 & 2.7 & 12.3 & 52 & 54.8 & 57 & 2.9 & 3.7 & 4.0 \\
\hline $88 \mathrm{I}$ & LD-T-4 & 35.4 & 56.7 & 90.4 & 0.0172 & 0.0 & 0.0 & 0.0 & 50 & 52.8 & 54 & 2.0 & 2.4 & 3.3 \\
\hline
\end{tabular}


102

Table_A.1 (cont.1 Complete repression data for Snake River releases of freeze-branded. juvenile spring and summer chinook salmon

\begin{tabular}{|c|c|c|c|c|c|c|c|c|c|c|c|c|c|c|}
\hline \multirow[b]{3}{*}{ Year } & & \multicolumn{13}{|c|}{ Measurements atMcNary } \\
\hline & & \multicolumn{3}{|c|}{ PLOW (kcfs) } & \multirow[b]{2}{*}{ DFLOW $^{-1}$} & \multicolumn{3}{|c|}{ SPILL (kcfs) } & \multicolumn{3}{|c|}{ Temperature } & \multicolumn{3}{|c|}{ Turbidity } \\
\hline & Code & Min. & Avg. & Max. & & Min. & Avg. & Max. & Min. & Avg. & Max. & Min. & Avg. & $\operatorname{Max}$ \\
\hline 83 & RD-su-3 & 2085 & 284.5 & 321.0 & $0 \Omega \Omega 17$ & 28.7 & 138.7 & 179.7 & 50 & 50.6 & 52 & 1.5 & 2.2 & 30 \\
\hline 85 & RD-R-2 & 187:0 & 219.4 & 265.5 & 0.0016 & 0.0 & 12.3 & 53.7 & 49 & 50.7 & 52 & 1.4 & 2.2 & 2.4 \\
\hline 86 & RA-Y-2 & 202.2 & 252.6 & 303.1 & 0.0016 & 0.0 & 28.6 & 76.1 & 48 & 49.7 & 51 & 2.0 & 2.4 & 2.7 \\
\hline 87 & RA-R-1 & 129.6 & 193.7 & 256.6 & 0.0038 & 0.0 & 19.2 & 60.4 & 51 & 51.5 & 52 & 2.7 & 3.0 & 3.3 \\
\hline 88 & LA-T-2 & 129.5 & 145.9 & 185.3 & 0.0023 & 0.0 & 0.0 & 0.0 & 51 & 52.3 & 54 & 1.8 & 2.7 & 3.5 \\
\hline 89 & R\#-7H-\# & 176.4 & 245.9 & 281.7 & 0.0021 & 0.0 & 20.1 & 47.5 & 52 & 52.2 & 54 & 2.3 & 2.6 & 3.4 \\
\hline 90 & \#-7U-\# & 170.8 & 223.5 & 276.1 & 0.0022 & 0.0 & 6.6 & 51.8 & 51 & 51.8 & 53 & 4.0 & 4.5 & 5.2 \\
\hline 83 & RD-T-1 & 260.0 & 294.2 & 311.0 & 0.0006 & 117.4 & 141.1 & 188.6 & 51 & 53.1 & 54 & 2.0 & 2.3 & 3.0 \\
\hline 84 & LD-J-1 & 299.6 & 332.6 & 367.7 & 0.0006 & 120.1 & 151.7 & 182.0 & 52 & 52.0 & 52 & 1.2 & 1.4 & 2.0 \\
\hline 85 & RD-R-3 & 210.9 & 226.3 & 251.0 & 0.0008 & 0.0 & 8.3 & 40.0 & 52 & 54.6 & 58 & 2.2 & 2.8 & 3.2 \\
\hline 86 & RD-Y-3 & 230.6 & 251.9 & 272.9 & 0.0007 & 0.0 & 23.8 & 39.1 & 50 & 50.6 & 51 & 2.0 & 2.5 & 2.7 \\
\hline 87 & LD-R-3 & 200.3 & 242.9 & 266.5 & 0.0012 & 1.6 & 40.8 & 71.8 & 52 & 52.0 & 52 & 2.9 & 3.2 & 3.5 \\
\hline 89 & RA-R-\# & 192.0 & 246.8 & 295.6 & 0.0018 & 0.0 & 20.1 & 57.7 & 54 & 54.4 & 55 & 2.2 & 3.0 & 3.8 \\
\hline 90 & LD-T-\# & 189.1 & 232.7 & 342.7 & 0.0024 & 0.0 & 22.4 & 105.0 & 54 & 55.2 & 56 & 3.5 & 4.0 & 4.3 \\
\hline 82 & RD-4-1 & 244.1 & 262.1 & 293.7 & 0.0007 & 14.3 & 44.6 & 83.8 & 48 & 49.0 & 50 & 0.8 & 1.5 & 1.8 \\
\hline 83 & RD-12-1 & 208.5 & 282.9 & 321.0 & 0.0017 & 28.7 & 142.1 & 179.7 & 50 & 50.4 & 51 & 1.5 & 2.1 & 2.6 \\
\hline 84 & RD-J-3 & 257.7 & 272.1 & 304.2 & 0.0006 & 60.9 & 85.0 & 122.2 & 48 & 48.5 & 49 & 1.5 & 2.0 & 2.6 \\
\hline 85 & LD-R-1 & 187.0 & 218.3 & 265.5 & 0.0016 & 0.0 & 10.6 & 53.7 & 49 & 50.7 & 52 & 1.4 & 2.1 & 2.4 \\
\hline 86 & LD-Y-1 & 202.2 & 251.5 & 303.1 & 0.0016 & 0.0 & 30.0 & 76.1 & 48 & 49.1 & 50 & 2.0 & 2.3 & 2.6 \\
\hline 87 & LD-R-2 & 129.6 & 205.2 & 256.6 & 0.0038 & 0.0 & 23.9 & 60.4 & 51 & 51.7 & 52 & 2.9 & 3.0 & 3.3 \\
\hline 88 & RD-T-4 & 129.5 & 154.9 & 213.2 & 0.0030 & 0.0 & 0.0 & 0.0 & 51 & 52.6 & 54 & 1.8 & 2.6 & 3.8 \\
\hline 89 & L\#-7H-\# & 176.4 & 237.9 & 281.7 & 0.0021 & 0.0 & 14.7 & 47.5 & 51 & 51.9 & 52 & 2.0 & 2.4 & 27 \\
\hline 90 & RA-T-\# & 170.8 & 222.6 & 261.0 & 0.0020 & 0.0 & 4.7 & 25.3 & 51 & 51.7 & 52 & 4.0 & 4.2 & 5.2 \\
\hline 83 & RD-T-2 & 280.7 & 293.8 & 307.3 & 0.0003 & 114.7 & 135.2 & 163.1 & 51 & 52.4 & 54 & 2.0 & 2.4 & 3.0 \\
\hline 84 & LD-J-3 & 254.4 & 297.0 & 367.7 & 0.0012 & 61.3 & 114.1 & 182.0 & 49 & 50.3 & 52 & 1.2 & 1.7 & 2.2 \\
\hline 85 & RD-R-1 & 216.8 & 236.2 & 265.5 & 0.0008 & 0.0 & 23.9 & 53.7 & 51 & 51.8 & 53 & 2.1 & 2.5 & 3.2 \\
\hline 86 & RD-Y-1 & 231.3 & 264.4 & 303.1 & 0.0010 & 2.2 & 38.6 & 76.1 & 49 & 49.3 & 50 & 2.0 & 2.3 & 2.6 \\
\hline 87 & RD-R-1 & 129.6 & 208.6 & 256.6 & 0.0038 & 0.0 & 24.9 & 60.4 & 51 & 51.7 & 52 & 2.9 & 3.1 & 3.3 \\
\hline 88 & RD-T-1 & 133.5 & 158.1 & 213.2 & 0.0028 & 0.0 & 0.0 & 0.0 & 51 & 52.8 & 54 & 1.8 & 2.6 & 3.8 \\
\hline 89 & LA-R-\# & 176.4 & 235.9 & 281.7 & 0.0021 & 0.0 & 14.8 & 47.5 & 51 & 51.8 & 52 & 2.0 & 2.4 & 2.5 \\
\hline 90 & LA-T-\# & 170.8 & 221.8 & 261.0 & 0.0020 & 0.0 & 4.6 & 25.3 & 51 & 51.8 & 52 & 4.0 & 4.2 & 5.2 \\
\hline 82 & RD-SU-\# & 345.0 & 368.9 & 390.9 & 0.0003 & 159.7 & 186.4 & 212.5 & 47 & 51.8 & 54 & 2.0 & 2.2 & 2.6 \\
\hline 83 & RD-T-3 & 206.7 & 247.3 & 321.0 & 0.0017 & 28.7 & 92.4 & 179.7 & 48 & 49.3 & 51 & 1.2 & 1.8 & 2.4 \\
\hline 87 & LA-J-\# & 129.6 & 193.7 & 256.6 & 0.0038 & 0.0 & 19.2 & 60.4 & 51 & 51.5 & 52 & 2.7 & 3.0 & 3.3 \\
\hline 88 & \#A-I\#-\# & 129.5 & 152.2 & 213.2 & 0.0030 & 0.0 & 0.0 & 0.0 & 51 & 52.4 & 54 & 1.8 & 2.7 & 3.8 \\
\hline 89 & \#D-J-\# & 176.4 & 234.6 & 281.7 & 0.0021 & 0.0 & 13.1 & 47.5 & 50 & 51.7 & 52 & 2.0 & 2.4 & 2.6 \\
\hline 90 & \#A-A-\#! & $\operatorname{lj} 0.8$ & 222.1 & 261.0 & 0.0020 & 0.0 & 3.6 & 25.3 & 51 & 51.6 & 52 & 4.0 & 4.2 & 5.2 \\
\hline 84 & RD-J-l & 298.8 & 310.1 & 327.7 & 0.0003 & 120.6 & 133.3 & 150.7 & 48 & 48.9 & 49 & 1.4 & 1.6 & 2.0 \\
\hline 85 & LD-R-3 & 175.3 & 210.6 & 249.3 & 0.0017 & 0.0 & 5.7 & 27.3 & 50 & 50.8 & 51 & 1.1 & 1.7 & 2.3 \\
\hline 86 & LD-Y-3 & 202.2 & 258.4 & 303.1 & 0.0016 & 0.0 & 38.1 & 76.1 & 48 & 48.6 & 49 & 2.0 & 2.3 & 2.6 \\
\hline 87 & LD-R-4 & 129.6 & 197.8 & 256.6 & 0.0038 & 0.0 & 20.8 & 60.4 & 51 & 51.6 & 52 & 2.9 & 3.0 & 3.3 \\
\hline 88 & LD-T-4 & 129.5 & 153.7 & 213.2 & 0.0030 & 0.0 & 0.0 & 0.0 & 51 & 52.5 & 54 & 1.8 & 2.7 & 3.8 \\
\hline
\end{tabular}


Appendix B

Complete Regression Data for Transportation Program Control Releases 
104

Table B.1 Complete regression data for transportation program control releases,

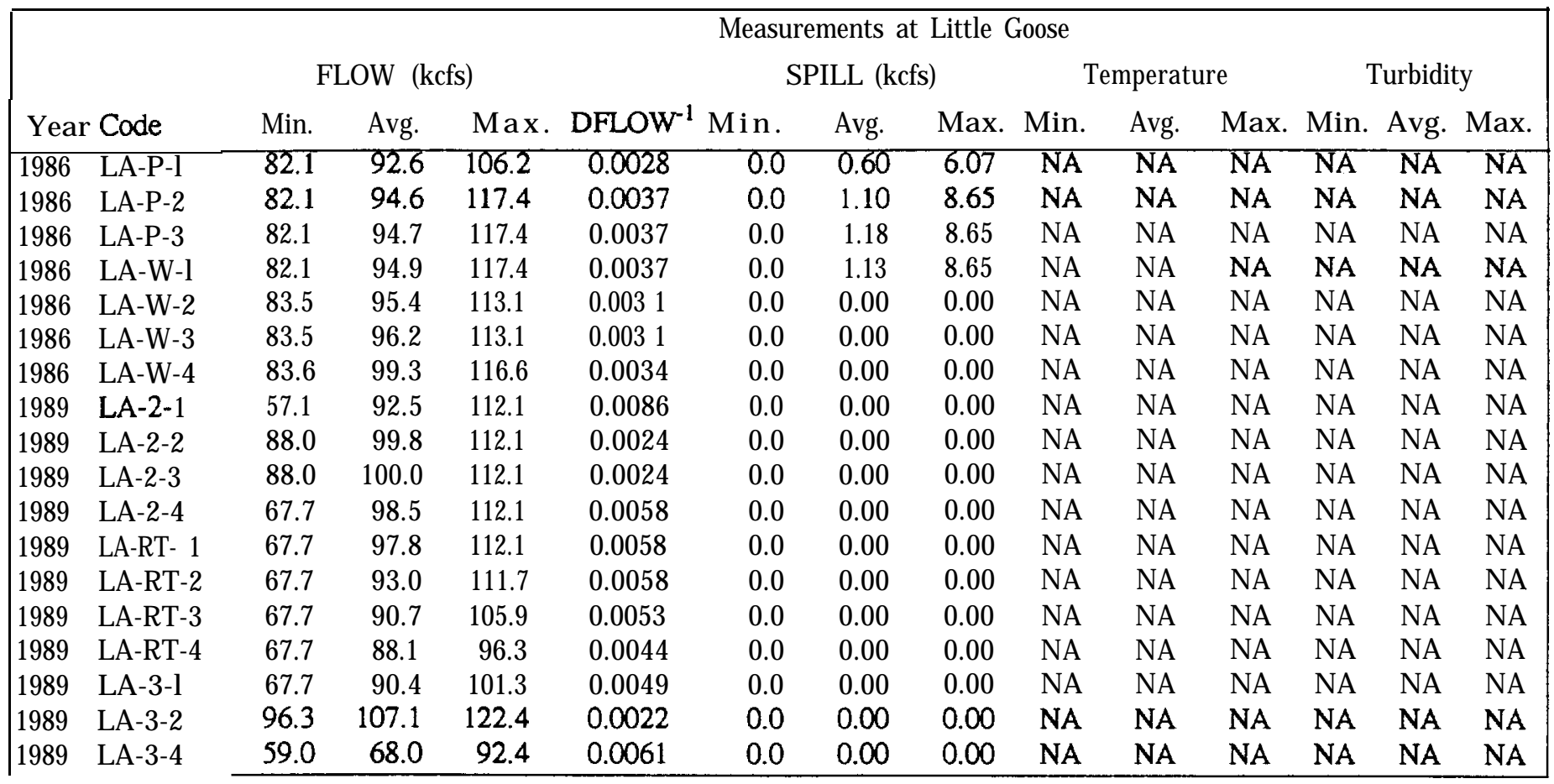

\begin{tabular}{|c|c|c|c|c|c|c|c|c|c|c|c|c|c|c|}
\hline \multirow[b]{3}{*}{ Year } & & \multicolumn{13}{|c|}{ Measurements at Lower Monumental } \\
\hline & & \multicolumn{3}{|c|}{ FLOW (kcfs) } & & \multicolumn{3}{|c|}{ SPILL (kcfs) } & \multicolumn{3}{|c|}{ Temperature } & \multicolumn{3}{|c|}{ Turbidity } \\
\hline & Code & Min. & Avg. & Max. & DFLOW $^{-1}$ & Min. & Avg. & Max. & Min. & Avg. & Max. & Min. & Avg. & Max. \\
\hline 1986 & LA-P- 1 & 79.4 & 93. & $9 \longdiv { 1 0 6 . 7 }$ & 0.0032 & 18.3 & 33.2 & 62.9 & 49 & 50.5 & 51 & 1.0 & 1.28 & 1.6 \\
\hline 1986 & LA-P-2 & 79.4 & 95.9 & 116.4 & 0.0040 & 18.3 & 33.4 & 49.6 & 50 & 50.9 & 52 & 1.0 & 1.37 & 1.6 \\
\hline 1986 & LA-P-3 & 79.4 & 95.7 & 116.4 & 0.0040 & 18.3 & 32.0 & 44.0 & 50 & 51.1 & 52 & 1.0 & 1.44 & 1.6 \\
\hline 1986 & LA-W- 1 & 79.4 & 95.8 & 116.4 & 0.0040 & 17.2 & 29.8 & 44.0 & 51 & 51.6 & 53 & 1.5 & 1.51 & 1.6 \\
\hline 1986 & LA-W-2 & 83.8 & 96.4 & 116.4 & 0.0033 & 17.2 & 28.1 & 44.0 & 51 & 51.9 & 53 & 1.5 & 1.50 & 1.5 \\
\hline 1986 & LA-W-3 & 83.8 & 96.6 & 116.4 & 0.0033 & 17.9 & 30.7 & 62.6 & 51 & 52.1 & 53 & 1.4 & 1.49 & 1.5 \\
\hline 1986 & LA-W-4 & 86.8 & 99.0 & 114.5 & 0.0028 & 22.7 & 34.7 & 62.6 & 51 & 52.1 & 53 & 1.4 & 1.48 & 1.5 \\
\hline 1989 & LA-2-1 & 63.7 & 93.3 & 116.0 & 0.0071 & 0.0 & 20.7 & 43.4 & 47 & 49.5 & 52 & 0.8 & 1.40 & 1.7 \\
\hline 1989 & LA-2-2 & 87.1 & 100.6 & 116.0 & 0.0029 & 13.1 & 31.8 & 43.4 & 49 & 50.8 & 52 & 1.3 & 1.51 & 1.7 \\
\hline 1989 & LA-2-3 & 87.1 & 100.1 & 116.0 & 0.0029 & 28.3 & 33.6 & 43.4 & 49 & 51.1 & 52 & 1.3 & 1.53 & 1.7 \\
\hline 1989 & LA-2-4 & -61.6 & 97.6 & 116.0 & 0.0076 & 23.3 & 33.8 & 43.4 & 51 & 51.6 & 52 & 1.3 & 1.52 & 1.7 \\
\hline 1989 & LA-RT- 1 & 61.6 & 97.7 & 116.0 & 0.0076 & 23.3 & 38.6 & 78.5 & 51 & 51.6 & 52 & 1.3 & 1.48 & 1.7 \\
\hline 1989 & LA-RT-2 & 61.6 & 92.6 & 108.8 & 0.0071 & 23.3 & 37.9 & 78.5 & 51 & 51.6 & 52 & 1.3 & 1.46 & 1.7 \\
\hline 1989 & LA-RT-3 & 61.6 & 90.7 & 108.8 & 0.0071 & 23.3 & 37.4 & 78.5 & 51 & 51.7 & 52 & 1.3 & 1.54 & 2.1 \\
\hline 1989 & LA-RT-4 & 61.6 & 87.0 & 97.5 & 0.0060 & 23.3 & 36.8 & 78.5 & 51 & 51.7 & 52 & 1.3 & 1.58 & 2.1 \\
\hline 1989 & LA-3-1 & 61.6 & 89.7 & 105.3 & 0.0067 & 23.3 & 36.6 & 78.5 & 51 & 51.9 & 54 & 1.3 & 1.66 & 2.1 \\
\hline 1989 & LA-3-2 & 92.1 & 106.8 & 119.9 & 0.0025 & 29.4 & 36.8 & 43.9 & 52 & 53.9 & 55 & 2.0 & 2.10 & 2.2 \\
\hline 1989 & LA-3-4 & 57.9 & 67.9 & 90.4 & 0.0062 & 0.0 & 11.1 & 26.0 & 53 & 53.5 & 55 & 2.2 & 2.81 & 3.2 \\
\hline
\end{tabular}


105

Table B.l (cont.1 Comolete regr\&on data for transportation program control release\&

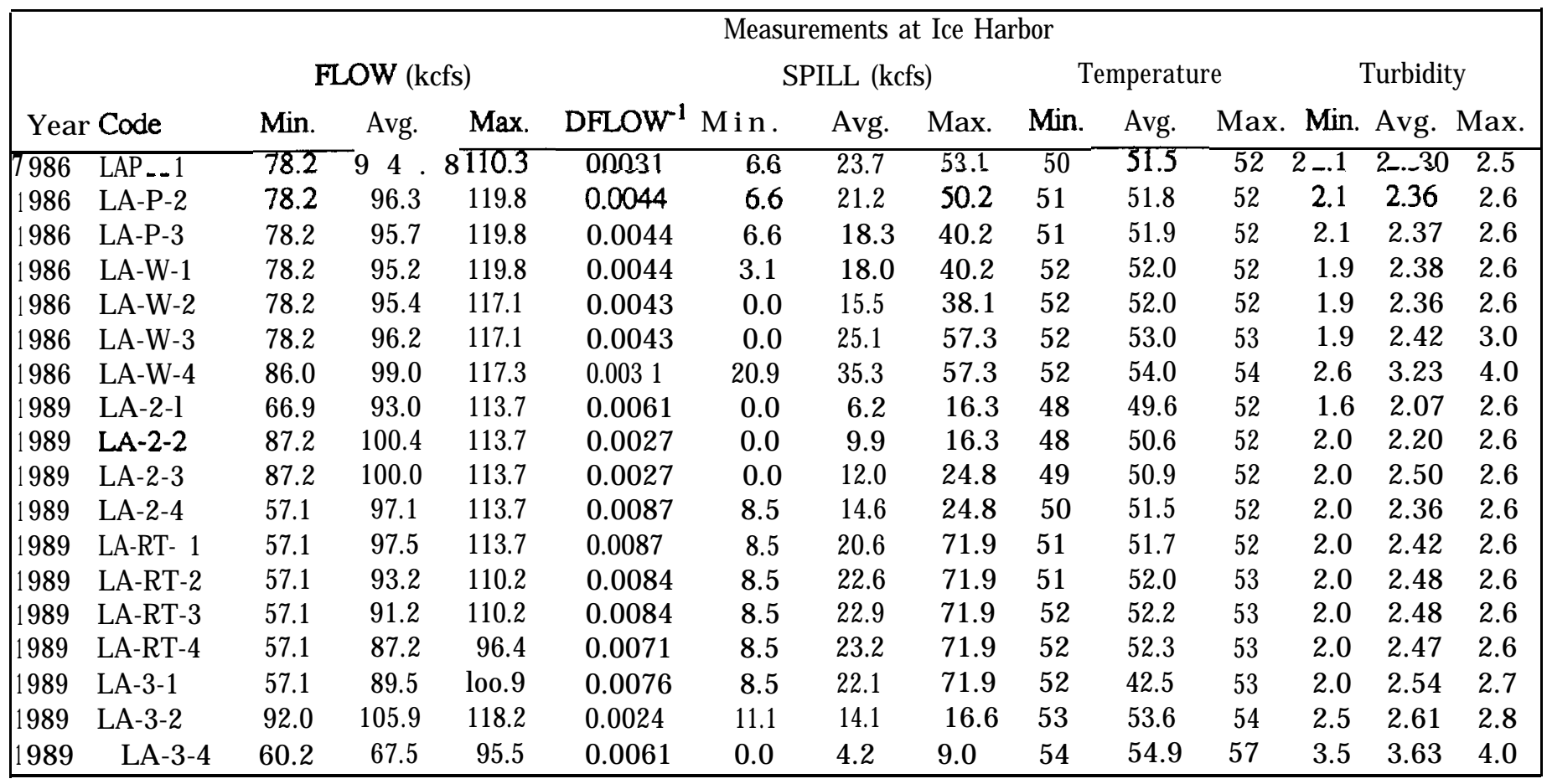

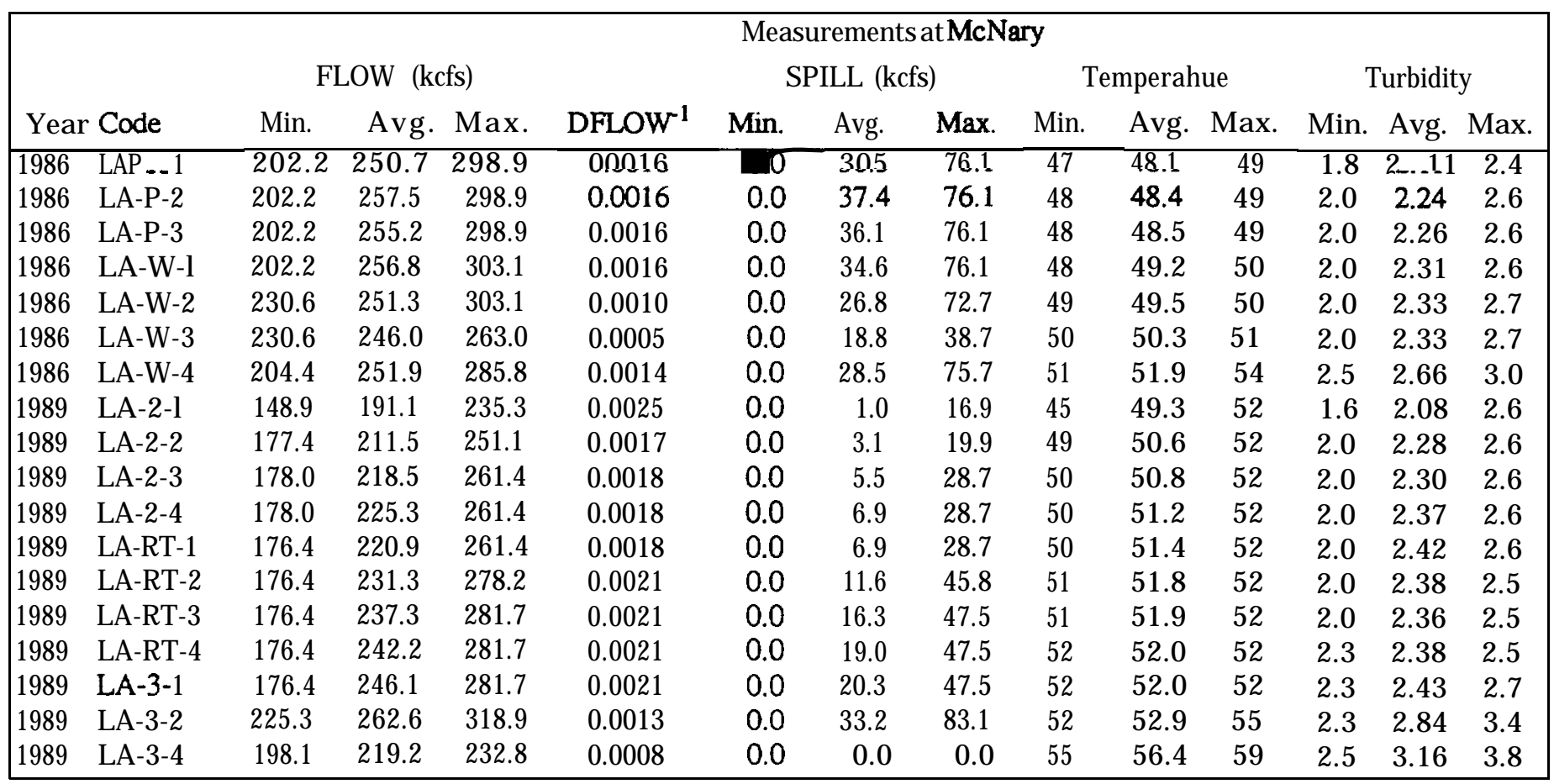




\section{Appendix C}

\section{Comment Letters and Responses to Comments}

A comment draft of this report was sent to 11 people at various agencies in the Columbia River community. Review comments were received from 4 people. Comments included letters with specific points and telephone calls. Formal comment letters were received from:

- Lyle Calvin, Consulting Statistician, Corvallis, Oregon

- John Stevenson, Pacific Northwest Utilities Conference Committee

. Michele DeHart, Fish Passage Center

John Williams of the National Marine Fisheries Service submitted comments informally via a telephone call.

All comments were considered, and the text was revised where appropriate. Copies of the formal letters and responses to the suggestions and criticisms are contained in this appendix. Because most comments were not listed in a uniform format, an attempt was made to extract the main point of each relevant remark. The response indicates how the remarks were addressed in the revised report.

The most substantial revision is the removal of the former Section 9, which dealt with the potential for using freeze-brand data to estimate survival rates through reaches of the river. The main purpose of the section was to point out an inconsistency of the procedure used to adjust distributions of collection numbers to allow estimation of median travel times. The problem we wished to illustrate was that the adjustment procedure paradoxically results in estimated numbers arriving at McNary Dam greater than the total that left Little Goose Dam for many of the brand groups. The section was dropped in light of the concerns of several reviewers, and because other papers (Dauble, et al. 1993; Skalski and Giorgi 1993) and studies (NMFS/UW 1993 Survival Study) more focused on survival per se have appeared. Section 2.2.2 now contains a brief discussion of the logical paradox, with survival estimate de-emphasized, and references to survival estimation using brand reports remain in the conclusions (Section 9.2). 
Comment: If fish within a given brand group are released all at once the distribution of observations at a downstream sites amounts to the distribution of individual travel times. Only if the group is released over a prolonged number of days is there a problem with interpreting the distributions as individual travel time (Stevenson).

Response: We agree that passage distributions for groups that were released all at once are equivalent to the distribution of individual travel times. However, the implication of the comment seems to be that for groups released all at once, the adjustment algorithm need not be applied to the passage distributions to obtain the median travel time for the group. We do not think this is true, because there is still a problem with transportation removals at Little Goose Dam. For example, consider a group released all at once in the tailrace of Lower Granite Dam. In an extreme case, suppose that the first (faster) half of the fish from the group pass Little Goose before the transportation program starts up, and none of them are removed. The second (slower) half of the group passes Little Goose during full transportation operations, and all of them are removed. The arrival distribution at McNary will indeed give individual travel times, but the distribution will be worthless for estimating the median travel time for the entire group because the distribution contains none of the slower fish.

In any case, for our analyses the distinction between instantaneous and prolonged releases is irrelevant. None of our groups was released all at once at the top of the index reach. Practically speaking, all groups were "released" into the reach over a prolonged period as they passed Lower Granite Dam, whether or not they were released all at once from the hatchery.

Finally, even when the distribution of passage can be interpreted as individual travel times, it is impossible to determine which individuals had which travel times. That is, if individual traits such as length or degree of smoltification are measured at the time of release, the distribution of the group's passage at downstream sites cannot he used to establish relationships between the individual traits and travel time. Technology such as PIT-tags, that allow identification of individuals at detection sites are required.

This comment prompted some changes in Section 2.2, page 10. 
Comment: Concerning surrogate measurements of the degree of smoltification, it seems that a measure that summarizes the smoltification of an entire group would be more likely to show a correlation to the travel time of the group if the fish were released all at once than if they were released over an extended period of time

Resnonse: This comment concerns the use of aggregate measures that summarize an individual characteristic for an entire group. Certainly the usefulness of such aggregate measures depends upon the degree of homogeneity of the trait within the group. Traits like smoltification change over time and groups measured and released all at once would certainly be expected to be more homogeneous than those released over an extended period. This limitation would apply equally to direct measurements of smoltification. No changes in the text were made regarding this comment.

Comment: Mortality in the Little Goose reservoir appears in the equations detailing the adjustment algorithm but does not appear in the text of Section 2.2. Reservoir mortality should be addressed (Stevenson).

Resnonse: A discussion of the effects of the reach mortality $\left(S_{r c h}\right)$ on the travel time estimate has been added to Section 2.2, in the first paragraph following the definition of the terms in Equation 3. In addition, $S_{r c h}$ is also discussed in the major section on sensitivity of the travel time estimates (Section 3.2).

Comment: It is unclear how the adjustment algorithms (Section 2.2) were applied. Were they used only once (or twice to adjust for transportation at Little Goose)? It would seem to make more sense if the algorithms were applied serially for all dams, with the output from the adjustment for each dam being used as the input for the next dam downstream (Calvin).

Response: Adjustments were made for removals and mortality at Lower Granite and Little Goose only. While further adjustments could be made for mortality at Lower Monumental and Ice Harbor dams, in the absence of transportation at these dams, the effect of such adjustments is to scale the amplitude of the distribution proportionately throughout the range. Because the median is not affected, we do not performed the adjustments for the lower reach dams. The dams for which adjustments are made have been clarified in Section 2.2. 
Comment: A more realistic model could be "built into" the adjustment algorithm. There is no reason that the same parameter estimates have to be used for every dam. For example, FGE might be expected to be the same for Little Goose and Lower Granite but different for the other three dams. Parameter estimates could be obtained by calling on the expertise in the region and/ or by "playing" with various estimates to give more reasonable estimates of the distributions. For example, the total arrival numbers at McNary Dam should not exceed the total number entering the reach below Lower Granite (Calvin).

Response: We remain concerned with the logical inconsistency that more fish are estimated to arrive at McNary than left Lower Granite, and we have done a little "playing," with mixed success, to try to come up with a combination of parameters that gives more reasonable distributions. However, regardless of the estimates used in the algorithm, we will still lack a measure of the uncertainty of the resulting travel time or survival estimates. This more serious statistical liability has discouraged us from more extensive investigation in this area. No changes in the text were made regarding this comment.

Comment: In the sensitivity analyses, were two parameters varied at one time? It seems logical to do so, especially for FGE and SE (Calvin).

Response: We did try varying the two parameters FGE and SE at the same time. The results did not add sufficient insight to warrant inclusion in the final report.

Comment: The results of the sensitivity analyses indicate that both travel time estimation and the regression analyses were robust over a wide range of parameter estimates. Several discussions and conclusions go beyond what the results of the sensitivity studies were showing. The authors by their own analyses have shown travel time estimates using freeze brand data are robust (DeHart).

Response: It is not our intent to condemn the use of freeze-brand data for travel time estimation on the basis of the results of our sensitivity analyses alone. The complete lack of any estimate of the uncertainty of the travel time estimates is a far more important liability, and one that is emphasized in the text far more than the sensitivity to parameter inputs. In some instances we have acknowledged that the results are fairly robust (e.g. Section 4.1: "The best-subsets regressions are very consistent"). In other cases, we have pointed out what we feel to be more unstable results (e.g. nearly $10 \%$ of the brand groups had estimated travel times vary by more 
than 2 days over the reasonable range of 0.3 to 0.7 for FGE). In most cases, however, we have made no conclusions at all regarding, simply reporting the results and leaving the reader to decide the importance the degree of sensitivity. Ms. DeHart sees the results as sufficiently robust; others may not agree.

Comment: The inclusion of minimum spill in the regression models is not useful, because of the inherent high correlation that occurs between it and average flow. Spill and flow could not occur together in FPC's (Berggren and Filardo, 1993) models because of a requirement that final models have high tolerance levels (i.e. the two variables are too highly correlated). Since spill is provided as a function of flow at the two key spill sites in the Snake River, we think any discussion of whether the flow or spill was the most important factor in predicting travel time is nonsensical (DeHart).

Response: It is not nonsensical to speculate, or indeed to design studies to find out, whether spill or flow is the more important influence on travel time, because the two variables are not necessarily highly correlated. Water can be spilled at a variety of flow levels and the respective effects of the two variables can be distinguished to some extent. The discussion is important because the respective recommended remedial measures would be different depending on which variable is more important. For example, it might be found that spilling water increases travel times, regardless of the flow level, because fewer fish are being held up in gatewells when the spillway passage route is available. We do not think it is useful in a multiple regression analysis to eliminate a model from consideration because it is difficult to interpret. If two of the variables in the available data set are highly correlated, we advocate determining whether new, less correlated data could be generated experimentally.

Comment: The authors claim that the low flow year of 1988 created a set of anchoring points that caused the resulting regressions to he insensitive to changes in the parameters used in the adjustment algorithm. The authors claim that what may be considered a fairly robust algorithm for the nine years of data analyzed, may not work well with other data sets. But what other data sets are the authors thinking about? (DeHart).

Resoonse: We acknowledge the relative stability of the regression results using the presently available data set. The "other data sets" we were thinking about are data sets that will be 
collected in the future. The point we are making is that the 1988 data points are providing an anchor in the present data set. It does not necessarily follow that the sensitivity results observed with these data, which include the anchor points, can be extrapolated to other, future years where such anchor points might not occur. The wording in the passage in question has been changed to clarify that future data sets are our concern.

Comment: Berggren and Filardo (1993) did not attempt to obtain population sizes in their approach, but stayed with standard passage index distributions. Therefore, their analyses of travel time are not called into question by the inconsistency of estimated population sizes resulting from the adjustment algorithm (DeHart).

Response: Whether or not the distributions used to estimate the travel times are divided by FGE to estimate population numbers, a problem remains. If a constant FGE is proper, then the only difference between our distributions and those of Berggren and Filardo (1993) is the constant scaling. The inconsistency remains, albeit more subtly in the Berggren and Filardo distributions. If the position is that FGE changes day-to-day, on the other hand, then are passage indices even applicable? The Berggren and Filardo (1993) approach, based on indices, would give any two days with equal passage indices equal weight in the passage distribution, even if the FGE values are vastly different, indicating that the actual number of fish passing on the two days are very discrepant. Surely this biases the travel time estimates.

Comment: The statement that the reciprocal of minimum flow was not used by Berggren and Filardo (1993) is wrong.

Response: The statement has been removed. 
Comment:-All the applicable modifications that are discussed in the conclusions and recommendations section have been in place in the Smolt Monitoring Program for several years (DeHart).

Response: A review of the Fish Passage Center 1992 Annual Report shows that the reaches on the Snake River for which travel time was estimated are hatchery-to-Lower Granite, in-river traps-to-Lower Granite, Lower Granite-to-McNary, and Little Goose-to-McNary (using PITtags). With the possible exception of the reaches above Lower Granite, these are all longer reaches, requiring summarization of conditions over longer periods, than we are advocating.

The adjustment algorithm has not been used in recent years; passage indices have been used directly to estimate travel times. This approach requires the assumption that the same proportion of fish are removed for transportation throughout the season, but probably does not bias estimates greatly when there is little spill, or very consistent spill over the entire season. However, Berggren (personal communication) has acknowledged that in years when there is significant spill that is not consistent through the season, the adjustment algorithm would again have to be used. 1993 might be such a year.

Indices of smoltification do not appear to be mentioned in the 1992 FPC Annual Report.

The FPC has not been pursuing new methodologies for estimating smolt survival through the mainstem Snake and Columbia Rivers.

Comment: The report yields no new information or analysis regarding freeze brand travel time estimation (DeHart).

Response:The contributions of the report include, but are not limited to the following:

- Identification of 11 additional hatchery releases useful for travel time regression analyses.

- Sensitivity analysis of travel time estimation and regression analyses.

- Consideration of additional variables in multiple regression analyses, including variables from several dams, rather than a single index site.

- Analysis of early attempts at direct measures of smoltification.

- Analysis of travel time for transportation control releases. 


\section{LITERATURE CITED IN APPENDIX C}

Dauble, D.D., J.R. Skalski, A. Hoffmann, and A.E. Giorgi. 1993. Evaluation and application of statistical methods for estimating smolt survival. Report to Bonneville Power Administration (Contract No. DE-AI79-90BP62611).

Skalski, J.R. and A.E. Giorgi. 1993. Juvenile passage proposal: Estimating smolt travel time and survival in the Snake and Columbia Rivers. Report to Bonneville Power Administration (Contract No. DE-AI79-87BP35885). 
April 14, 1993

Mr. Steven G. Smith

Center for Quantitative Sciences

University of Washington

3737 15th Avenue N.E.

Seattle, Washington 98105

Dear Steve:

I have reviewed the paper prepared by you, Al Giorgi, and John Skalski titled "Statistical Evaluation of Travel Time Estimation Based on Data from Freeze-Branded Chinook Salmon on the Snake River, 19821990. " I found the paper to be well written and believe it will prove to be a valuable reference in future travel time analyses. I have some general comments which may be of use. They are presented below.

On page three, paragraph 2 of section 2.1, you discuss why freeze-branded hatchery fish were used, more specifically, why experimental hatchery groups were excluded. The explanation that experimental fish may behave differently caused me to wonder how the test fish might behave in comparison with wild fish. It may be useful to address this issue.

In the first paragraph of section 2.2 on page 10, you make the statement, "Freeze brands, on the other hand, can not give individual-based information. Bather, the information obtained from freeze brands is entirely group-based." I would disagree with this statement. The statement is only true if fish within d given brand group are released over an extended period of time. But, if the fish within a given brand group are released all at once and the brands are recorded on a specific day, travel time for each fish is available. I have enclosed a copy of a paper prepared by me and Dr. Darryll Olsen outlining the treatment of such data.

In your discussion detailing how you reconfigure the daily passage distribution on pages 11 and 12 , it appears that reservoir mortality has been omitted from the discussion. However, it appears in equation 2 , which develops the algorithm for this process. It would be useful if you address reservoir mortality in your discussion.

In section 2.3.1, you discuss the use of a surrogate parameter in lieu of smoltification data. It would be helpful to nie if you could discuss your thoughts on how the relationship for brand groups released over an extended period (a week or more) may differ from brand release groups released on a single day. My thought is that brand groups released on a daily basis may show a greater correlation to travel time than brand groups that are released over a one-week period. The rationale is that the extended release strategy may mask some of the behavioral traits brought on by increased physiological development. 
Mr. Steven G. Smith

April 14, 1993

Page 2

In closing, I appreciate the opportunity to review your paper and believe it will be of great value in the future. I hope these comments are of use to you. If you have any questions, please feel free to give me a call at (503) 223-9343.

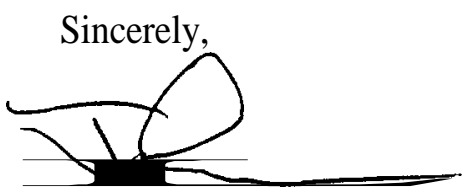

John Stevenson

Senior Fish and Wildlife Analyst

CC: $\quad$ Al Giorgi, Don Chapman Consultants, Inc. John Skalski, University of Washington

Pat Poe, Bonneville Power Administration

Enclosure 
LYLE D. CALVIN

CONBULTINE ETATIBTICIAN

3463 N.W. CREST DRIVE

CORVALIIE, DREGON 97330

Phone (503) 757-1224

March 18, 1993

Dr. Steven G. Smith

Center for Quantitative Science HR-20

University of Washington

Seattle, WA 98195

Dear Steve:

As you know, Pat poe sent me a copy of your draft report on Travel Time Estimation from Freeze-Branded Chinook and asked for a review with comments to be sent to you.

It was a pleasure to read a paper that was so well written with ideas so clearly expressed and with so few grammatical or typing errors. Most of what few there are can be caught with a spellchecker. A couple of exceptions are "than" (then) in the third line of the third paragraph on page 18 and one of the "of"s in the first line of the second paragraph on page 49. Also, the structure of the first complete sentence on page 93 seems to have a problem.

Although the error in the travel time estimates caused by errors in the parameter estimates is probably not as important or as large as the error in the survival estimates, it is of major concern. Rather than just passing it off and using the same estimates that the Fish Passage Center did, wouldn't it be better to go back to the algorithms and play with various estimates (much as was done in the sensitivity analyses) and try to come up with estimates that give more realistic estimates of survival? It seems natural to suspect the survival estimates more than the FGE or Spill parameters but all or any of them could be modified. Also, there is no reason that the same parameter estimates have to be used for every dam. For example, FGE might be expected to be the same for $L G O$ and LGR but different for the other three dams. I'd suggest that you might want to talk to some of the more experienced people in NMFS or the Corps.

The algorithms on pages 11-14 are logical ones for any one dam. It is not clear to me whether you used them only once (or twice to adjust for transportation at LGO) to represent the effect over all five dams or whether you used them first for LGR and then used the output of that as input to LGO and so on for all five dams. It seems that the latter procedure should have been used but I can't find anything that says that was what was done. This, of course, requires reach survival estimates between any pair of dams and I find a reference only to the reach between IGR and LGO. Since the algorithms are non-linear, I think the 
estimates would be different using the two procedures. If I have misunderstood what you have done, then perhaps you should look at your explanation to see if others might also misunderstand it.

The sensitivity analyses go a long way toward answering the questions regarding the accuracy of the estimates of the parameters. However, you have varied only one parameter at a time. Did you try varying two parameters at a time, particularly FGE and $S E$ ? It seems logical to do so. If not, is there some reason that you didn't?

The three paragraphs above cover my primary concerns with your paper. In addition, I have the following comments on other minor points :

Page 12. These algorithms assume that the fish randomly select routes of passage.

Page 55. As you recognize, there are too few years to expect that the "Leave-One-Year-out" to give an effective sensitivity analysis.

Page 67. In the Individual-Dam analysis, is travel time calculated differently, say, for the reach from the dam to MCN? It might make more sense if it were.

Page 81. I am glad to see your comment that control releases would provide a wider range of conditions if they were conducted in low flow years. If we are to obtain this kind of information we must be willing to run some studies in low flow years.

Page 87. Even though strict confidence intervals are not possible, some measure of the range of the estimates might be made be developing subjective distributions for each of the parameters and randomly selecting values to insert into the algorithms to provide a stochastic model. By resampling with other randomly selected values, a range of travel time estimates could be obtained, giving an interval somewhat analogous to a confidence interval.

Page 88. Here, and elsewhere, you recommend experiments to manipulate dam operations as a method of resolving the relative importance of certain variables. If anything, this point needs to be stressed more.

Page 93. Your first recommendation is that future studies should focus on shorter reaches and shorter periods of time. An alternative approach, not necessarily better, is to develop a more complicated model.

Copies: Pat Poe, John Skalski, Al Giorgi

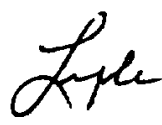




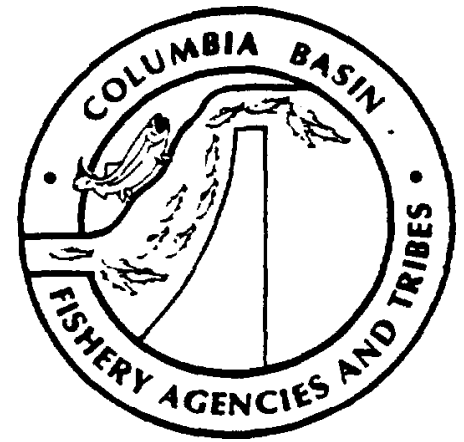

March 23, 1993

\section{FISH PASSAGE CENTER}

2501 S.W. FIRST AVE. SUITE 230 • PORTLAND, OR $\mathbf{9 7 2 0 1 - 4 7 5 2}$

Pat Poe

Bonneville Power Administration

P.O. Box 3621-PJI

Portland, OR 97208-362 1

Dear Pat:

In response to your request, the FPC staff have reviewed the draft report entitled "Statistical Evaluation of the Travel Time Estimation Based on Data from Freeze-Branded Chinook Salmon on the Snake River, 1982-1990", by Smith, Giorgi, and Skalski under contract to Bonneville Power Administration. We offer the following comments for your consideration:

\section{General Comments}

It is apparent from the tone of the report that Smith, Giorgi, and Skalski were trying their hardest to discredit the use of freeze brand data for estimating travel time in the Snake River. Several discussions and conclusions go beyond what the results of the sensitivity studies were showing. In fact, we were very pleased with the results of the sensitivitv analysis of the parameter inputs into the transportation removal adjustment algorithms. The study documented that the travel time estimation was robust over a wide range of parameter inputs. The resulting regressions were also robust, and showed similar models to those presented in Berggren and Filardo (in press [due out in 1993)). Some of the following specific comments address our concerns relative to the tone of the discussions and conclusions of this report, while other comments are more of an editorial nature. The report shows that travel time estimation from use of freeze brands results in acceptable estimates of travel time.

\section{Specific Comments}

1. On page 17, the authors state that "Berggren and Filardo (1992) used the reciprocal of the average flow, but when considering raw minimum flow, did not use the reciprocal." This statement is wrong. The reciprocal of minimum flow was used. On pages 20-21 of our manuscript, we state that the MINFLOW' variable was the first variable entered by the stepwise regression for subyearling chinook in John Day reservoir. but was removed after the fourth step when the average flow variable (FLOW') entered the model. High correlation between MINFLOW ${ }^{-1}$ and FLOW' precluded both variables in the model together.

2. All references to Berggren and Filardo (1992) should have the published date changed to 1993.

3. Footnote to Table 4 is wrong. The threshold for significance should be $|r| \geq 0.304$ based on $\boldsymbol{n}=\mathbf{4 2}$ (degrees of freedom $=40$ ) instead of $n=18$. See Table 19, which has the correct footnote. The correct threshold was used in Table 4, even though the footnote is wrong. 
4. On page 24. the authors state that their 4-variable model contained minimum spill (MINSP), and that spill inclusion in their model was "a distinguishing feature of [their] basic analysis." We do not think this is useful. because of the inherent high correlation that occurs between it and average flow. At Lower Monumental and Ice Harbor dams, spill has typically been provided as a percentage of daily average flow. In the early stages of our analyses. we too had looked at average spill variables, but later dropped them from further consideration because of the high correlation between spill and flow at Ice Harbor and Lower Monumental dams where most spill has occurred over the years of study. The authors state that "spill and flow volumes are generally highly correlated," but they do not discuss the impact on model coefficients when highly correlated variables are included in the model together. To reduce this impact, we required that all variables remaining in the final model have high tolerance levels $>\mathbf{0 . 5 0}$ (defined in SYSTAT as 1 minus the multiple correlations between a predictor variable and all other predictor variables in the model). With such a requirement, spill and flow could not remain together in the same model. Since spill is provided as a function of flow at the two key spill sites in the Snake River, we think any discussion of whether the flow or spill was the most important factor in predicting travel time is nonsensical.

5. On page 58. the authors try to make the case that the low flow year of 1988 created a set of anchoring Points that basically caused the resulting regressions to be insensitive to changes in the parameters used in the travel time adjustment algorithm. Therefore. what may be considered a fairly robust algorithm for the nine years of data being analyzed. may not work well with other data sets. But what other data sets are the authors thinking about? This algorithm is very specific for use in just the Lower Granite Dam to McNary Dam index reach. Up to this Point in the report, we have been pleased that the sensitivity results have shown that the adjustment algorithm worked well over the range of parameter values expected. and only faltered when extreme combinations of fish guidance and spill efficiency values were entered. The authors expose their bias by this ineffectual attempt to downplay the validity of the approach.

6. On page 85 (and again on page 91), the authors state that population sizes obtained with the algorithms cannot be used to estimate survival through the index reach. This is because the population size at McNary Dam was estimated to, be higher than that of the fish entering the index reach. Because of the failure to compute survival values. the authors conclude there is "reason to doubt travel time estimates derived from brand recapture data." This is a very broad sweeping statement. They go on to state that similar inconsistency is present in the approach used by Berggren and Filardo (1992). However. Berggren and Filardo did not attempt to obtain population sizes in their approach. but stayed with standard passage index distributions. The passage index accounts for the spill. but is not divided by FGE as in equation (1) on page 11. Our value for $N_{a}$ in equation (2) on page 12 was the daily passage index value for the brand group. Since the authors' sensitivity analyses showed the travel time estimates to be robust over a wide range of parameter values (including FGE values) in equation (2), we feel that their contention of a "reason to doubt travel time estimates" is not valid. When estimates of population sizes are sought. then the reliability of the FGE estimate becomes more crucial. It appears that the authors used an FGE of 0.5 at both Lower Granite and McNary dams. A FGE value of 0.75 would be more appropriate for McNary Dam. which would lower the McNary Dam estimated population sizes by about $33 \%$.

7. In the middle of page 90 . the wording "... and with the minimum spill at Lower Granite" should be corrected to say Lower Monumental instead of Lower Granite.

8. On page 94 line 4. the word "individual" has one two many letter i's. 
9. On page 96, the authors show an FPC memo by Berggren (1991) as cited literature. First, we could not find this citation in the text of the report. Second, if it does exist in the text, then it should be simply footnoted, rather than listed as Literature Cited.

10. The conclusions and recommendations section of the report suggests changes to the freeze brand travel time estimation methods. Again, here the authors show their obvious bias. They infer that problems associated with batch marks (freeze brands) are not recognized and have not been addressed. However, all of the applicable modifications that are discussed in this section have been in place in the Smolt Monitoring Program for several years, and were originated and implemented by the Fish Passage Center and the agencies and tribes, long before this draft product was produced.

To summarize, the report yielded no new information or analysis regarding freeze brand travel time estimation. The authors by their own analyses have shown travel time estimates using freeze brands are robust. Therefore, the trave time analyses conducted can be considered to be accurate depictions of the system. The report fails to indicate that any estimation, regardless of mark used, incorporates assumptions regarding FGE. The validity and accuracy of FGE assumptions will always affect these estimates.

The report shows apparent bias, in that the authors exhibit that their primary task was to cast doubt on travel time estimates generated using freeze branded fish. It is unfortunate that Bonneville Power Administration expended funds on this project, because the results of the analysis are not useful or helpful. In fact, because the authors failed to include any mention of the results of their sensitivity analysis that show travel time estimates to be robust, the report threatens to be misleading and add further controversy.

BPA chose to fund this project outside the Implementation Planning Process. If the agencies and tribes had been involved in the selection, review, and design of this project, the expenditure of funds would have had beneficial and applicable results.

Sincerely,

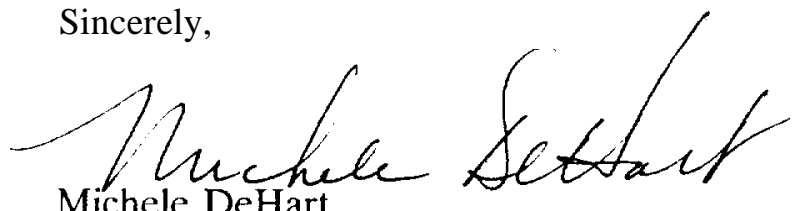

Fish Passage Center Manager

cc: Steve Smith,

UofW-Quantitative Sciences

$116-93 . \mathrm{lb}$ 